(C) Copyright 2018

Abhishek Kaluri 


\title{
Real-Time Prediction of Lean Blowout using Chemical Reactor Network
}

\author{
Abhishek Kaluri \\ A thesis \\ submitted in partial fulfillment of the \\ requirements for the degree of \\ Master of Science \\ University of Washington \\ 2018 \\ Committee: \\ Igor Novosselov \\ Philip Malte \\ John Kramlich \\ Program Authorized to Offer Degree: \\ Department of Mechanical Engineering
}




\title{
University of Washington
}

\begin{abstract}
Real-Time Prediction of Lean Blowout using Chemical Reactor Network
\end{abstract}

\author{
Abhishek Kaluri \\ Chair of the Supervisory Committee: \\ Research Assistant Professor, Igor V. Novosselov \\ Department of Mechanical Engineering
}

The lean blow-out (LBO) of gas turbine combustors is a concern that can limit the rate of descent for an aircraft, the maneuverability of military jets, and cause a costly and time-intensive reignition of land-based gas turbines. This work explores the feasibility of a model-based combustor monitoring for the real-time prediction of combustion system proximity to LBO. The approach makes use of (1) real-time temperature measurements in the reactor, coupled with (2) the use of a real-time chemical reactor network (CRN) model to interpret the data as it is collected. The approach is tested using a laboratory jet-stirred reactor (JSR), operating on methane at near atmospheric pressure. The $\mathrm{CRN}$ represents the reactor as three perfectly stirred reactors (PSRs) in series with a recirculation pathway, the model inputs include real-time reactor temperature measurements and mass flows of fuel and air. The goal of the CRN is to provide a computationally fast means of interpreting measurements in real time with regard to blowout proximity. The free radical concentrations and their trends and ratios are studied in each reactor zone. The results indicate that the hydroxyl radical maximum concentration moves downstream as the reactor approaches LBO. The ratio of hydroxyl radical concentrations in the jet region 
versus the recirculation region is proposed as a criterion for the LBO proximity. This real-time, model-based monitoring methodology sheds insight into combustion processes in aerodynamically stabilized combustors as they approach LBO. 


\section{TABLE OF CONTENTS}

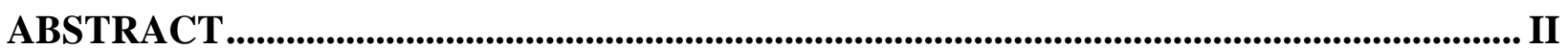

LIST OF FIGURES ........................................................................................................................ VI

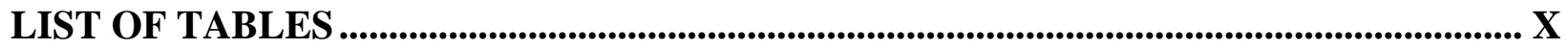

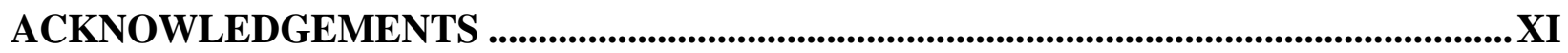

CHAPTER 1. INTRODUCTION ................................................................................................... 1

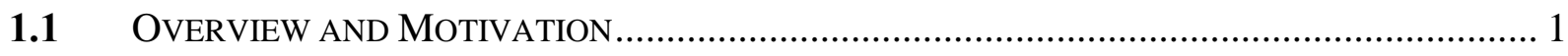

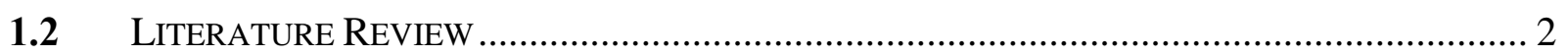

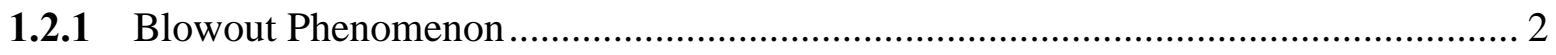

1.2.2 Lean Blowout Prediction .................................................................................. 3

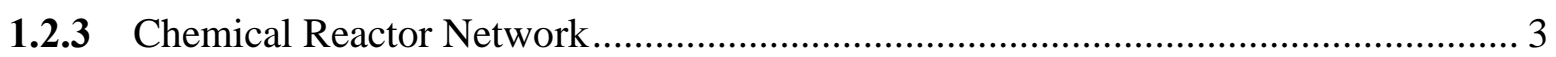

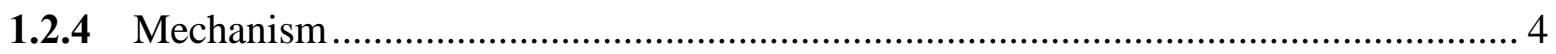

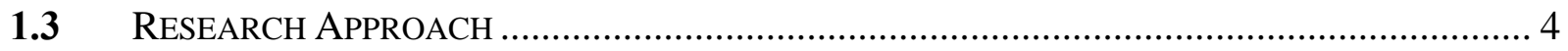

CHAPTER 2. EXPERIMENTAL METHODS.................................................................................... 6

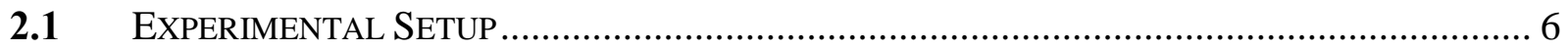

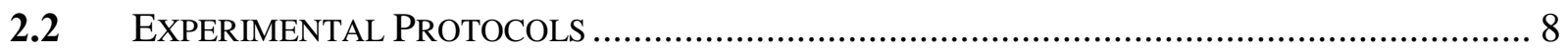

CHAPTER 3. CHEMICAL REACTOR NETWORK: DEVELOPMENT AND

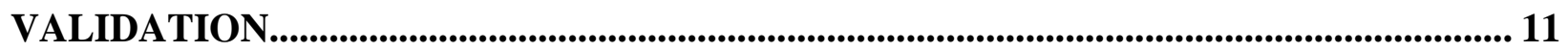

3.1 EXPERIMENTAL EVALUATION OF THE CRN APPROACH................................................. 12

CHAPTER 4. LEAN BLOWOUT EXPERIMENTS ............................................................... 17

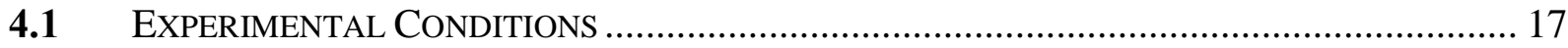

4.2 Blowout Modeling - Major Combustion SPECIES ................................................... 19

4.3 MODELED SPECIES CONCENTRATION USING CRN …….................................................. 22

CHAPTER 5. CONCLUSIONS AND FUTURE WORK ........................................................ 28

REFERENCES........................................................................................................................................ 30

APPENDIX A - GAS ANALYZERS......................................................................................... 34

APPENDIX B - CONTROL SYSTEM ............................................................................................ 35

APPENDIX C - TEMPERATURE MEASUREMENT................................................................... 36

APPENDIX D - IGNITER........................................................................................................ 37

APPENDIX E - EXPERIMENTAL STANDARD OPERATING PROCEDURE................. 38

APPENDIX F - EQUIVALENCE RATIOS USING GAS ANALYZERS............................. 41 
APPENDIX G - ANALYSIS OF FREE RADICALS AND DATA FOR ADDITIONAL AIR

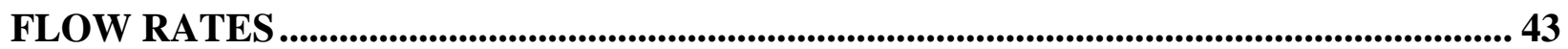

APPENDIX H - DAMKOHLER NUMBER ANALYSIS ................................................... 62 


\section{LIST OF FIGURES}

Fig. 1: Schematic of the experimental setup; sampling locations and direction of flow inside the JSR are indicated. Detailed description of premixer can be found in Lee [49]

Fig. 2: Schematic showing interaction and direction of data flow between various modules of the experimental setup. Solid line represent physical flow, dashed line represents data flow. .....8

Fig. 3: Left - CFD solution of Karalus [32] with the overlaid CRN zones. The velocity vectors are colored by reaction rate of CO destruction $\left[\mathrm{kg} / \mathrm{m}^{3}-\mathrm{s}\right]$. Right $-\mathrm{CRN}$ model with flow splits and

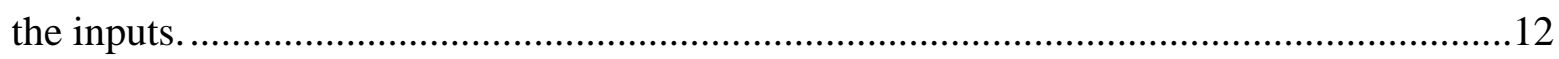

Fig. 4: Measured temperatures in the recirculation zone for $\Phi=0.65-0.80$; airflow rates of 1.0

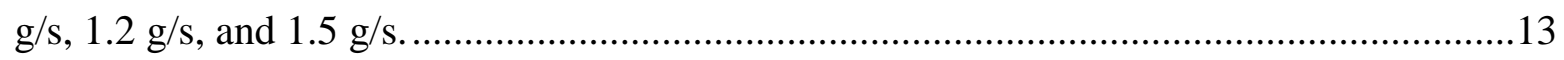

Fig. 5: The measured $\mathrm{CO}$ dry concentration and computed concentration using CRN in different elements for $\Phi$ range: $0.65-0.80$ and at air flow rates of $1.0 \mathrm{~g} / \mathrm{s}, 1.2 \mathrm{~g} / \mathrm{s}$, and $1.5 \mathrm{~g} / \mathrm{s}$. The CO is sampled from the recirculation region of the JSR.

Fig. 6: The measured $\mathrm{CO}_{2}$ dry concentration and computed concentration using $\mathrm{CRN}$ in different elements for $\Phi$ range: $0.65-0.80$ and at air flow rates of $1.0 \mathrm{~g} / \mathrm{s}, 1.2 \mathrm{~g} / \mathrm{s}$, and $1.5 \mathrm{~g} / \mathrm{s}$. The $\mathrm{CO} 2$ is sampled from the recirculation region of the JSR.

Fig. 7: The measured $\mathrm{CO}$ and $\mathrm{CO}_{2}$ concentration (dry) and computed concentration using $\mathrm{CRN}$ in different elements for $\Phi$ range: $0.65-0.80$ and at air flow rates of $1.2 \mathrm{~g} / \mathrm{s}$. The gases are sampled from the recirculation region of the JSR.

Fig. 8: The measured $\mathrm{O}_{2}$ dry concentration and computed concentration using $\mathrm{CRN}$ in different elements for $\Phi$ range: $0.65-0.80$ and at air flow rates of $1.0 \mathrm{~g} / \mathrm{s}, 1.2 \mathrm{~g} / \mathrm{s}$, and $1.5 \mathrm{~g} / \mathrm{s}$. The $\mathrm{O}_{2}$ is sampled from the recirculation region of the JSR.

Fig. 9: Temperature in different elements of the $\mathrm{CRN}$ and the experimental temperature, which is also the input to the PST3 for an air flow rate of $1.2 \mathrm{~g} / \mathrm{s}$. The $\Phi$ is varied from 0.80 to 0.62 at $\mathrm{t}=0 \mathrm{~s}$.

Fig. 10: Experimental and CRN concentrations of (a) $\mathrm{CO}_{2}$ (b) $\mathrm{O}_{2}$ and (c) $\mathrm{CO}$ for an air flow rate of $1.2 \mathrm{~g} / \mathrm{s}$ and blowout equivalence ratio of 0.62 (Starting $\Phi 0.80$ ). The experimental concentrations are corrected for the 18 seconds delay in sampling line....

Fig. 11: Concentration of $\mathrm{CH}_{4}$ computed using CRN in (a) different elements (b) PST3 of CRN for an air flow rate of $1.2 \mathrm{~g} / \mathrm{s}$ and $\Phi$ of 0.62 near blowout.............................................23

Fig. 12: (a) The concentration of hydroxyl radicals $(\mathrm{OH})$ as a function of time (s) in different elements, predicted by CRN and the corresponding experimental temperature from the recirculation zone (K) until $\mathrm{LBO}(\mathrm{b}) \mathrm{OH}$ concentrations as the function of recirculation zone

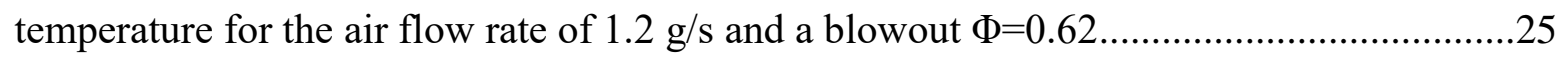

Fig. 13: Concentration of hydroxyl radicals $(\mathrm{OH})$ in different elements, of the $\mathrm{CRN}$ as a function of time inside the JSR at different lab times near the blowout and for air flow rate $1.2 \mathrm{~g} / \mathrm{s}$ and blowout $\Phi 0.62$.

Fig. 14: Schematic diagram of control box that houses the electronics to control and gather data from JSR .35 
Fig. 15: Schematic diagram of igniter and transformer.

Fig. 16: Experimental and modeled concentrations of (a) $\mathrm{CO}_{2}$ (b) $\mathrm{O}_{2}$ and (c) $\mathrm{CO}$ for an air flow rate of $1.0 \mathrm{~g} / \mathrm{s}$ and blowout equivalence ratio of 0.62 (initial $\Phi=0.79$ ). The experimental concentrations are corrected for the 18 seconds delay in sampling line.

Fig. 17: Experimental and modeled concentrations of (a) $\mathrm{CO}_{2}$ (b) $\mathrm{O}_{2}$ and (c) $\mathrm{CO}$ for an air flow rate of $1.5 \mathrm{~g} / \mathrm{s}$ and blowout equivalence ratio of 0.62 (initial $\Phi=0.78$ ). The experimental concentrations are corrected for the 18 seconds delay in sampling line. .45

Fig. 18: Experimental and modeled concentrations of (a) $\mathrm{CO}_{2}$ (b) $\mathrm{O}_{2}$ and (c) $\mathrm{CO}$ for an air flow rate of $1.0 \mathrm{~g} / \mathrm{s}$ and blowout equivalence ratio of 0.62 (initial $\Phi=0.79$ ). The experimental concentrations are not corrected for the 18 seconds delay in sampling line.

Fig. 19 Experimental and CRN concentrations of (a) $\mathrm{CO}_{2}$ (b) $\mathrm{O}_{2}$ and (c) $\mathrm{CO}$ for an air flow rate of $1.2 \mathrm{~g} / \mathrm{s}$ and blowout equivalence ratio of 0.62 (Starting $\Phi 0.80$ ). The experimental concentrations are not corrected for the 18 seconds delay in sampling line.

Fig. 20 Experimental and CRN concentrations of (a) $\mathrm{CO}_{2}$ (b) $\mathrm{O}_{2}$ and (c) $\mathrm{CO}$ for an air flow rate of $1.5 \mathrm{~g} / \mathrm{s}$ and blowout equivalence ratio of 0.62 (Starting $\Phi 0.78$ ). The experimental concentrations are not corrected for the 18 seconds delay in sampling line. .50

Fig. 21: Left - The concentration of $\mathrm{H}$ atom as a function of time for each CRN element and the corresponding experimental temperature. Right - $\mathrm{H}$ atom concentrations as the function of measured temperature for the air flow rate of $1.2 \mathrm{~g} / \mathrm{s}$ and a final $\Phi=0.62$.

Fig. 22: Left - The concentration of $\mathrm{O}$ atom as a function of time for each CRN element and the corresponding experimental temperature. Right - $\mathrm{O}$ atom concentrations as the function of measured temperature for the air flow rate of $1.2 \mathrm{~g} / \mathrm{s}$ and a final $\Phi=0.62$

Fig. 23: Left - The concentration of $\mathrm{CH}_{3}$ atom as a function of time for each CRN element and the corresponding experimental temperature. Right - $\mathrm{CH}_{3}$ atom concentrations as the function of measured temperature for the air flow rate of $1.2 \mathrm{~g} / \mathrm{s}$ and a final $\Phi=0.62$. .52

Fig. 24: Left - The concentration of $\mathrm{HCO}$ atom as a function of time for each CRN element and the corresponding experimental temperature. Right - $\mathrm{HCO}$ atom concentrations as the function of measured temperature for the air flow rate of $1.2 \mathrm{~g} / \mathrm{s}$ and a final $\Phi=0.62 \ldots \ldots \ldots .52$

Fig. 25: Left - The concentration of $\mathrm{CH}$ atom as a function of time for each CRN element and the corresponding experimental temperature. Right - $\mathrm{CH}$ atom concentrations as the function of measured temperature for the air flow rate of $1.2 \mathrm{~g} / \mathrm{s}$ and a final $\Phi=0.62$ .53

Fig. 26: Left - The concentration of $\mathrm{CH}_{2} \mathrm{O}$ atom as a function of time for each $\mathrm{CRN}$ element and the corresponding experimental temperature. Right - $\mathrm{CH}_{2} \mathrm{O}$ atom concentrations as the function of measured temperature for the air flow rate of $1.2 \mathrm{~g} / \mathrm{s}$ and a final $\Phi=0.62 \ldots \ldots . . .53$

Fig. 27 Concentration of Formyl radical (HCO) in different elements, of the CRN as a function of time inside the JSR at different lab times near the blowout and for air flow rate of $1.2 \mathrm{~g} / \mathrm{s}$ and $\Phi=0.62$ .54

Fig. 28: Left - The concentration of $\mathrm{OH}$ atom as a function of time for each $\mathrm{CRN}$ element and the corresponding experimental temperature. Right - $\mathrm{OH}$ atom concentrations as the function of 
measured temperature for air flow rates of (a) $1.0 \mathrm{~g} / \mathrm{s}$ and (b) $1.5 \mathrm{~g} / \mathrm{s}$ and blowout equivalence ratios of 0.62 .

Fig. 29 Left - The concentration of $\mathrm{H}$ atom as a function of time for each CRN element and the corresponding experimental temperature. Right - $\mathrm{H}$ atom concentrations as the function of measured temperature for the air flow rate of $1.0 \mathrm{~g} / \mathrm{s}$ and a final $\Phi=0.62$.....

Fig. 30: Left - The concentration of $\mathrm{O}$ atom as a function of time for each CRN element and the corresponding experimental temperature. Right - $\mathrm{O}$ atom concentrations as the function of measured temperature for the air flow rate of $1.0 \mathrm{~g} / \mathrm{s}$ and a final $\Phi=0.62 \ldots \ldots \ldots \ldots \ldots \ldots \ldots \ldots \ldots . . .56$

Fig. 31: Left - The concentration of HCO atom as a function of time for each CRN element and the corresponding experimental temperature. Right - $\mathrm{HCO}$ atom concentrations as the function of measured temperature for the air flow rate of $1.0 \mathrm{~g} / \mathrm{s}$ and a final $\Phi=0.62$.........56

Fig. 32: Left - The concentration of $\mathrm{CH}_{3}$ atom as a function of time for each $\mathrm{CRN}$ element and the corresponding experimental temperature. Right $-\mathrm{CH}_{3}$ atom concentrations as the function of measured temperature for the air flow rate of $1.0 \mathrm{~g} / \mathrm{s}$ and a final $\Phi=0.62$ .56

Fig. 33: Left - The concentration of $\mathrm{CH}$ atom as a function of time for each $\mathrm{CRN}$ element and the corresponding experimental temperature. Right - $\mathrm{CH}$ atom concentrations as the function of measured temperature for the air flow rate of $1.0 \mathrm{~g} / \mathrm{s}$ and a final $\Phi=0.62$

Fig. 34: Left - The concentration of $\mathrm{CH}_{2} \mathrm{O}$ atom as a function of time for each CRN element and the corresponding experimental temperature. Right $-\mathrm{CH}_{2} \mathrm{O}$ atom concentrations as the function of measured temperature for the air flow rate of $1.0 \mathrm{~g} / \mathrm{s}$ and a final $\Phi=0.62$..........57

Fig. 35: Left - The concentration of $\mathrm{H}$ atom as a function of time for each CRN element and the corresponding experimental temperature. Right - $\mathrm{H}$ atom concentrations as the function of measured temperature for the air flow rate of $1.5 \mathrm{~g} / \mathrm{s}$ and a final $\Phi=0.62$

Fig. 36: Left - The concentration of $\mathrm{O}$ atom as a function of time for each CRN element and the corresponding experimental temperature. Right - $\mathrm{O}$ atom concentrations as the function of measured temperature for the air flow rate of $1.5 \mathrm{~g} / \mathrm{s}$ and a final $\Phi=0.62$

Fig. 37: Left - The concentration of $\mathrm{HCO}$ atom as a function of time for each CRN element and the corresponding experimental temperature. Right - HCO atom concentrations as the function of measured temperature for the air flow rate of $1.5 \mathrm{~g} / \mathrm{s}$ and a final $\Phi=0.62$..........58

Fig. 38: Left - The concentration of $\mathrm{CH}_{3}$ atom as a function of time for each $\mathrm{CRN}$ element and the corresponding experimental temperature. Right $-\mathrm{CH}_{3}$ atom concentrations as the function of measured temperature for the air flow rate of $1.5 \mathrm{~g} / \mathrm{s}$ and a final $\Phi=0.62 \ldots \ldots \ldots \ldots \ldots \ldots \ldots \ldots . .58$

Fig. 39: Left - The concentration of $\mathrm{CH}_{2} \mathrm{O}$ atom as a function of time for each CRN element and the corresponding experimental temperature. Right $-\mathrm{CH}_{2} \mathrm{O}$ atom concentrations as the function of measured temperature for the air flow rate of $1.5 \mathrm{~g} / \mathrm{s}$ and a final $\Phi=0.62$..........59

Fig. 40: Left - The concentration of $\mathrm{CH}$ atom as a function of time for each $\mathrm{CRN}$ element and the corresponding experimental temperature. Right - $\mathrm{CH}$ atom concentrations as the function of measured temperature for the air flow rate of $1.5 \mathrm{~g} / \mathrm{s}$ and a final $\Phi=0.62$ 
Fig. 41: Concentration of hydroxyl radicals $(\mathrm{OH})$ in different elements, of the $\mathrm{CRN}$ as a function of residence time inside the JSR at different lab times near the blowout and for air flow rates of (a) $1.0 \mathrm{~g} / \mathrm{s}$ (b) $1.5 \mathrm{~g} / \mathrm{s}$ and a final $\Phi=0.62$.

Fig. 42: Concentration of Formyl radicals (HCO) in different elements, of the CRN as a function of time inside the JSR at different lab times near the blowout and for air flow rates of (a) 1.0

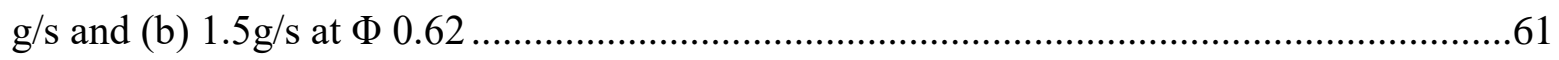

Fig. 43: Damkohler number (Da) as a function of time inside the JSR at different lab times near the blowout and for air flow rates of (a) $1.0 \mathrm{~g} / \mathrm{s}$ (b) $1.2 \mathrm{~g} / \mathrm{s}$ and (c) $1.5 \mathrm{~g} / \mathrm{s}$ and a blowout $\Phi$ 0.62 .

Fig. 44: (a) Mixing and (b) Chemical timescales used for calculation of Da for different air flow rates of $1.0 \mathrm{~g} / \mathrm{s}, 1.2 \mathrm{~g} / \mathrm{s}$, and $1.5 \mathrm{~g} / \mathrm{s}$ .64 


\section{LIST OF TABLES}

Table 1: Real-time Blowout Experimental conditions. The cases in bold are chosen as a baseline and are used to for analysis

Table 2: The time and temperature for the blowout for each experiment. Time to reach the event in seconds is indicated in parenthesis. The crossover in $\mathrm{OH}$ concentration Event 1 (PST3>PSR1), Event 2 (PSR1 blowout) and Event 3 (PST3>PSR2) are shown for each experiment. N/A indicates that reactor reached blowout before Event 3 is observed. .........26

Table 3: Temperature measurement in the JSR at various distances from the center ..................36

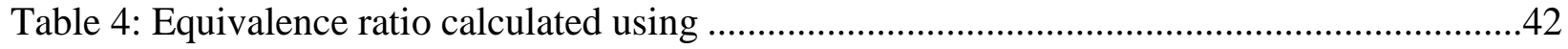

Table 5: Blowout Damkohler Number for various experimental air flow rates and blowout $\Phi$...64 


\section{ACKNOWLEDGEMENTS}

Foremost, I would like to thank Prof. Igor Novosselov for providing me this great opportunity to work on this interesting research topic. His guidance, unique perspective and critical thinking towards a research problem have put me on a path to think critically based on first principles.

I am grateful to Prof. Philip Malte for providing his deep theoretical knowledge, rich experimental experience and a great sense of humor during our meetings. Without his help and expertise, the experiments would not have been possible.

I would like to thank Prof. John Kramlich for the three important courses pertaining to my research: Advanced energy conversion systems, Graduate thermodynamics and Combustion, where he focused on fundamental problem-solving skills and brought in the real-world significance of the otherwise theory-heavy subjects.

In addition, I would like to especially thank the committee for patiently reviewing my thesis and providing valuable feedback to strengthen the presentation of my work and future technical writing in general. I would like to express my gratitude to Prof. Igor Novosselov for providing the funding for the experiments and the fellowship.

Thanks to my friends and colleagues at NRG lab and the University of Washington for their support. Special thanks to Armen Nalbandyan and Saurabh Gupta for aiding me during the lengthy experiments.

Last but not least, I would like to thank my parents and brother for their love and support throughout this endeavor. 


\section{Chapter 1. Introduction}

\subsection{Overview and Motivation}

The growth of population and the advancement of technology are driving a continuous increase in the demand for energy. Fossil fuels are projected to stay a primary source of energy for mankind for the immediate future [1]. A consequence of the use of fossil fuels is generating of products of combustion. These include the main products of water and carbon dioxide, and also environmental pollutants such as oxides of nitrogen $(\mathrm{NO})$, carbon monoxide $(\mathrm{CO})$, unburnt hydrocarbon species, aldehydes, sulfur species, and particulate matter $(\mathrm{PM})$. $\mathrm{NO}$ x reacts with water vapor in the atmosphere to form acidic compounds that affect humans, crops, livestock and marine life. NOx leads to ground-level ozone, and it also reacts with volatile organic compounds forming photochemical smog that affects the human respiratory system. Other species generated by NOx in the atmosphere include nitrate radicals, nitroarenes and nitrosamines. These cause various effects on human health including biological mutations [2].

$\mathrm{NO}_{\mathrm{X}}$ is formed at high temperature during combustion. $\mathrm{NO}_{\mathrm{X}}$ formation rates in flames are a nearly exponential function of temperature, so one way to reduce $\mathrm{NO}_{\mathrm{x}}$ production is by using lean premixed combustion which reduces the flame temperature. The reduction of temperature, however, leads to two of the principal challenges in lean premixed combustion: flame stability and lean flame blowout. Prevention of blowout is a critical goal for land-based power generation and for aero-engines. During throttling of aero-engines, control over the airflow rate can be challenging due to the inertia of the compressor [3], causing a critical undershoot of the equivalence ratio leading to a flame blowout. Therefore, a wide safety margin is generally maintained in aeroengines to remain within a safe operating envelope for all conditions restricting the rate of power change in the engine, constraining the maneuverability of military jets and increasing the time of descent for the aircraft. For land-based power generation applications, fluctuations in power demand during low power operation may cause blowout resulting in an expensive and timeconsuming shutdown, purge, and restart procedures, and these can create frequency stability issues [4].

Current blowout monitoring approaches are based on the sensing of the low-frequency combustion oscillations that precede the blowout event. This approach requires expensive equipment and modifications to the combustors. The objective of this study is to develop a real- 
time modeling and analytical tool to assess the system proximity to blowout using real-time chemical kinetic modeling. The approach can significantly reduce the cost and hardware needed for an active blowout detection and control.

In this work, we demonstrate a simple, computationally efficient chemical reactor network model tuned for a range of the combustor operation envelope can compute non-measurable combustion parameters in real time and can be used to predict proximity to lean blowout. In order to investigate the approach, a laboratory JSR is used to conduct experiments. A CRN comprising of three PSR elements and real-time temperature input is developed to model the JSR. The model monitors the combustor free radical species and reports the results in real time, allowing to estimate the non-measurable combustion parameters including reactor proximity to blowout.

\subsection{Literature Review}

\subsubsection{Blowout Phenomenon}

The lean flame blowout condition is associated with the lowest equivalence ratio that can sustain a flame within a specific combustion geometry [5]. The LBO process depends both on the rate of chemistry and the gas residence time in the flame stabilization region. Earlier research was primarily based on correlating the blowout based on experimental results to Damkohler number (Da). The Damkohler number is defined as the ratio of mixing time to the chemical time $\left(\tau_{\text {mix }} / \tau_{\text {chem }}\right)$. Longwell et al. [6] proposed that blowout occurs when the rate of entrainment of reactants into the recirculation zone cannot be balanced by the rate of burning of those gases. Zukoski and Marble [7] observed that at blowout, the free-stream combustible mixture has a contact time with the wake behind the stabilizer equal to the ignition time of the mixture. Yamaguchi et al. [8] proposed a flamelet description based on local extinction due to flame stretch. Chauduri [9] discussed the behavior of the flame near blowout in terms of flame shape, velocity, and local extinguishing and re-ignition events. Spalding [10] and Kundu et al. [11] studied the role of the recirculation zone on blowout criteria. Nicholson and Field [12] and Chao et al. [13] reported increased flame detachment and reattachment events near blowout. King [14] investigated the effect of parameters such as inlet temperature, pressure and velocity on afterburner lean blowout. Hottel [15] explored the effect of combustion parameters on lean blowout in baffle type combustors. 


\subsubsection{Lean Blowout Prediction}

Recent studies have focused on identifying markers of LBO approach and LBO prevention strategies. For example, Nair and Lieuwen [16] observed changes in the low- frequency acoustic spectrum - an increased presence of time localized and intermittent events in acoustic data approaching blowout. Li et al. [17] used FFT power spectrum analysis of low-frequency temperature fluctuations, measured by a tunable diode laser, for early blowout detection in a partially premixed, swirl-stabilized dump combustor. Mukhopadhyay et al. [18] used a symbolic time series analysis based on the chemiluminescence signal of $\mathrm{CH}^{*}$ radical for partially and fully premixed flows. Yi and Gutmaek [19] observed intensified low-frequency oscillations in $\mathrm{OH}^{*}$ measurements near LBO and used two indices: normalized chemiluminescence root mean square and normalized cumulative duration of LBO precursors to characterize the approach of a blowout. Griebel et al. [20] studied the appearance of increased activity in the $\mathrm{OH}$ chemiluminescence signal to predict LBO in hydrogen enriched methane combustion. Thornton et al. [21] used the change in the electrical properties of the products, detected by electrodes integrated into fuel nozzle, as a detector. Muruganandam et al. [22],[23] investigated LBO precursors based on $\mathrm{OH}^{*}$ chemiluminescence as well as the acoustic disturbances near LBO. Current methods used for active prediction and control of LBO require engine hardware modifications, such as optical access, and these are generally expensive and intrusive.

\subsubsection{Chemical Reactor Network}

The concept of combustor modeling using the CRN, consisting of combinations of PSR and plug flow reactor (PFR) elements, was introduced to model the combustion process by Bragg [24]. In a PSR the gases are assumed to mix instantaneously, which is appropriate when the chemical time is much slower than the mixing time. The PSR reactor concept is implemented by balancing the Arrhenius source terms of net production of each species by convective removal of that species from the PSR control volume. PFR element assumes one-dimensional plug flow and is often used to model post flame process.

The CRN models have most commonly been used to study pollutant emissions in laboratory reactors and gas turbine engines, e.g. [25-30] employed a two element reactor to study the influence of lean blowout limit of an industrial gas turbine. Lefebvre [31] established a quantitative relationship between aspects of combustion and physical properties of the combustor based on the well-stirred reactor concept. Karalus [32] used a two element CRN to study the 
behavior of $\mathrm{OH}$ in hydrogen and methane flames on convective time scale through the jet-stirred reactor. A CRN for industrial swirl-stabilized combustors has been reported in the literature [3335].

A number of authors have investigated the numerical implementation of CRN modeling. Related to this work, the in-house CRN code was originally developed by Pratt and co-workers who also applied the software to model high-intensity combustors, e.g., Pratt and Wormeck [36], Pratt and Radhakrishnan [37], Radhakrishnan and Pratt [38], Pratt [39]. The PSR reactor concept is implemented by balancing the Arrhenius source terms of net production of each species by convective removal of that species from the PSR control volume. The PFR is modeled by a series of PSRs. The code has been modified by other researchers [32], [40], [41]. One of the major benefits of this code is in the implementation of the fast convergence algorithm, , which enables fast chemical kinetic calculations in more complex reactor networks.

\subsubsection{Mechanism}

GRI 3.0 is an optimized chemical kinetic mechanism to model natural gas combustion [37]. It contains 325 reaction steps and 52 species. The GRI 3.0 mechanism has been validated using experimental data for methane, ethane, hydrogen and carbon monoxide. For example, Hu et al. found good agreement between the laminar burning velocities calculated experimentally and computationally using the GRI 3.0 mechanism for the methane-hydrogen-air flame [38]. Flame speed validation [42-45] and ignition delay comparison with experiment data [46], [47] have been reported for GRI 3.0

\subsection{Research Approach}

This thesis examines the application of a real-time modeled-based approach to determine reactor proximity to a blowout. The research combines an experimental and modeling study to achieve the following objectives:

- Construct a real-time CRN (RT-CRN) based on the real-time temperature and fuel-air flow rate input.

- Validate the RT-CRN using the experimental $\mathrm{CO}, \mathrm{CO}_{2}$ and $\mathrm{O}_{2}$ concentrations data for JSR operating over a range of airflow rates and equivalence ratios under steady-state conditions. 
- Examine utility of RT-CRN to predict the exhaust gas concentrations in transient blowout experiments.

- Study the behavior of free radicals near blowout and use the trends to develop a blowout prediction methodology. 


\section{Chapter 2. Experimental Methods}

\subsection{Experimental Setup}

The experimental study focuses on characterizing lean blowout of methane in a high intensity, back-mixed, JSR. The JSR serves as a laboratory idealization of the primary zone of a gas turbine combustor. The total volume of the reactor used in this study is $15.8 \mathrm{cc}$. The JSR has two main zones: the jet zone and the recirculation zone. The JSR comprises a stainless steel premixer, Inconel nozzle block and a ceramic reactor as shown in figure 1 . The air and fuel entry into the JSR are metered through Sierra instruments mass-flow controllers (MFC) that are controlled via National Instruments MyRio. The air is supplied from the filtered shop air line at a pressure of 80 psig. The fuel is supplied from a high-pressure cylinder at a regulated pressure of $80 \mathrm{psig}$. A premixed fuel-air mixture enters the reactor through a $2 \mathrm{~mm}$ choked nozzle with a sonic jet velocity of approximately $411 \mathrm{~m} / \mathrm{s}, 456 \mathrm{~m} / \mathrm{s}$ and $504 \mathrm{~m} / \mathrm{s}$ for air flow rates of $1.0 \mathrm{~g} / \mathrm{s}, 1.2 \mathrm{~g} / \mathrm{s}$, and $1.5 \mathrm{~g} / \mathrm{s}$. The inlet jet velocity is based on the isentropic discharge equation [48]:

$$
u_{0}=\sqrt{\frac{2 \gamma R T}{\gamma-1}\left[1-\left(\frac{P_{J S R}}{P_{\text {Premix }}}\right)^{\frac{\gamma-1}{\gamma}}\right]}
$$

Where:

$\checkmark=$ Ratio of specific heats for methane and air mixture

$\mathrm{T}=$ Temperature at the inlet of JSR $(390 \mathrm{~K})$

PJSR $=$ Pressure inside the Jet-Stirred Reactor $(1 \mathrm{~atm})$

$P_{\text {Premix }}=$ Measured pressure inside the premixing chamber ( $2 \mathrm{~atm}, 2.4 \mathrm{~atm}$, and $3 \mathrm{~atm}$ for air flow rates of $1.0 \mathrm{~g} / \mathrm{s}, 1.2 \mathrm{~g} / \mathrm{s}$, and $1.5 \mathrm{~g} / \mathrm{s}$ respectively)

The temperature and species measurements in the JSR are collected at $2 / 3$ height of the reactor, as shown in Figure 1. An R-type thermocouple (TC), coated with alumina in order to prevent catalytic effects, is used for the temperature measurement inside the JSR. K-type thermocouples are used for monitoring the temperature of reactants in the injector/premixer. The thermocouple data are relayed to the LabVIEW environment using a TC DAQ by Omega Systems. In the steady-state conditions experiments, the temperature correction for radiative heat loss to walls is calculated to be $21 \mathrm{~K}-43 \mathrm{~K}$ [49]. However, in the transient RT-CRN calculations the 
temperature is not corrected due to the uncertainty of the temperature difference between the gases and the walls; the gas temperature changes rapidly, the wall temperature changes slower and in the blowout experiments it is higher than the temperature of the gas. In order to maintain consistency, the uncorrected thermocouple temperature (for heat loss/gain) is used for all experiments.

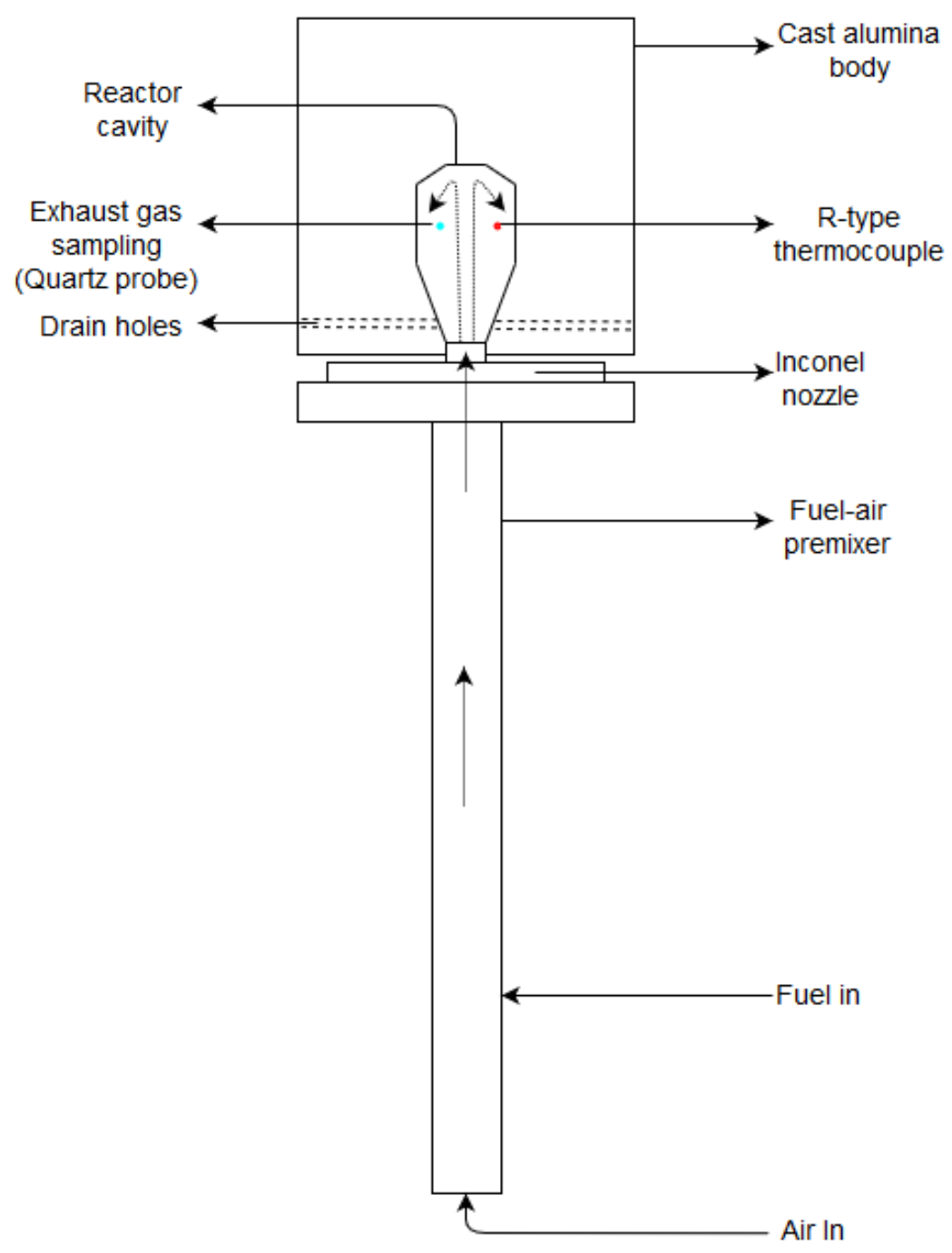

Fig. 1: Schematic of the experimental setup; sampling locations and direction of flow inside the JSR are indicated. Detailed description of premixer can be found in Lee [49]

Figure 2 shows the data flow between the various modules. The gas samples are collected from the JSR using water-cooled quartz probes [50]. The gases are sampled $9 \mathrm{~mm}$ from the center of the JSR at a 2/3rd the height of the reactor, which corresponds to the location of the recirculation 
zone (Appendix C). Before entering the analyzers, the gases are passed through an ice chamber in order to condense the water vapor in the sample. The sample flow then passes through the three gas analyzer (VA 3000 by Horiba Instruments) to measure $\mathrm{CO}, \mathrm{CO}_{2}$, and $\mathrm{O}_{2}$ (figure 2). The data from the analyzers are collected via a National Instruments (NI) MyRio data acquisition card connected via the LabVIEW interface. The sampling frequency is $100 \mathrm{~Hz}$. In addition to data from gas analyzers, MyRio is used to acquire the mass flow from the MFC, The data passed to LabView environment is also used to calculate the global combustion parameters such as equivalence ratio, residence time, as well as the real-time detailed $\mathrm{CRN}$ calculations.

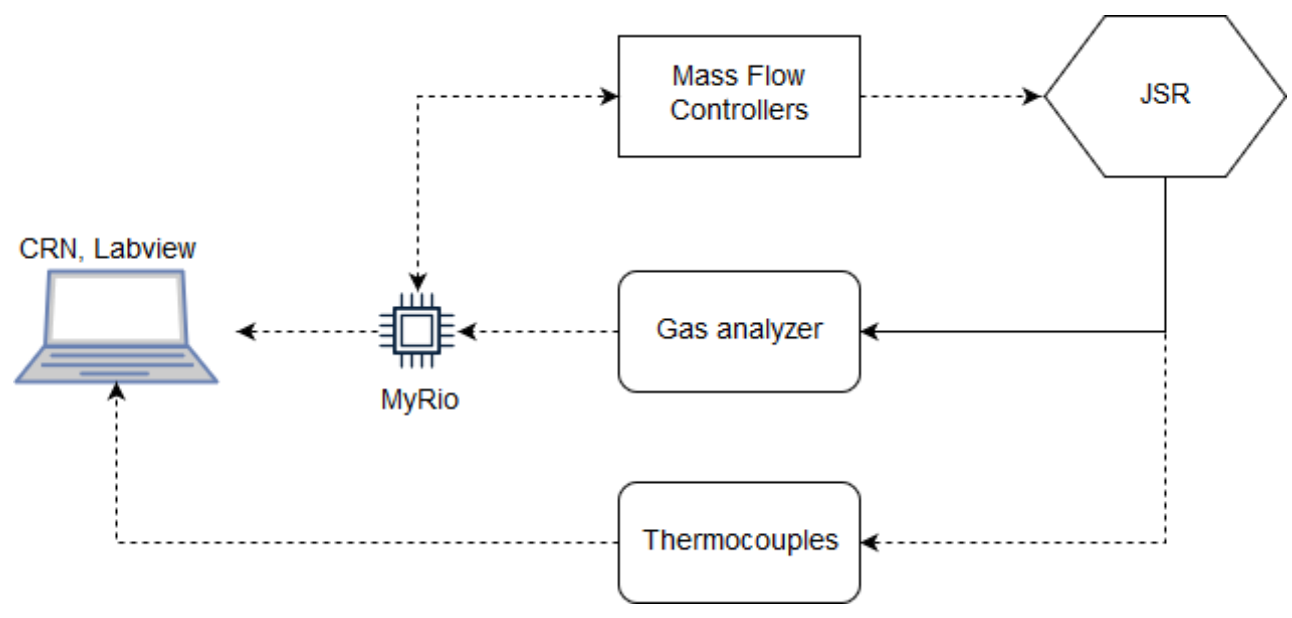

Fig. 2: Schematic showing interaction and direction of data flow between various modules of the experimental setup. Solid line represents physical flow, dashed lines represent data flow.

\subsection{Experimental Protocols}

Two types of experiments are conducted: (i) steady-state experiments for tuning the RT-CRN model and (ii) blowout experiments to evaluate RT-CRN model prediction in the transient combustion region. The steady-state experiments have been conducted at three different reactor load conditions: the air flow rate was set at either $1.0 \mathrm{~g} / \mathrm{s}, 1.2 \mathrm{~g} / \mathrm{s}$ or $1.5 \mathrm{~g} / \mathrm{s}$. With the air flow rate set, temperature and JSR gas composition data have been collected at different equivalence ratios. The nominal residence times were $2.8 \mathrm{~ms}, 2.3 \mathrm{~ms}$, and $1.9 \mathrm{~ms}$ for the air flow rates of $1.0 \mathrm{~g} / \mathrm{s}, 1.2$ $\mathrm{g} / \mathrm{s}$, and $1.5 \mathrm{~g} / \mathrm{s}$ at $1800 \mathrm{~K}$. In each experiment, the total air flow rate of the combustor was held constant, and the fuel flow rate was decreased in steps. By maintaining a constant air flow rate, variations in the combustor's flow dynamic behavior, residence time, and turbulence levels remain relatively constant. In the steady-state experiments, the flow conditions (both fuel and air flow rates) were held constant for at least 15 minutes in order to reach the steady-state combustor 
operation (as confirmed by temperature and the gas concentration measurements). The data from the steady-state experiments are used to evaluate and tune the CRN model.

The blowout experiments were conducted at three different air-flow rates $(1.0 \mathrm{~g} / \mathrm{s}, 1.2 \mathrm{~g} / \mathrm{s}$, and $1.5 \mathrm{~g} / \mathrm{s}$ ). In the blowout experiments, the initial reactor state was set at a stable operating condition. The initial equivalence ratio was in the range $\Phi=0.78-0.80$ for all airflow rates and the measured uncorrected recirculation zone temperature is $1730 \mathrm{~K}-1790 \mathrm{~K}$. After reaching the steady-state conditions, the flow rate of fuel is reduced as a step function to a fuel-air equivalence ratio below the LBO limit as determined in the steady-state experiments. In the transient experiments, the high reactor wall temperature at the start of the experiment was able to sustain the combustion at the lower $\Phi$ due to the external heating of the reacting mixture before the reactor wall cools down to reach a new steady state condition. The final $\Phi$ values in the transient experiments were set to achieve LBO at various laboratory times. Lower values for the final $\Phi$ causes the most rapid temperature drop and the shortest time to LBO. Depending on the final $\Phi$ selected, LBO occurs within 9-550 seconds. At least three values of the final $\Phi$ conditions for all combustor loading levels were used. Each blowout condition is repeated at least three times to show the repeatability of the data.

In these blowout experiments, the uncorrected thermocouple temperature measurements were provided to the $\mathrm{CRN}$ code. At the initial steady-state (high $\Phi$ ) the thermocouple loses heat to the wall and reports a lower temperature than the gas temperature. As the fuel flow rate is reduced, the thermocouple may report a higher temperature than the gas temperature, at this point, the walls are hotter than the gas resulting in radiative heating of the TC probe. Hence, during the transient state, it is difficult to calculate the thermocouple heat loss/gain correction. In order to maintain consistency, uncorrected temperature values were used for steady state experiments, although previous work can provide guidance on the TC correction for steady state JSR operation [46]. The combustor equivalence ratio was calculated using two independent methods: (i) via measured fuel and air mass flow rates, (ii) using the measured exhaust gas composition. For consistency, the equivalence ratios reported in this work have been calculated based on exhaust gas composition (See Appendix F). The mass flow controller model equivalence ratios were consistently higher than the $\Phi$ calculated using exhaust gas composition. A constant difference of $11.4 \%$ between MFC and exhaust gas based equivalence ratios for $1.0 \mathrm{~g} / \mathrm{s}$ and $1.2 \mathrm{~g} / \mathrm{s}$; and $13.7 \%$ difference for 
$1.5 \mathrm{~g} / \mathrm{s}$ air flow rate is observed in all the cases. This difference could be attributed to leaks in the probe line and the errors associated with MFC calibration. 


\section{Chapter 3. Chemical Reactor Network: Development and Validation}

The CFD simulations of the JSR [28], [32] have been used as guidance for the CRN development. The JSR is divided into a free jet region, an impinging jet region and a recirculation zone with $75 \%$ gas entrainment from recirculation zone into the flame zone [51]. Figure 3(b) shows the schematic of the CRN. In stable, higher $\Phi$ operation, the jet region contains the flame zone which consists of a thin strained flame on the sides of the inlet jet and a flame brush at the end of the jet. In the CRN, the free jet region is treated as a single adiabatic PSR1 of relatively small constant volume. The impinging jet region contains the immediate post flame zone; there the jet impinges on the combustor wall and reverses direction; the zone is modeled as an adiabatic PSR2. During stable and higher $\Phi$ operation, the PSR2 simulates the fall off in free radial concentrations as the reacting gases travel through the JSR, from flame zone to downwards flow into the recirculation zone. Conditions in each zone change depending on the input conditions to the model. During stable combustion (T>1700 K), the PSR1 models the flame zone, the PSR2 represents the near post flame zone. However, at lower values of $\Phi$ the premixed fuel-air jet of PSR1 may not ignite due to the insufficient residence time, and ignition occurs in PSR2 due to the extended residence time required for ignition (attained from the combined PSR1 and PSR2). The recirculation zone is modeled as PST3 (PSR with assigned temperature). The uncorrected measured temperature is used in the real-time model as input for the PST. Although the mixing rates in the recirculation zone are lower than in the flame zone, the chemical rates are also low which merits the use of the PSR element. The perfectly stirred element describes the intense turbulent mixing in the recirculation zone, and the real-time temperature feedback from the combustor captures the practical, non-adiabatic nature of the combustor. With the real-time temperature feedback into PST3 and 75\% recirculation from PST3 to PSR1, the physical phenomenon where the recirculation zone interacts with the flame zone is incorporated.

The volumes of the elements (i.e., zones) are calculated based on the CFD solution of Karalus [32]. The PSR1 volume is calculated as a region of upward moving flow, limited by the height of the eye of the recirculation zone (See Figure 3a). The PSR1 zone inputs are the fuel-air jet and all of the entrained flow from the recirculation zone. The PSR2 is the volume of upward moving flow directly downstream of the flame zone to the point where the jet impinges on the top wall, and it begins moving away from the center. PST3 element models the downwards flow. The gas cools due to its proximity to the wall, so this zone cannot be modeled as an adiabatic element. The 
temperature input is taken from the thermocouple measurement located in the annular flow region $3.5 \mathrm{~mm}$ away from the wall.
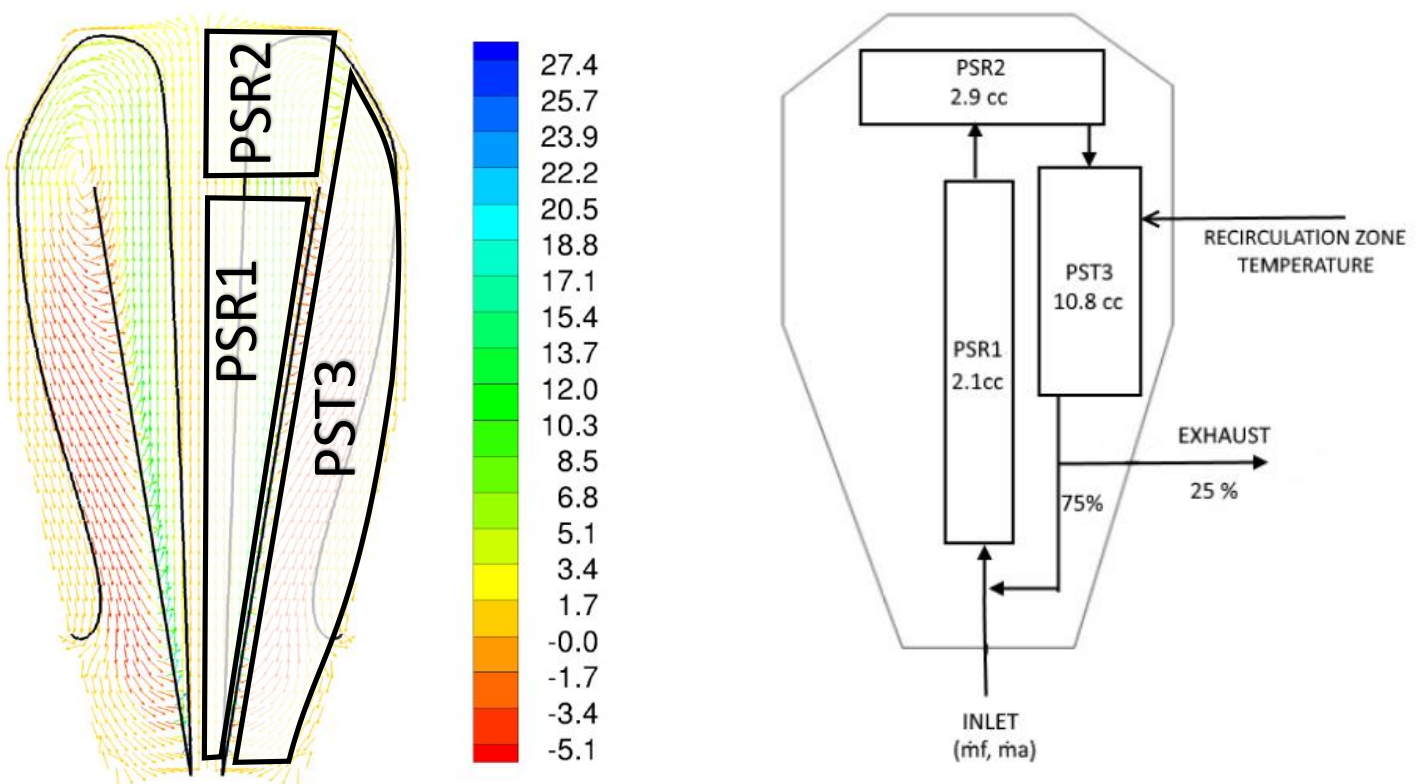

Fig. 3: Left - CFD solution of Karalus [32] with the overlaid CRN zones. The velocity vectors are colored by reaction rate of $\mathrm{CO}$ destruction $\left[\mathrm{kg} / \mathrm{m}^{3}\right.$-s]. Right - CRN model with flow splits and the inputs.

\subsection{Experimental Evaluation of the CRN Approach}

The steady-state experimental data for a range of operating conditions are used to evaluate the RT-CRN model. The air flow rates are varied as $1.0 \mathrm{~g} / \mathrm{s}, 1.2 \mathrm{~g} / \mathrm{s}$, and $1.5 \mathrm{~g} / \mathrm{s}$. For each loading, the $\Phi$ range is $0.66-0.80$. The temperature, $\mathrm{CO}, \mathrm{CO}_{2}$ and $\mathrm{O}_{2}$ data are collected in the recirculation zone using the gas sampling system. Figure 4 shows the recirculation zone temperature at different equivalence ratios at various air flow rates. Lower air flow rates show the reduced combustion temperature for the same $\Phi$ due to a greater heat loss. 


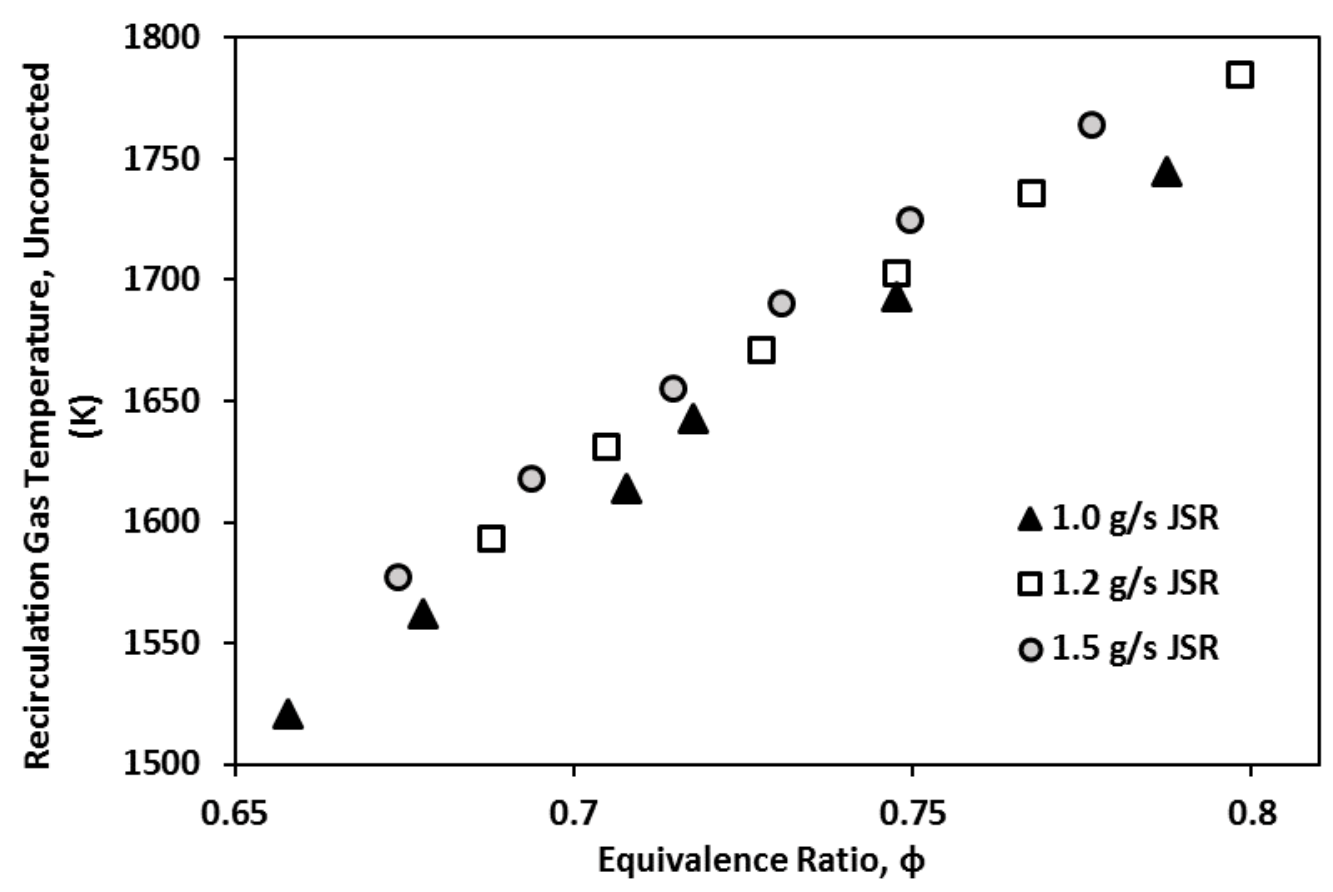

Fig. 4: Measured temperatures in the recirculation zone for $\Phi=0.65-0.80$; airflow rates of $1.0 \mathrm{~g} / \mathrm{s}, 1.2 \mathrm{~g} / \mathrm{s}$, and $1.5 \mathrm{~g} / \mathrm{s}$.

Figures 5 - 8 compare the dry concentrations of the $\mathrm{CO}, \mathrm{CO}_{2}$, and $\mathrm{O}_{2}$ measured experimentally and corresponding concentrations computed in each element of the CRN model. The modeled recirculation $\mathrm{CO}$ is in good agreement with the experimental data, the measured levels in PST3 are slightly higher. The experimental data falls between the PSR2 and the PST3 levels. Some uncertainties in $\mathrm{CO}$ measurement include: (i) $\mathrm{CO}$ oxidation in the in the probe and (ii) the probe location effect - possible local chemistry quenching in the jet impingement on the top combustor wall where the heat transfer coefficient and the temperature difference is the highest, which will result in elevated $\mathrm{CO}$ concentrations moving down the wall. As the equivalence ratio is reduced from the maximum values, the $\mathrm{CO}$ concentration decrease slightly, however, incomplete combustion at the lower equivalence ratios results in the quenching of $\mathrm{CO}$ to $\mathrm{CO}_{2}$ oxidation in PSR2 and PST3, leading to increased CO. In PSR1, the CO is the highest except for the lower $\Phi$ conditions where combustion cannot be sustained, and the element blows out due to limited residence time in the free jet region. In these cases, the CO concentrations in PSR1 are very similar to those of PST3 as the recirculating gas is entrained into the PSR1. For the solutions where the PSR1 does not sustain combustion, the ignition of the premixed fuel and air with added hot gasses from the recirculation zone happens in PSR2, which is shown by high CO levels in that element. 
As the flame moves into the second element, the PSR 1 is acting as a preheat element where some initial fuel break down occurs as shown by CO levels being slightly higher than in the PST3. The initial chain branching chemistry is also observed, the free radicals and the methane concentrations change as described later in this work.

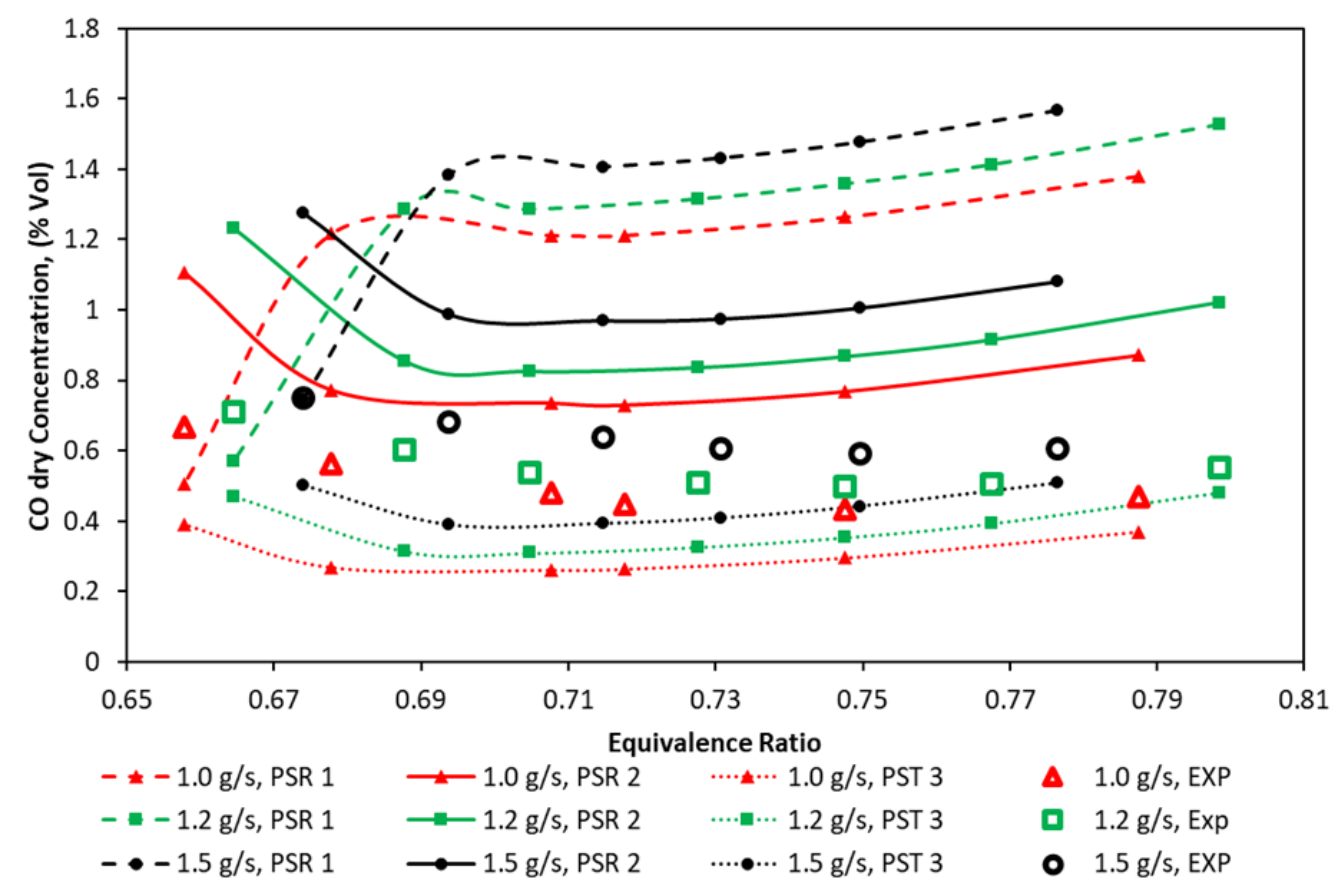

Fig. 5: The measured $\mathrm{CO}$ dry concentration and computed concentration using CRN in different elements for $\Phi$ range: $0.65-0.80$ and at air flow rates of $1.0 \mathrm{~g} / \mathrm{s}, 1.2 \mathrm{~g} / \mathrm{s}$, and $1.5 \mathrm{~g} / \mathrm{s}$. The $\mathrm{CO}$ is sampled from the recirculation region of the JSR.

Figure 6 shows that the $\mathrm{CO}_{2}$ concentration in the recirculation zone decreases with decreasing equivalence ratio due to a reduction in fuel flow rate. The $\mathrm{CO}_{2}$ concentration computed by the CRN agrees with the experimental values. Similar to $\mathrm{CO}$, the $\mathrm{CO}_{2}$ values lie between the PSR2 and PST3 values. Figure 7 shows the $\mathrm{CO}$ and $\mathrm{CO}_{2}$ for the $1.2 \mathrm{~g} / \mathrm{s}$ case. At lower temperatures, the $\mathrm{CO}$ to $\mathrm{CO}_{2}$ oxidation is quenched, resulting in an increase in $\mathrm{CO}$ while decreasing $\mathrm{CO}_{2}$ concentration. 


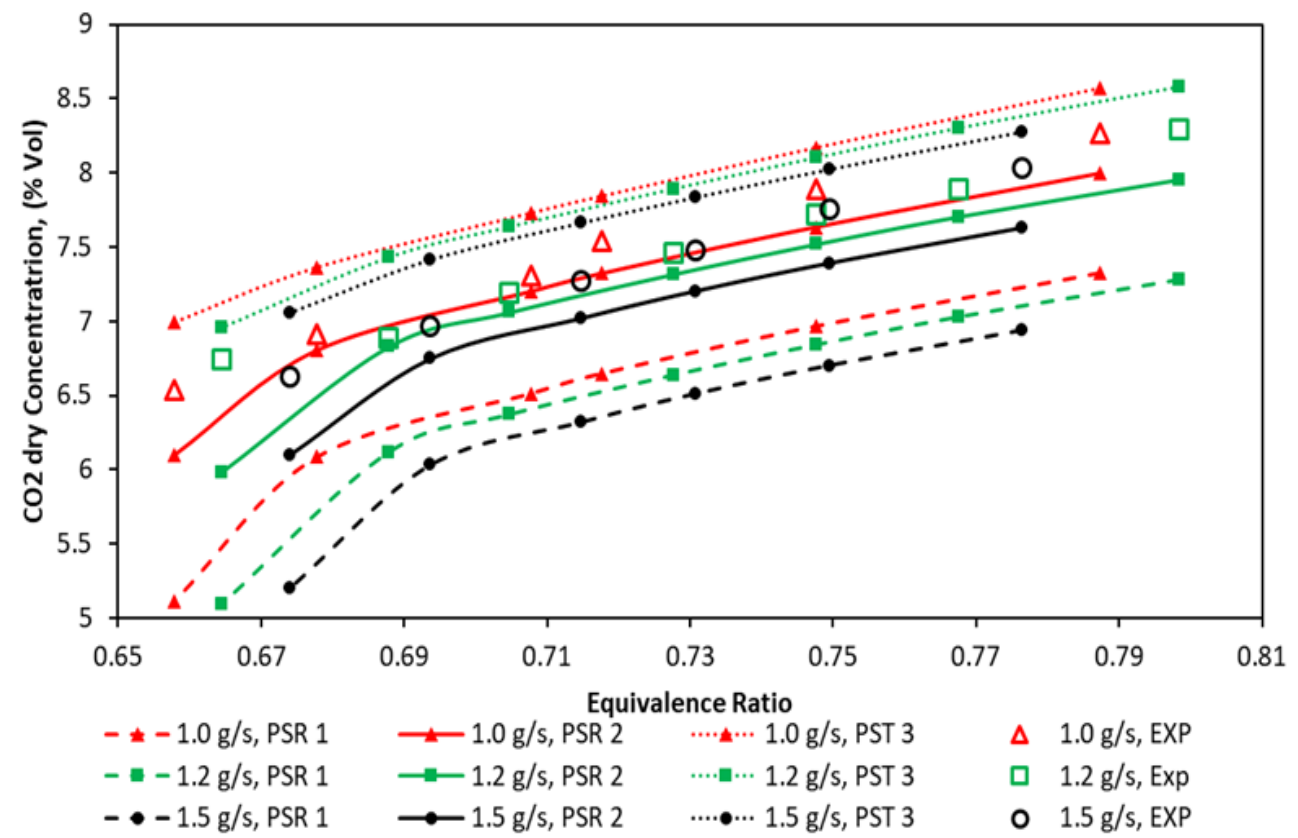

Fig. 6: The measured $\mathrm{CO}_{2}$ dry concentration and computed concentration using $\mathrm{CRN}$ in different elements for $\Phi$ range: $0.65-0.80$ and at air flow rates of $1.0 \mathrm{~g} / \mathrm{s}, 1.2 \mathrm{~g} / \mathrm{s}$, and $1.5 \mathrm{~g} / \mathrm{s}$. The $\mathrm{CO} 2$ is sampled from the recirculation region of the JSR.

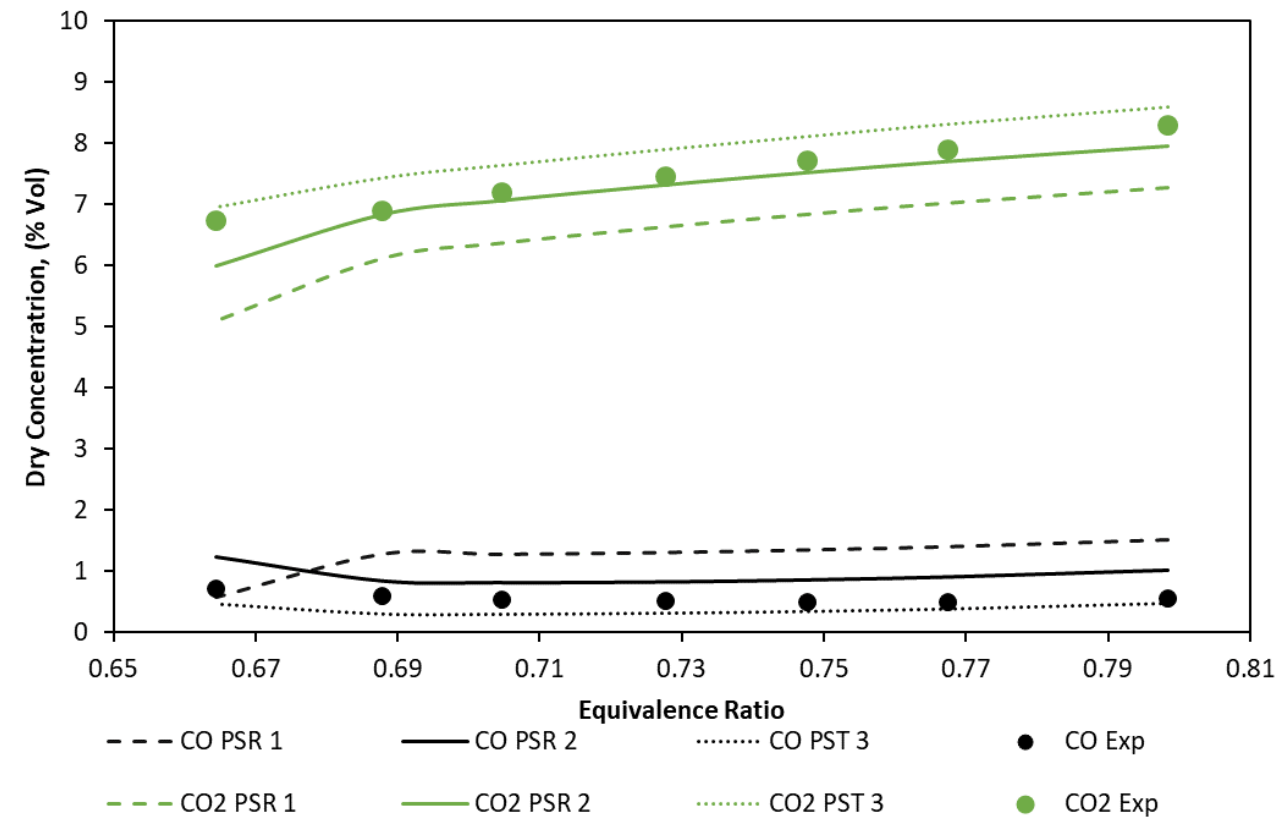

Fig. 7: The measured $\mathrm{CO}$ and $\mathrm{CO}_{2}$ concentration (dry) and computed concentration using $\mathrm{CRN}$ in different elements for $\Phi$ range: $0.65-0.80$ and at air flow rates of $1.2 \mathrm{~g} / \mathrm{s}$. The gases are sampled from the recirculation region of the JSR. 
Figure 8 shows the concentration of $\mathrm{O}_{2}$; the data and the model are in excellent agreement. The concentration of $\mathrm{O}_{2}$ increases with the decreasing equivalence ratio because of decreasing fuel and hence requiring less $\mathrm{O}_{2}$ for combustion. The PSR1 $\mathrm{O}_{2}$ levels are higher than the levels in the post-flame and the recirculation zone elements, due to delayed oxygen consumption in the reactor. For the lower $\Phi$, the high $\mathrm{O}_{2}$ in the PRS1 indicates the local extinction in the PSR1; the flame ignition occurs in the PSR2.

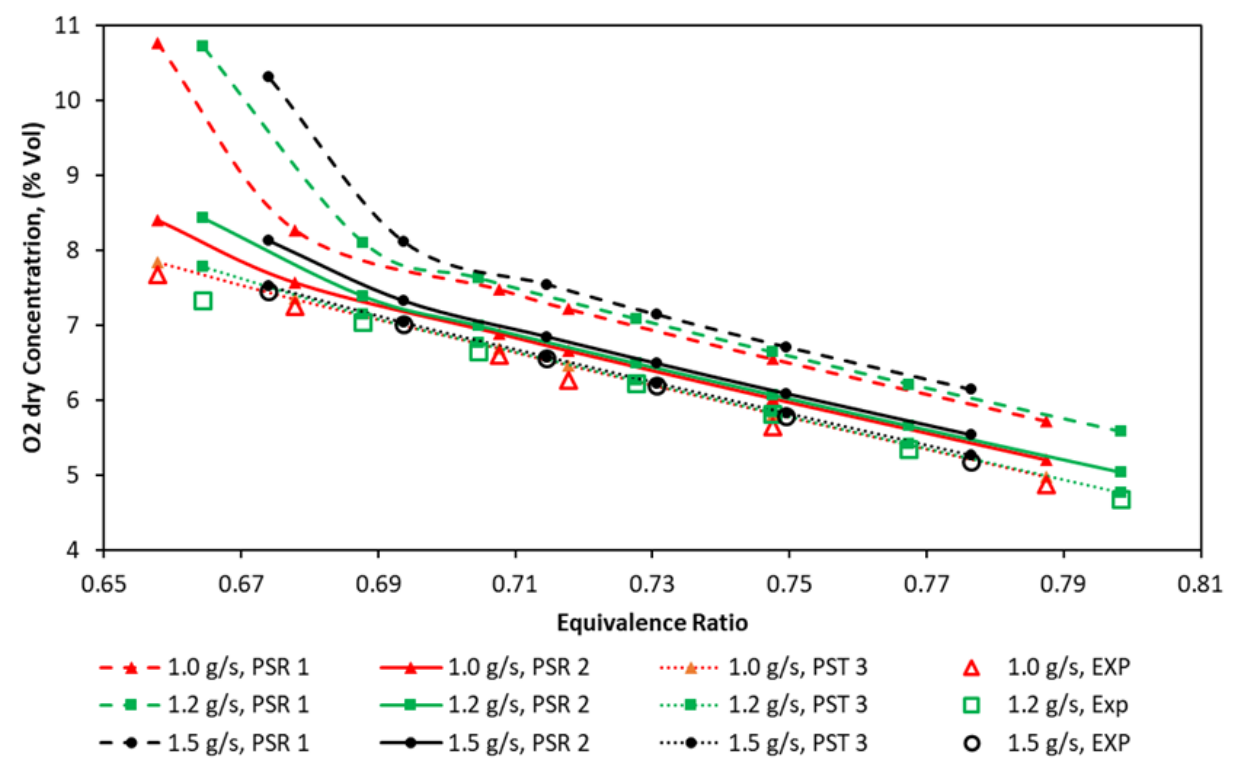

Fig. 8: The measured $\mathrm{O}_{2}$ dry concentration and computed concentration using CRN in different elements for $\Phi$ range: $0.65-0.80$ and at air flow rates of $1.0 \mathrm{~g} / \mathrm{s}, 1.2 \mathrm{~g} / \mathrm{s}$, and $1.5 \mathrm{~g} / \mathrm{s}$. The $\mathrm{O}_{2}$ is sampled from the recirculation region of the JSR. 


\section{Chapter 4. Lean Blowout Experiments}

\subsection{Experimental Conditions}

To investigate the transient behavior of the reactor approaching the blowout, RT-CRN is operated in parallel to the experiment. In addition to the major combustion species, the RT-CRN computes the free radical concentrations in different elements based on the real-time experimental temperature input to PST3, the fuel, and air mass flowrates into the PSR1. A series of transient blowout experiments are conducted as shown in Table 1. Each case is repeated three times to show the repeatability and the effect of day-to-day variations in the ambient environment. The initial temperature conditions are $\mathrm{T}_{\text {initial }}=1730-1780 \mathrm{~K}$ (uncorrected for thermocouple heat loss), the fuel flow rate is reduced to an equivalence ratio at which reactor cannot sustain stable combustion. Once the $\Phi$ is reduced, the temperature inside the reactor drops. During the reactor cooling period, the RT-CRN uses the temperature measurement in the recirculation zone as the PST3 input; the $\mathrm{CRN}$ solution is updated in real time. The final blowout temperature and the time to LBO are recorded (Table 1).

Table 1: Real-time Blowout Experimental conditions. The cases in bold are chosen as a baseline and are used to for analysis.

\begin{tabular}{ccccc}
\hline $\begin{array}{c}\text { Air Flow rate } \\
(\mathrm{g} / \mathrm{s})\end{array}$ & $\begin{array}{c}\text { Equivalence Ratio } \\
\Phi\end{array}$ & $\begin{array}{c}\text { Day 1 Temp, K } \\
(\text { Time, } \mathrm{s})\end{array}$ & $\begin{array}{c}\text { Day 2 Temp, K } \\
(\text { Time, } \mathrm{s})\end{array}$ & $\begin{array}{c}\text { Day 3 Temp, } \\
\text { K (Time, s) }\end{array}$ \\
\hline \hline \multirow{2}{*}{1.0} & 0.58 & $1485(17)$ & $1465(27)$ & $1478(17)$ \\
& 0.60 & $1481(91)$ & $1466(54)$ & $1483(63)$ \\
& 0.62 & $\mathbf{1 4 8 2 ( 1 6 8 )}$ & $1486(122)$ & $1461(190)$ \\
& 0.63 & $1473(172)$ & $1495(173)$ & $1506(122)$ \\
& & & & \\
1.2 & 0.60 & $1513(9)$ & $1503(17)$ & $1515(10)$ \\
& 0.62 & $1502(32)$ & $1481(69)$ & $\mathbf{1 4 7 5 ( 4 5 )}$ \\
& 0.637 & $1485(109)$ & $1508(116)$ & $1483(231)$ \\
& 0.655 & $1517(222)$ & $1512(553)$ & $1527(232)$ \\
& & & & \\
& 0.62 & $\mathbf{1 5 0 5}(\mathbf{2 0})$ & $1520(27)$ & $1530(13)$ \\
& 0.64 & $1527(56)$ & $1528(141)$ & $1554(44)$ \\
& 0.65 & $1563(387)$ & $1565(269)$ & $1567(112)$ \\
\hline \hline
\end{tabular}

The flow conditions for air flow rate of $1.2 \mathrm{~g} / \mathrm{s}$ and $\Phi$ change from 0.80 to 0.62 as a step function is taken for a base case to demonstrate the monitoring approach (indicated as bold in Table 1). The plots for air flow rates of $1.0 \mathrm{~g} / \mathrm{s}$ and $1.5 \mathrm{~g} / \mathrm{s}$ are provided in the appendix G. Figure 
9 shows that the temperature measurements in the reactor respond to the change in fuel flow rate nearly instantaneous, showing gas temperature drop in recirculation zone. Before $\mathrm{t}=0 \mathrm{~s}$, the reactor is stable at an equivalence ratio of 0.80 and the recirculation zone temperature is $1743 \mathrm{~K}$. Starting at $\mathrm{t}=0 \mathrm{~s}$ (change in the $\Phi$ to 0.62 ), the initial steady-state temperature drops asymptotically. The combustion is sustained for 45 seconds before blowout occurs at a measured temperature of 1467 $\mathrm{K}$. This transient stability is due to the thermal inertia of the system, resulting in heat addition from the hot walls of the reactor to the gas mixture. At the initial steady state $(\Phi=0.8)$, the PSR 1 temperature is $1687 \mathrm{~K}$, lower than PST3 $(1744 \mathrm{~K})$. The immediate post flame zone PSR2 is 1748 $\mathrm{K}$, is slightly higher than in the recirculation zone. At $\mathrm{t}=0 \mathrm{~s}$, the RT-CRN instantaneously responds to the change in $\Phi$, as seen from a decrease in PSR1 and PSR2 temperatures. At $\mathrm{t} \sim 6$ sec the model predicts PSR1 blowout event; the temperature drops to the $1335 \mathrm{~K}$-- the solution corresponding to non-reacting mixing between the recirculation gas and the fresh charge. Some minor fuel decomposition in PSR1 occurs as shown by the modeled species concentration plots. After $30 \mathrm{~s}$ the code failed to obtain a converged solution.

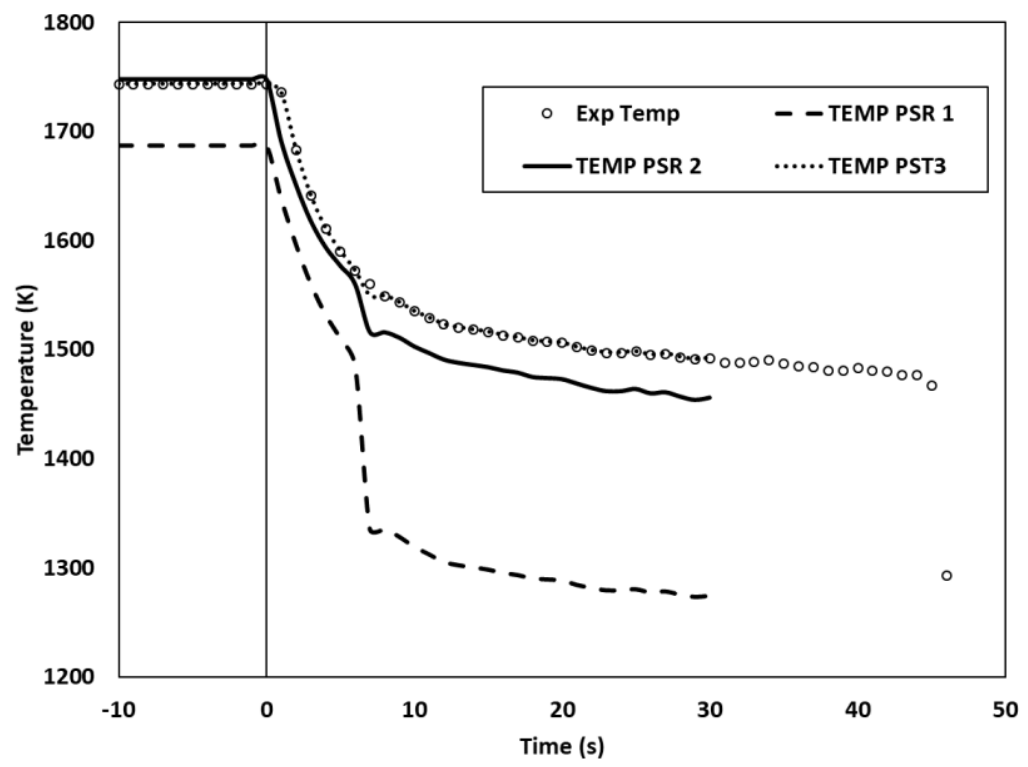

Fig. 9: Temperature in different elements of the $C R N$ and the experimental temperature, which is also the input to the PST3 for an air flow rate of $1.2 \mathrm{~g} / \mathrm{s}$. The $\Phi$ is varied from 0.80 to 0.62 at $\mathrm{t}=0 \mathrm{~s}$. 


\subsection{Blowout Modeling - Major Combustion Species}

In this section, the ability of the RT-CRN to predict the concentrations of $\mathrm{CO}, \mathrm{CO}_{2}$, and $\mathrm{O}_{2}$ in the transient blowout experiments is discussed. The computed results are compared with the experimental data. Figure 10 shows the measured and modeled $\mathrm{CO}, \mathrm{CO}_{2}$, and $\mathrm{O}_{2}$ data for the baseline experiment: an air flow rate of $1.2 \mathrm{~g} / \mathrm{s}$ as the equivalence ratio is changed from 0.80 to 0.62. The gas concentrations are measured and computed by $\mathrm{CRN}$, the real-time recirculation zone temperature input to the PST3 is also plotted. Once the equivalence ratio is reduced at $\mathrm{t}=0 \mathrm{~s}$, the temperature changes instantaneously, but the experimental gas measurement shows a delay of 18 to about 40 seconds. The delay is attributed to the to the sample transport time from the JSR to the instrument and analyzing time delay within the Horiba VA 3000 analyzer. In addition to the $18 \mathrm{~s}$ delay, the gas in the sample line diffuses longitudinally resulting in a gradual response of the analyzer which results in an additional response ramp up to around $25 \mathrm{~s}$. The experimental data in figure 10 are adjusted to account for 18 seconds delay where the change in the sample gas concentration is first observed by the analyzer. When adjusted for the delay, the RT-CRN trends show good agreement with the measured species concentration.

When $\Phi$ is reduced, the modeled $\mathrm{CO}_{2}$ change first as a step function due to a decrease in $\Phi$, and then more gradually due to a reduction in combustion efficiency as the temperature reduces. The experimental $\mathrm{CO}_{2}$ concentration reduces more gradually due to the sample line mixing (not a perfect plug flow), however, the final values are close to the predicted in the PSR2 and PSR3. The reduction in combustion efficiency can be observed by the trends of $\mathrm{CO}$ and $\mathrm{CH}_{4}$. Figures $10 \mathrm{c}$ and 11 show the increase of concentrations of the $\mathrm{CO}$ (measured and modeled) and $\mathrm{CH}_{4}$ (modeled) due to incomplete combustion. After the PSR1 blowout ( $\mathrm{t} \sim 6 \mathrm{sec}$ ), $\mathrm{CO}_{2}$ concentration remains constant, similar to temperature trends. The experimental $\mathrm{O}_{2}$ concentrations are in good agreement with the PST3 concentrations which represents the recirculation region. As the reactor approaches blowout, the $\mathrm{O}_{2}$ consumption decreases, hence increasing its concentration in the exhaust.

The experimental $\mathrm{CO}$ trend shows a rise in concentration as the reactor approaches blowout due to the poor oxidation of $\mathrm{CO}$ to $\mathrm{CO}_{2}$ at the lower combustion temperatures. $\mathrm{CO}$ data does not track the combustion behavior during the changes in operating conditions. As discussed before, the difficulties with the measurement are due to oxidation of $\mathrm{CO}$ to $\mathrm{CO}_{2}$ at the tip of the hot sample probe and the quenching of $\mathrm{CO}$ oxidation pathway near the cooler reactor wall. The measured $\mathrm{CO}$ concentration is between the PSR2 and PST3 predictions for the entire range of the experimental 
conditions. The CRN model sheds insights into the $\mathrm{CO}$ behavior in the different regions of the reactor. During stable (higher $\Phi$ ) operation, the model predicts the highest CO concentration in the flame PSR1 and the lowest in the recirculation zone PST3. Immediately after the change in $\Phi$, the $\mathrm{CO}$ drops in all elements corresponding to lower fuel (and hence the carbon) concentration in the system. As the reactor cools, the $\mathrm{CO}$ rises in all elements as a result of the reduced $\mathrm{CO}$ to $\mathrm{CO}_{2}$ oxidation associated with the lower combustion temperatures. The incomplete combustion trend in the PSR1 is also seen in the increased values of $\mathrm{CH}_{4}$ during the cooling of the combustor (figure 11), discussed later. After the PSR1 element fails to ignite, the PSR2 CO concentration increases indicating the movement of flame from PSR1 to PSR2. The PSR1 CO levels become just slightly higher than PST3 levels as a result of partial fuel decomposition to $\mathrm{CO}$ in the PSR1. Therefore, the PSR1 CO consists of $\mathrm{CO}$ from the recirculation zone and $\mathrm{CO}$ from partial decomposition of the fresh charge. Additional analysis of the free radical concentration, as presented later, shows that partial pre-flame fuel oxidation occurs in the PSR1. As the combustor cools down further, the $\mathrm{CO}$ concentration in PSR2 and PST3 increases following the experimental data trend. Similar trends are observed for air flow rates of $1.0 \mathrm{~g} / \mathrm{s}$ and $1.5 \mathrm{~g} / \mathrm{s}$ (see Appendix G).

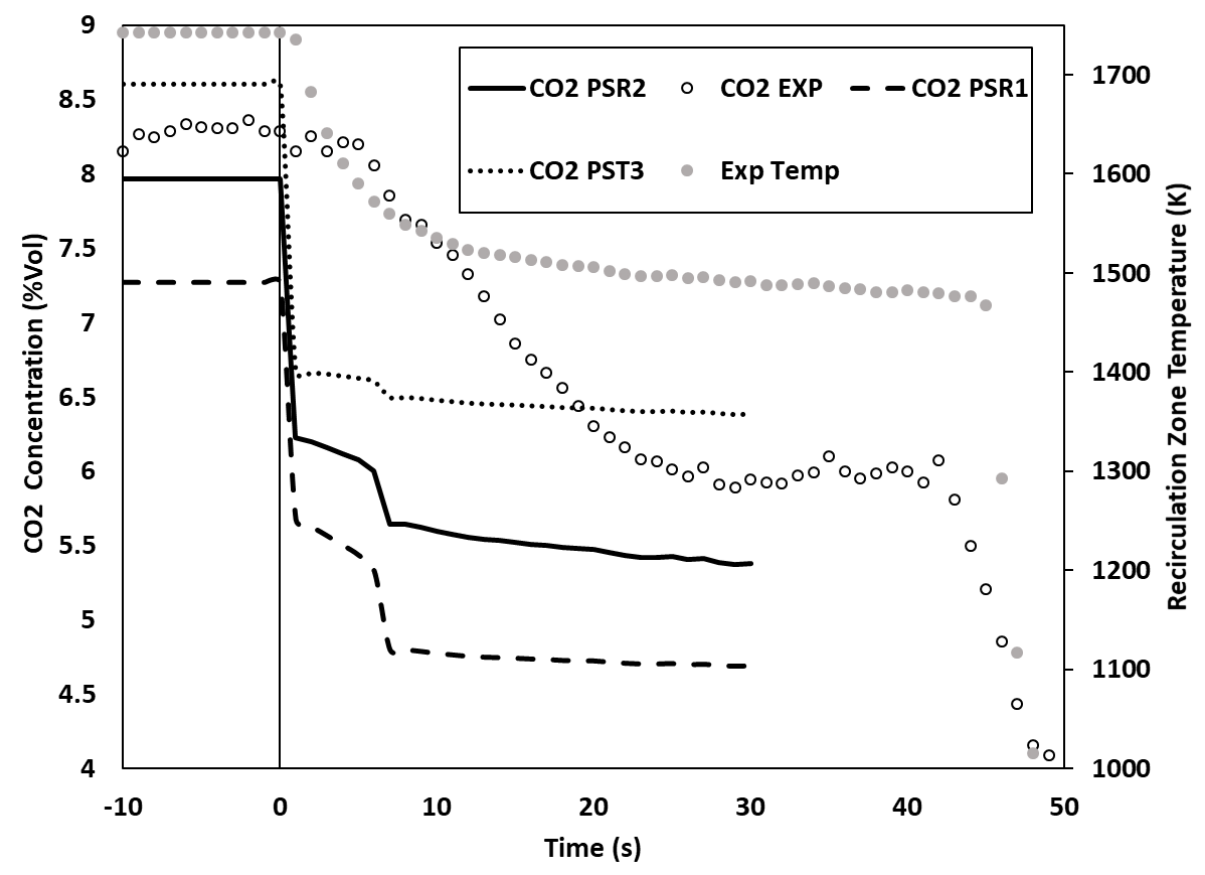

(a) 


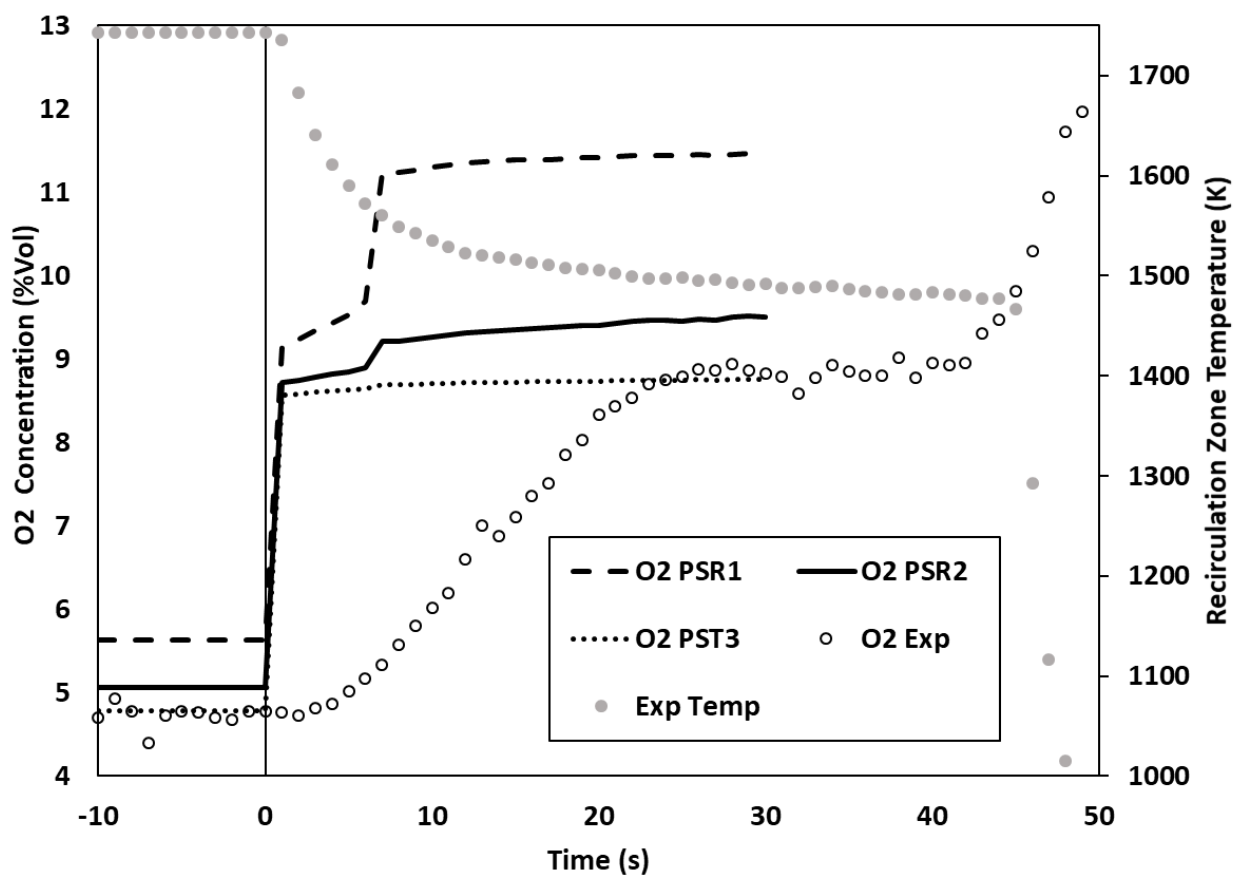

(b)

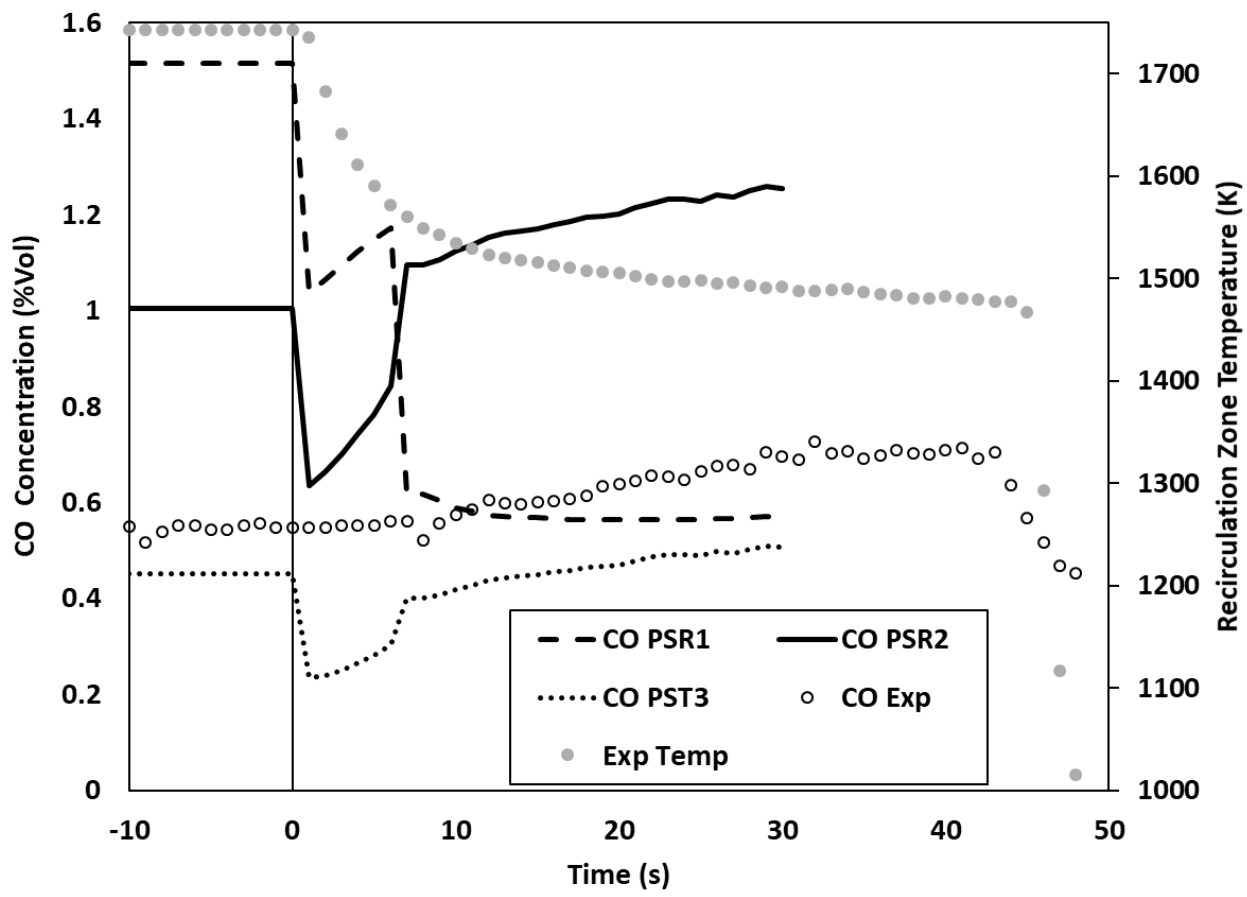

(c)

Fig. 10: Experimental and $\mathrm{CRN}$ concentrations of (a) $\mathrm{CO}_{2}$ (b) $\mathrm{O}_{2}$ and (c) $\mathrm{CO}$ for an air flow rate of $1.2 \mathrm{~g} / \mathrm{s}$ and blowout equivalence ratio of 0.62 (Starting $\Phi$ 0.80). The experimental concentrations are corrected for the 18 seconds delay in sampling line. 


\subsection{Modeled Species Concentration Using CRN}

In addition to the major combustion species, the RT-CRN computes non-measured species concentrations including zonal concentrations of fuel and the free radicals. The concertation of free radicals in the JSR is analyzed to determine their behavior approaching blowout. In particular, hydroxyl radical $(\mathrm{OH})$ concentration is of interest. The $\mathrm{OH}$ is an intermediate species produced during hydrocarbon combustion, where it is the most persistent radical in flames and whose behavior has been correlated to blowout $[30,52,53]$. $\mathrm{OH}$ has been suggested as a good indicator of flame stability [52]. Levels of other radicals such as $\mathrm{O}, \mathrm{H}, \mathrm{CH}, \mathrm{CH}_{3}, \mathrm{H}_{2} \mathrm{CO}$, and $\mathrm{HCO}$ can be used in stability analysis, are shown in Appendix G.

Methane concentration is not measured in this study, but the $\mathrm{CH}_{4}$ trends approaching blowout are modeled using the RT-CRN. Figure 11 shows that for the air flow rate of $1.2 \mathrm{~g} / \mathrm{s}$ as the reactor approaches blowout, $\mathrm{CH}_{4}$ concentration spikes in PSR1 when it blows out (at t $\sim 6 \mathrm{~s}$ ) as the ignition moves to PSR2. In PST3 (Figure 11b) the methane is already consumed, its concentration is lower than elements 1 and 2. $\mathrm{CH}_{4}$ concentration in PST3 spikes up initially when PSR1 blows out and slowly increases as the combustion efficiency reduces at the lower temperatures, indicating that the unburned fuel escapes from a PSR2 near blowout. 


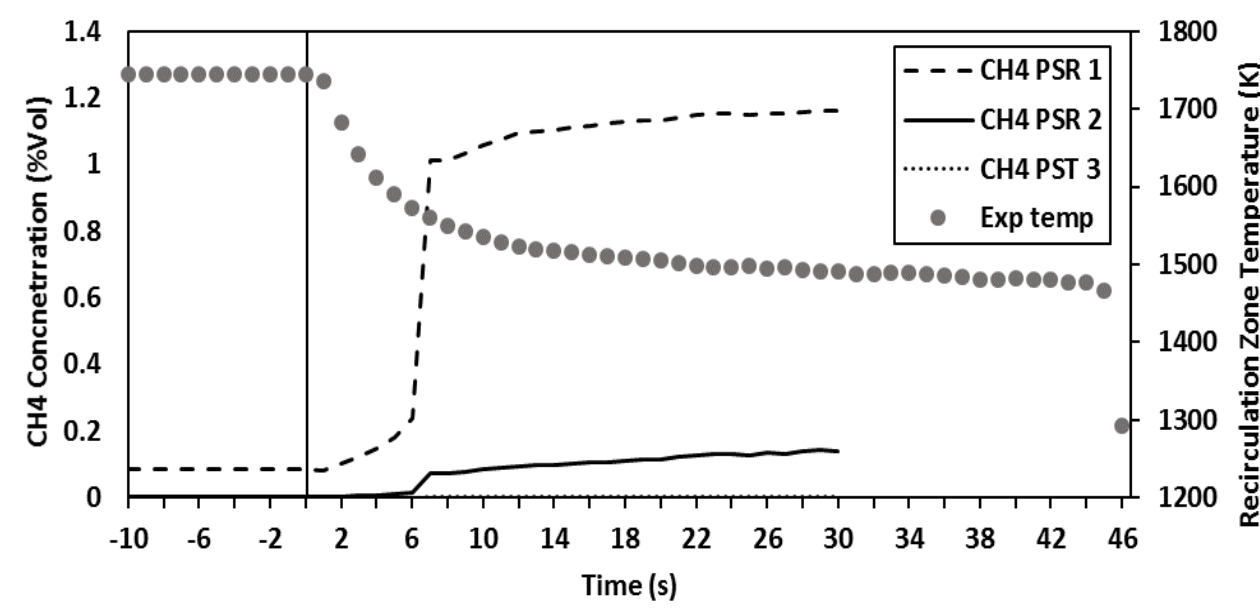

(a)

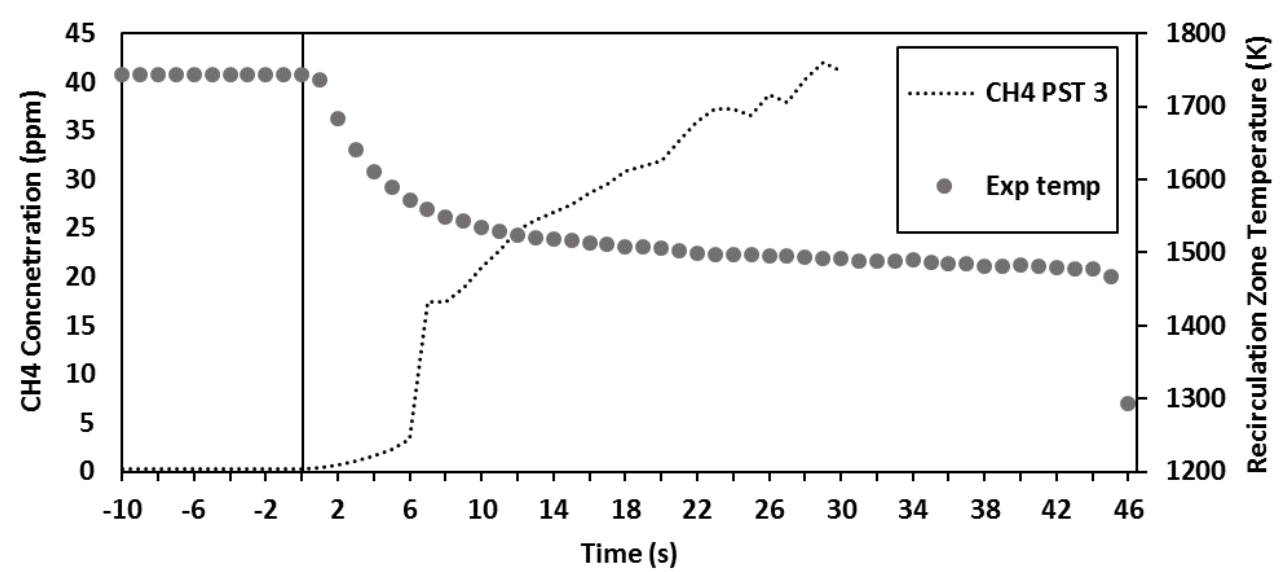

(b)

Fig. 11: Concentration of $\mathrm{CH}_{4}$ computed using CRN in (a) different elements (b) PST3 of CRN for an air flow rate of $1.2 \mathrm{~g} / \mathrm{s}$ and $\Phi$ of 0.62 near blowout.

Figure 12 shows the modeled behavior of $\mathrm{OH}$ radical for the baseline case (air flow rate of 1.2 $\mathrm{g} / \mathrm{s} ; \Phi 0.80 \rightarrow 0.62$ ). The $\mathrm{OH}$ ratio between the element and their trends are proposed as criteria for the proximity to blowout. Three distinct events are observed in the combustor model. At the stable combustion conditions, the $\mathrm{OH}$ concentration in PSR1 and PSR2 is high, corresponding to a stable burning solution in those zones. The PSR2 representing the immediate post-flame region has slightly higher $\mathrm{OH}$ concentrations. By the time the gases reach the recirculation zone, $\mathrm{OH}$ is reduced. Immediately after reducing the $\Phi, \mathrm{OH}$ concentration in the PSR1 decreases rapidly and leads to Event 1 - the concentration of $O H$ in PSRI reduces below the level of PST3. At a later time, PSR1 fails to obtain a burning solution; Event 2 - PSR1 blowout as indicated by a large drop in OH concentration, mixing solution is calculated in the PSRI. (The code fails to converge around 
the PSR1 extinction point and sometimes needs to be restarted during the real-time operation. In this situation, the next converged solution is plotted.) Once the PSR1 blows out, the PST3 OH concentration increases, representing the movement of flame to PSR2. PST3 partially acts as a post-flame region. Later, similar to the Event 1, the $\mathrm{OH}$ concentration in PSR2 reduces below the level of PST3. Event 3 is defined as PSR2 OH is equal to PSR3. The $\mathrm{OH}$ level in the second element diminishes further indicating the movement of flame into recirculation zone. However, at this point, the CRN solution is not valid since the PST3 element does not solve the energy equation and cannot predict proper ignition kinetics.

Since the JSR blow out is observed shortly after the PSR1 and PSR2 (which represent upward moving flow) are depleted of $\mathrm{OH}$ and other free radicals, we propose that the flame is globally stable as long as the ignition event occurs in the jet. The JSR fails to sustain the combustion if the flame ignition is pushed into the recirculation region. Similar trends are observed for air flow rates of $1.0 \mathrm{~g} / \mathrm{s}$ and $1.5 \mathrm{~g} / \mathrm{s}$ (Appendix G). Figure 12b shows the $\mathrm{OH}$ level as a function of measured combustion temperature. High temperature combustion conditions show high $\mathrm{OH}$ concentration in the jet, the $\mathrm{OH}$ levels in the jet drop below the recirculation zone levels at the lower combustion temperature approaching blowout. 


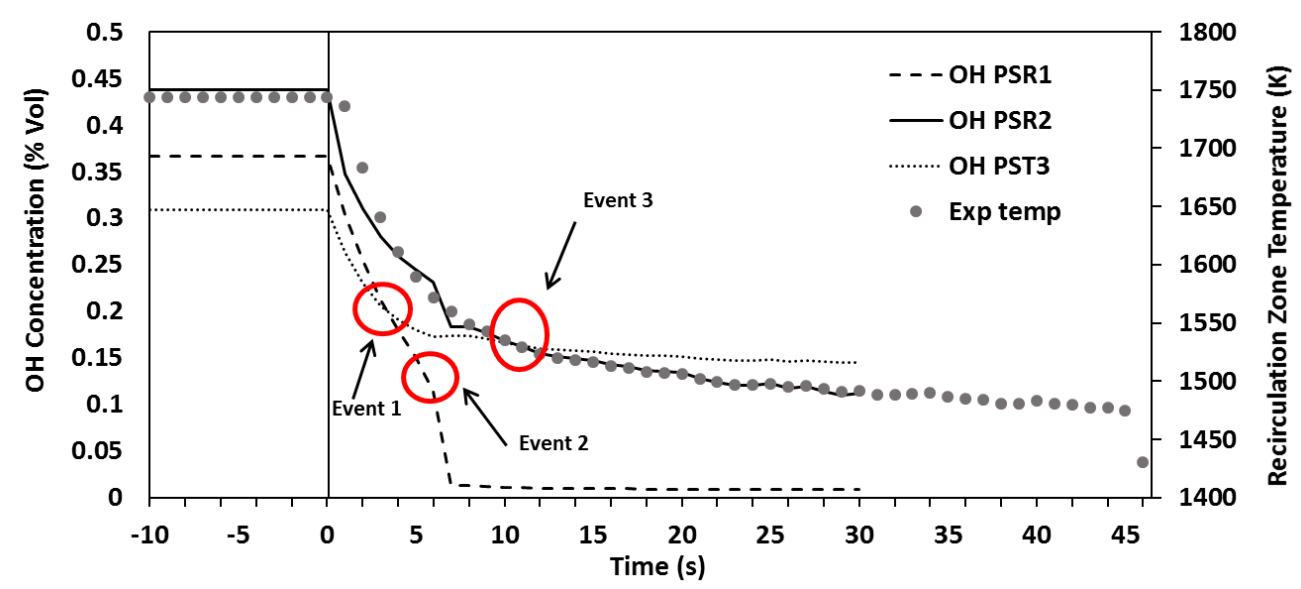

(a)

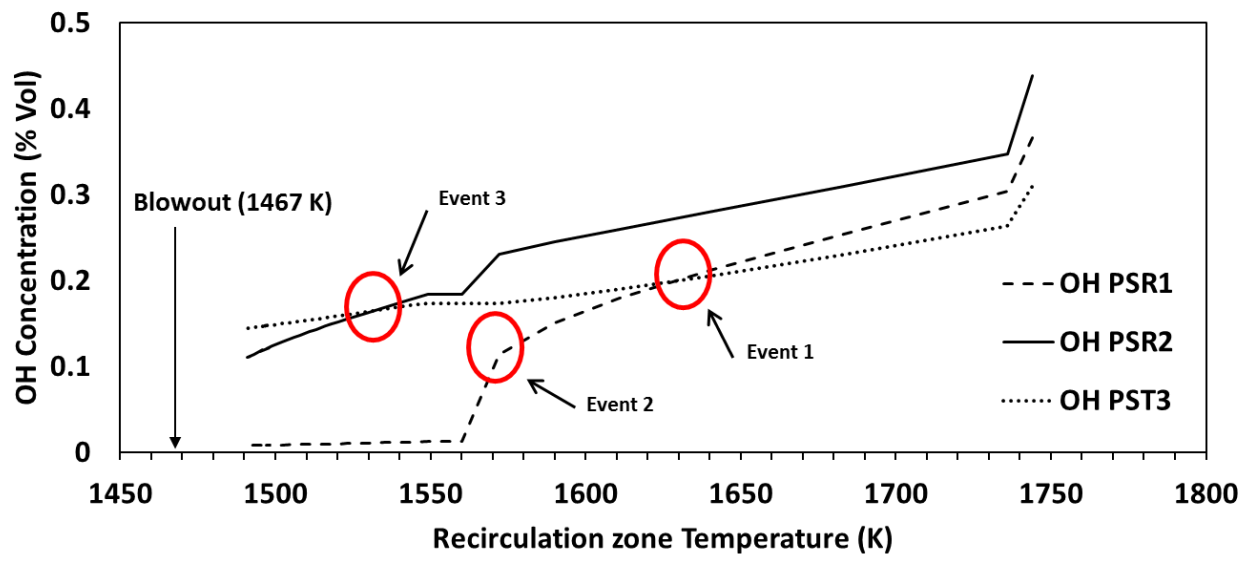

(b)

Fig. 12: (a) The concentration of hydroxyl radicals $(\mathrm{OH})$ as a function of time (s) in different elements, predicted by $\mathrm{CRN}$ and the corresponding experimental temperature from the recirculation zone (K) until $\mathrm{LBO}$ (b) $\mathrm{OH}$ concentrations as the function of recirculation zone temperature for the air flow rate of $1.2 \mathrm{~g} / \mathrm{s}$ and a blowout $\Phi=0.62$

As summarized in table 2, similar trends in $\mathrm{OH}$ radical are examined for different air flow rates and equivalence ratios. The temperatures at which the three events preceding blowout occur, along with the time, the event occurred for each case is shown. The modeled $\mathrm{OH}$ concentrations shows that the events 1-3 occur before the actual blowout. Reactor loading plays a role in blowout time and temperature, the higher the loading, the faster reactor blows out. This is consistent with the reactor residence time reduction, which leads to the decrease of the Da number as discussed later in Appendix H. 
Table 2: The time and temperature for the blowout for each experiment. Time to reach the event in seconds is indicated in parenthesis. The crossover in OH concentration Event 1 (PST3>PSR1), Event 2 (PSR1 blowout) and Event 3 (PST3>PSR2) are shown for each experiment. N/A indicates that reactor reached blowout before Event 3 is observed.

\begin{tabular}{|c|c|c|c|c|c|c|l|}
\hline $\begin{array}{c}\text { AIR } \\
\mathbf{( G / S )}\end{array}$ & $\mathbf{\Phi}$ & $\begin{array}{c}\text { EXP 1 BO } \\
\text { TEMP K } \\
\text { (TIME, S) }\end{array}$ & $\begin{array}{c}\text { EXP 2 BO } \\
\text { TEMP, K } \\
\text { (TIME, S) }\end{array}$ & $\begin{array}{c}\text { EXP 3 BO } \\
\text { TEMP, K } \\
\text { (TIME, S) }\end{array}$ & $\begin{array}{r}\text { EVENT 1 } \\
\text { TEMP, K } \\
\text { (TIME,S) }\end{array}$ & $\begin{array}{c}\text { EVENT 2 } \\
\text { TEMP, K } \\
\text { (TIME, S) }\end{array}$ & $\begin{array}{l}\text { EVENT 3 } \\
\text { TEMP K } \\
\text { (TIME, S) }\end{array}$ \\
\hline $\mathbf{1}$ & 0.58 & $1485(17)$ & $1465(27)$ & $1478(17)$ & $1578(6,5,8)$ & $\begin{array}{c}1560 \\
(7,6,9)\end{array}$ & $\begin{array}{l}1513 \\
(11,11,13)\end{array}$ \\
\hline & 0.6 & $1481(91)$ & $1466(54)$ & $1483(63)$ & $1578(10,7,9)$ & $\begin{array}{c}1554 \\
(13,8,10)\end{array}$ & $\begin{array}{l}1507 \\
(42,20,31)\end{array}$ \\
\hline & 0.62 & $1482(168)$ & $1486(122)$ & $1461(190)$ & $1576(10,10,9)$ & $\begin{array}{c}1551 \\
(18,16,15)\end{array}$ & $\begin{array}{l}1497 \\
(106,90,62)\end{array}$ \\
\hline & 0.63 & $1473(172)$ & $1495(173)$ & $1506(275)$ & $1578(10,14,10)$ & $\begin{array}{c}1549 \\
(21,28,22)\end{array}$ & $\begin{array}{l}1495 \\
(173,116, N A)\end{array}$ \\
\hline 1.2 & 0.602 & $1513(9)$ & $1503(17)$ & $1515(10)$ & $1603(4,5,4)$ & $\begin{array}{c}1580 \\
(5,6,6)\end{array}$ & $\begin{array}{l}1536 \\
(8,10,9)\end{array}$ \\
\hline & 0.62 & $1502(32)$ & $1481(69)$ & $1467(44)$ & $1611(6,6,4)$ & $\begin{array}{c}1573(8, \\
7,6)\end{array}$ & $\begin{array}{l}1530 \\
(17,15,11)\end{array}$ \\
\hline & 0.637 & $1485(109)$ & $1508(116)$ & $1483(231)$ & $1618(6,7,5)$ & $\begin{array}{c}1571 \\
(13,12,9)\end{array}$ & $\begin{array}{l}1526 \\
(65,52,24)\end{array}$ \\
\hline & 0.655 & $1517(222)$ & $1512(553)$ & $1527(232)$ & $1616(7,8,8)$ & $\begin{array}{c}1572 \\
(21,32,26)\end{array}$ & $\begin{array}{l}1520 \\
(184,313, N A)\end{array}$ \\
\hline 1.5 & 0.62 & $1505(20)$ & $1520(27)$ & $1530(13)$ & $1693(2,3,3)$ & $\begin{array}{c}1597 \\
(5,5,5)\end{array}$ & $\begin{array}{l}1570 \\
(7,8,8)\end{array}$ \\
\hline & 0.638 & $1527(56)$ & $1528(141)$ & $1554(44)$ & $1694(3,4,4)$ & $\begin{array}{c}1603 \\
(7,9,8)\end{array}$ & $\begin{array}{l}1566 \\
(12,24,26)\end{array}$ \\
\hline & 0.655 & $1563(387)$ & $1565(269)$ & $1567(117)$ & $1676(4,4,4)$ & $\begin{array}{c}1598 \\
(35,24,16)\end{array}$ & $\begin{array}{l}1565 \\
(245,241,111)\end{array}$ \\
\hline
\end{tabular}

Figure 13 shows the behavior of calculated $\mathrm{OH}$ as a function of flow time. The flow/Lagrangian (or convective) residence time is calculated as time spent by a fluid particle in each element. On average, the fluid particle goes around the JSR four times due to the $75 \%$ recirculation assumption. The $\mathrm{OH}$ levels as a function of convective flow time in the JSR are plotted at different experimental times after reducing the fuel flow (1-30seconds). Initially, at $\mathrm{t}=1 \mathrm{sec}$ after the $\Phi$ change, the $\mathrm{OH}$ concentration is higher in the jet and in the impingement zone (PSR1 and PSR2). At later times, as the combustor cools, the production of $\mathrm{OH}$ shifts to the downstream the reactor associated with greater convective time. After the PSR1 blows out (t 6s), the $\mathrm{OH}$ concentration in PSR1 drops as the flame ignition has moved to PSR2. Approaching the blowout, the concentrations in PSR2 and PST3 are of the similar level, indicating that, for the combusting region (outside of the cold jet core - PSR1), the JSR approaches a well-stirred condition. The limitation of this analysis is the use of only three-element model that limits spatial 
resolution required for more detailed analysis. However, it is in-line with the previous analysis performed by Karalus [32].

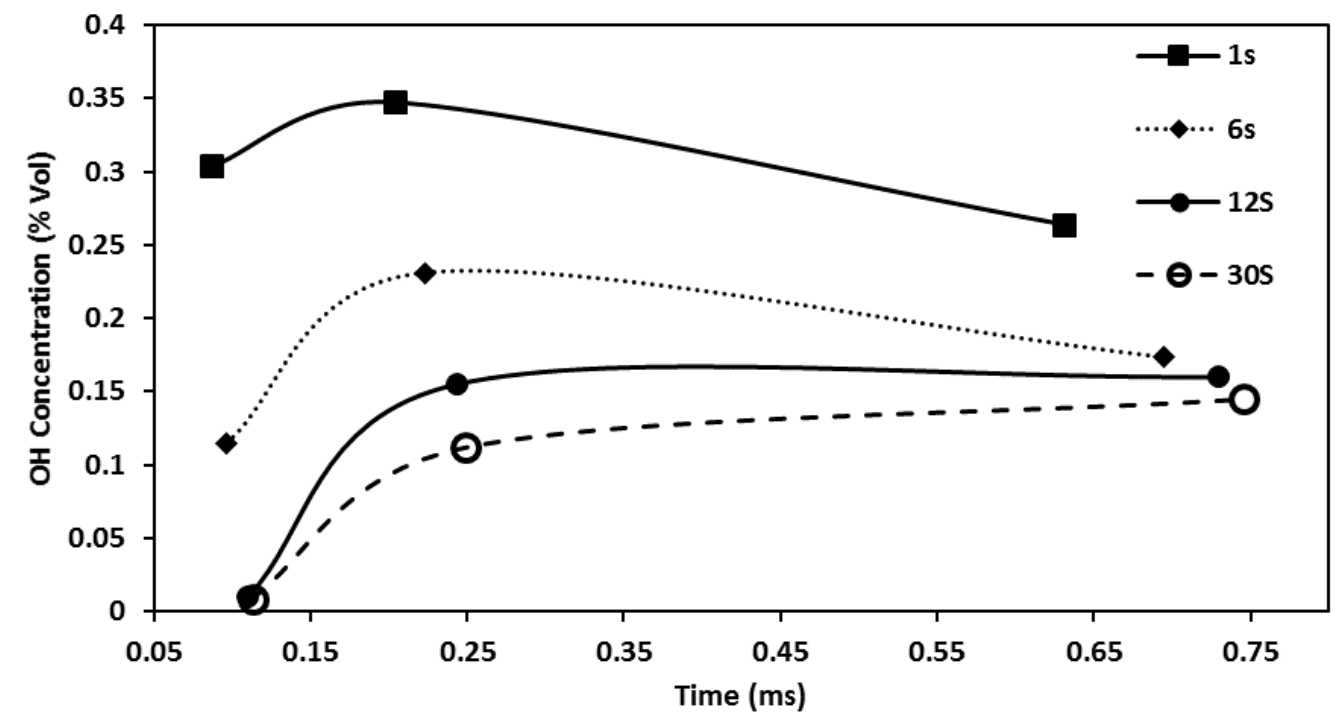

(b)

Fig. 13: Concentration of hydroxyl radicals $(\mathrm{OH})$ in different elements, of the CRN as a function of time inside the JSR at different lab times near the blowout and for air flow rate $1.2 \mathrm{~g} / \mathrm{s}$ and blowout $\Phi 0.62$ 


\section{Chapter 5. Conclusions and Future Work}

This research explores the concept of using the Real-Time Chemical Reactor Network as a tool for real-time process monitoring and LBO prediction. An experimental study coupled with modeling and analysis of the results are performed; the conclusions and discussion points from this work are:

- A three-element CRN consisting PSR1 (free jet region), PSR2 (impinging jet region), and PST3 (recirculation region) is constructed and evaluated using the $\mathrm{CO}, \mathrm{CO}_{2}$, and $\mathrm{O}_{2}$ data from steady-state JSR experiments. Measured recirculation zone temperature, fuel, and air mass flow rates are used as an input to the model; the approach enables the calculation of non-measurable combustion parameters, including the reaction rates and free radical concentration in different zones of the combustor in real time. The model is in good agreement with the experimental data over a range of equivalence ratios from 0.80 to 0.58 and combustor loading conditions of $1.0 \mathrm{~g} / \mathrm{s}-1.5 \mathrm{~g} / \mathrm{s}$ (residence times of $2-4 \mathrm{~ms}$ ).

- The RT-CRN monitors the major combustion species and the free radical concentrations during transient blowout experiments. This approach monitors numerous chemical species concentrations and their chemical kinetic rates in real time, whereas the typical ex-situ gas measurements show an 18 - 45 seconds delay associated with sample transport and analysis time.

- Hydroxyl radical trends computed by RT-CRN are used as criteria for LBO proximity. During the high-temperature ( $\mathrm{T}>1700 \mathrm{~K}$ ) stable combustion, the $\mathrm{OH}$ concentration in the flame and the post-flame zones are greater than the recirculation zone. As the combustor approaches blowout, the $\mathrm{OH}$ concentration in the jet region (PSR1) drops below the levels in the recirculation zone. When the jet region fails to ignite due to the insufficient residence time, the ignition shifts to PSR2. If the combustion temperature continues to drop, a similar pattern in the PSR2 is observed; OH level in PSR2 becomes smaller than PST3. This event is associated with a global blowout since the combustion cannot be sustained in the recirculation region by itself. The PST 3 solution is not calculated from the first principles, and PST reactor is stabilized by the external energy input.

- A preliminary analysis of the modeled free radicals such as $\mathrm{H}, \mathrm{O}, \mathrm{CH}, \mathrm{CH}_{3}$, and $\mathrm{HCO}$ is performed to determine their behavior and relationship to local and global flame extinction events (presented in the Appendix G). The RT-CRN is capable of describing the fuel-air 
charge preheat and early fuel break-up via ignition delay chemistry. After the local extinction of PSR1, it acts as the region of pre-combustion reactions. The initial fuel breakdown in the fresh fuel-air charge mixed with hot recirculation gas results in the spike of the early flame radical $\mathrm{CH}_{3}, \mathrm{CH}, \mathrm{HCO}$, and $\mathrm{H}$. However, the energy-releasing reactions are not triggered until gas reached PSR2. The partial decomposition of the fuel in the PSR1 aids the mixture ignition in the PSR2.

Future work may include.

- Design of model-based control system for JSR

- Expanding the RT-CRN ability to different combustor geometries

- Investigation of $\mathrm{OH}$ trends near blowout for alternative fuels

- Investigation of free radicals in the pre-flame region and its influence on LBO

- Improvement the numerical algorithm to decrease the convergence time and increase the code stability near blowout 


\section{References}

[1] Abas, N., Kalair, A., and Khan, N., 2015, "Review of fossil fuels and future energy technologies," Futures, 69, pp. 31-49.

[2] Riess, J., 1998, "Nox: how nitrogen oxides affect the way we live and breathe," US Environmental Protection Agency, Office of Air Quality Planning and Standards.

[3] Rosfjord, T. J., and Cohen, J. M., 1995, "Evaluation of the transient operation of advanced gas turbine combustors," Journal of Propulsion and Power, 11(3), pp. 497-504.

[4] Meegahapola, L., and Flynn, D., 2015, "Characterization of gas turbine lean blowout during frequency excursions in power networks," IEEE Transactions on Power Systems, 30(4), pp. 18771887.

[5] Heyne, J. S., Colket, M. B., Gupta, M., Jardines, A., Moder, J. P., Edwards, J. T., Roquemore, M., Li, C., and Rumizen, M., "Year 2 of the National Jet Fuels Combustion Program: Towards a Streamlined Alternative Jet Fuels Certification Process," Proc. 55th AIAA Aerospace Sciences Meeting, p. 0145.

[6] Longwell, J. P., Frost, E. E., and Weiss, M. A., 1953, "Flame stability in bluff body recirculation zones," Industrial \& Engineering Chemistry, 45(8), pp. 1629-1633.

[7] Zukoski, E. E., and Marble, F. E., "Experiments concerning the mechanism of flame blowoff from bluff bodies," Proc. Proceedings of the Gas Dynamics Symposium on Aerothermochemistry, pp. 205-210.

[8] Yamaguchi, S., Ohiwa, N., and Hasegawa, T., 1985, "Structure and blow-off mechanism of rod-stabilized premixed flame," Combustion and Flame, 62(1), pp. 31-41.

[9] Chaudhuri, S., Kostka, S., Renfro, M. W., and Cetegen, B. M., 2010, "Blowoff dynamics of bluff body stabilized turbulent premixed flames," Combustion and flame, 157(4), pp. 790-802.

[10] Spalding, D., 1953, "Theoretical aspects of flame stabilization: an approximate graphical method for the flame speed of mixed gases," Aircraft Engineering and Aerospace Technology, 25(9), pp. 264-276.

[11] Kundu, K., Banerjee, D., and Bhaduri, D., 1977, "Theoretical analysis on flame stabilization by a bluff-body," Combustion Science and Technology, 17(3-4), pp. 153-162.

[12] Nicholson, H., and Field, J. P., "Some experimental techniques for the investigation of the mechanism of flame stabilization in the wakes of bluff bodies," Proc. Symposium on combustion and flame, and explosion phenomena, Elsevier, pp. 44-68.

[13] Chao, Y.-C., Chang, Y.-L., Wu, C.-Y., and Cheng, T.-S., 2000, "An experimental investigation of the blowout process of a jet flame," Proceedings of the Combustion Institute, 28(1), pp. 335-342.

[14] King, C. R., 1957, "Experimental investigation of effects of combustion-chamber length and inlet total temperature, total pressure, and velocity on afterburner performance," National advisory committee on aeronautics.

[15] Hottel, H., Williams, G., Jensen, W., Tobey, A., and Burrage, P., "Modeling studies of baffletype combustors," Proc. Symposium (International) on Combustion, Elsevier, pp. 923-935.

[16] Nair, S., and Lieuwen, T., 2005, "Acoustic detection of blowout in premixed flames," Journal of Propulsion and Power, 21(1), pp. 32-39.

[17] Li, H., Zhou, X., Jeffries, J. B., and Hanson, R. K., 2007, "Active control of lean blowout in a swirl-stabilized combustor using a tunable diode laser," Proceedings of the Combustion Institute, 31(2), pp. 3215-3223. 
[18] Mukhopadhyay, A., Chaudhari, R. R., Paul, T., Sen, S., and Ray, A., 2013, "Lean blow-out prediction in gas turbine combustors using symbolic time series analysis," Journal of Propulsion and Power.

[19] Yi, T., and Gutmark, E. J., 2007, "Real-time prediction of incipient lean blowout in gas turbine combustors," AIAA journal, 45(7), pp. 1734-1739.

[20] Griebel, P., Boschek, E., and Jansohn, P., 2007, "Lean blowout limits and NOx emissions of turbulent, lean premixed, hydrogen-enriched methane/air flames at high pressure," Journal of engineering for gas turbines and power, 129(2), pp. 404-410.

[21] Thornton, J. D., Straub, D. L., Chorpening, B. T., Huckaby, E. D., Richards, G. A., and Benson, K., 2004, "A combustion control and diagnostics sensor for gas turbines," ASME. Turbo Expo: Power for Land, Sea, and Air, Volume 2, pp. 535-543.

[22] Muruganandam, T., Nair, S., Neumeier, Y., Lieuwen, T., and Seitzman, J., 2002, "Optical and acoustic sensing of lean blowout precursors," AIAA, 3732, pp. 7-10.

[23] Muruganandam, T., Nair, S., Scarborough, D., Neumeier, Y., Jagoda, J., Lieuwen, T., Seitzman, J., and Zinn, B., 2005, "Active control of lean blowout for turbine engine combustors," Journal of Propulsion and Power, 21(5), pp. 807-814.

[24] Bragg, S., 1953, "Application of reaction rate theory to combustion chamber analysis," AERONAUTICAL RESEARCH COUNCIL LONDON (UNITED KINGDOM).

[25] Rutar, T., and Malte, P. C., "NOx formation in high-pressure jet-stirred reactors with significance to lean-premixed combustion turbines," Proc. ASME Turbo Expo 2001: Power for Land, Sea, and Air, American Society of Mechanical Engineers, pp. 776-783.

[26] Schlegel, A., Benz, P., Griffin, T., Weisenstein, W., and Bockhorn, H., 1996, "Catalytic Stabilization of Lean Premixed Combustion: Method for Improving NOx Emissions," Combustion and Flame, 105(3), pp. 332-340,.

[27] Feitelberg, A. S., Tangirala, V. E., Elliott, R. A., Pavri, R. E., and Schiefer, R. B., "Reduced NOx diffusion flame combustors for industrial gas turbines," Proc. ASME Turbo Expo 2000: Power for Land, Sea, and Air, American Society of Mechanical Engineers, pp. 757-765.

[28] Fackler, K. B., Karalus, M., Novosselov, I., Kramlich, J., Malte, P., and Vijlee, S., 2016, "NOx behavior for lean-premixed combustion of alternative gaseous fuels," Journal of Engineering for Gas Turbines and Power, 138(4).

[29] Sturgess, G., and Shouse, D. T., 1996, "A Hybrid Model for Calculating Lean Blow-outs in Practical Combustors," AIAA Paper, 96(3125).

[30] Sigfrid, I. R., Whiddon, R., Collin, R., and Klingmann, J., 2014, "Influence of reactive species on the lean blowout limit of an industrial DLE gas turbine burner," Combustion and Flame, 161(5), pp. 1365-1373.

[31] Lefebvre, A. H., 1998, Gas turbine combustion, CRC press.

[32] Karalus, M. F., 2014, "An investigation of lean blowout of gaseous fuel alternatives to natural gas,"Ph.D Dissertation University of Washington.

[33] Rubin, P., and Pratt, D., 1991, "Zone combustion model development and use: Application to emissions control," American Society of Mechanical Engineers, pp. 1-41.

[34] Mellor, A., 1996, "NOx and CO emissions models for gas-fired, lean premixed combustion turbine: Final report," Vanderbit University, Nashville, TN.

[35] Novosselov, I. V., 2002, "Eight-Step Global Kinetic Mechanism on Methane Oxidation with Nitric Oxide Formation for Lean-Premixed Combustion Turbines,"MSME Thesis, University of Washington. 
[36] Pratt, D. T., and Wormeck, J. D., 1976, "CREK, Combustion Reaction Equilibrium and Kinetics in Laminar and Turbulent Flows," Report TEL-76-1, Department of Mechanical Engineering, Washington State University, Pullman, WA.

[37] Pratt, D. T., and Radhakrishnan, K., 1984, "CREK1D: A computer code for transient, gasphase combustion kinetics," NASA Technical Memorandum.

[38] Radhakrishnan, K., and Pratt, D. T., 1988, "Fast Algorithm for Calculating Chemical Kinetics in Turbulent Reacting Flows," Comb. Sci. Tech., pp. 155-176.

[39] Pratt, D. T., 1997, "Calculation of Chemically Reactive Flows with Complex chemistry," in Studies in Convection, B.E. Launder, Editor, Academic Press, 2.

[40] Novosselov, I. V., 2006, "Chemical reactor networks for combustion systems modeling,"Ph.D Disseration, University of Washington.

[41] Nicol, D. G., 1996, "The Chemical Reactor Model Combustion Code," Section 4.6 in Mellor, A.M., Editor. "NOx and CO Emissions Models for Gas-Fired, Lean Premixed Combustion Turbine: Final Report," Vanderbilt University, Nashville, TN.

[42] Ren, J.-Y., Qin, W., Egolfopoulos, F., Mak, H., and Tsotsis, T., 2001, "Methane reforming and its potential effect on the efficiency and pollutant emissions of lean methane-air combustion," Chemical Engineering Science, 56(4), pp. 1541-1549.

[43] Ren, J.-Y., Qin, W., Egolfopoulos, F., and Tsotsis, T., 2001, "Strain-rate effects on hydrogenenhanced lean premixed combustion," Combustion and Flame, 124(4), pp. 717-720.

[44] Sher, E., and Refael, S., 1988, "A simplified reaction scheme for the combustion of hydrogen enriched methane/air flame," Combustion science and technology, 59(4-6), pp. 371-389.

[45] Di Sarli, V., and Di Benedetto, A., 2007, "Laminar burning velocity of hydrogen-methane/air premixed flames," International Journal of Hydrogen Energy, 32(5), pp. 637-646.

[46] Safta, C., and Madnia, C., 2006, "Autoignition and structure of nonpremixed CH 4/H 2 flames: detailed and reduced kinetic models," Combustion and flame, 144(1), pp. 64-73.

[47] Chaumeix, N., Pichon, S., Lafosse, F., and Paillard, C.-E., 2007, "Role of chemical kinetics on the detonation properties of hydrogen/natural gas/air mixtures," International Journal of Hydrogen Energy, 32(13), pp. 2216-2226.

[48] Zucrow, M. J., and Hoffman, J. D., 1976, "Gas dynamics," New York: Wiley, 1976.

[49] Lee, J. C. Y., 2000, "Reduction of NOx emission for lean prevaporized-premixed combustors,"Ph.D Dissertation University of Washington.

[50] Kramlich, J. C., and Malte, P. C., 1978, "Modeling and measurement of sample probe effects on pollutant gases drawn from flame zones," Combustion Science and Technology, 18(3-4), pp. 91-104.

[51] Fackler Jr, K. B., 2011, "A study of pollutant formation from the lean premixed combustion of gaseous fuel alternatives to natural gas,"Ph.D Dissertation University of Washington.

[52] Stöhr, M., Boxx, I., Carter, C., and Meier, W., 2011, "Dynamics of lean blowout of a swirlstabilized flame in a gas turbine model combustor," Proceedings of the Combustion Institute, 33(2), pp. 2953-2960.

[53] Dieke, G., and Crosswhite, H., 1962, "The ultraviolet bands of OH fundamental data," Journal of Quantitative Spectroscopy and Radiative Transfer, 2(2), pp. 97-199.

[54] Miller, J. A., Kee, R. J., and Westbrook, C. K., 1990, "Chemical kinetics and combustion modeling," Annual Review of Physical Chemistry, 41(1), pp. 345-387.

[55] Krasnoperov, L. N., Chesnokov, E. N., Stark, H., and Ravishankara, A., 2004, "Unimolecular dissociation of formyl radical, $\mathrm{HCO} \rightarrow \mathrm{H}+\mathrm{CO}$, studied over 1- 100 bar pressure range," The Journal of Physical Chemistry A, 108(52), pp. 11526-11536. 
[56] Santner, J., Haas, F. M., Dryer, F. L., and Ju, Y., 2015, "High temperature oxidation of formaldehyde and formyl radical: A study of 1, 3, 5-trioxane laminar burning velocities," Proceedings of the Combustion Institute, 35(1), pp. 687-694.

[57] Timonen, R. S., Ratajczak, E., Gutman, D., and Wagner, A. F., 1987, "The addition and dissociation reaction atomic hydrogen+ carbon monoxide. dblharw. oxomethyl. 2. Experimental studies and comparison with theory," Journal of Physical Chemistry, 91(20), pp. 5325-5332.

[58] Li, B., Li, X., Yao, M., and Li, Z., 2015, "Methyl Radical Imaging in Methane-Air Flames Using Laser Photofragmentation-Induced Fluorescence," Applied spectroscopy, 69(10), pp. 11521156.

[59] Shanbhogue, S. J., Husain, S., and Lieuwen, T., 2009, "Lean blowoff of bluff body stabilized flames: Scaling and dynamics," Progress in Energy and Combustion Science, 35(1), pp. 98-120.

[60] Hong, S., Shanbhogue, S. J., and Ghoniem, A. F., 2015, "Impact of fuel composition on the recirculation zone structure and its role in lean premixed flame anchoring," Proceedings of the Combustion Institute, 35(2), pp. 1493-1500.

[61] Turns, S. R., 1996, An introduction to combustion, McGraw-hill New York.

[62] Göttgens, J., Mauss, F., and Peters, N., "Analytic approximations of burning velocities and flame thicknesses of lean hydrogen, methane, ethylene, ethane, acetylene, and propane flames," Proc. Symposium (International) on Combustion, Elsevier, pp. 129-135. 


\section{Appendix A - Gas Analyzers}

The combustion gases are drawn through water-cooled quartz probe using a metal bellows pump. The sample Teflon line is heated using an Omega Lux heating tape and heat controller in order to prevent condensation. The water vapor from the sample is removed by passing it through a set of impingers immersed in an ice bath. The sample gas is passed through a three gas (CO, $\left.\mathrm{CO}_{2}, \mathrm{O} 2\right)$ Horiba VA 3000 analyzer.

Horiba VA-3000:

The Horiba analyzer is used to measure dry gas concentrations of $\mathrm{CO}, \mathrm{CO}_{2}$ and $\mathrm{O}_{2}$ in the sampled gas. The $\mathrm{CO}, \mathrm{CO}_{2}$ are measured based on the NDIR method whereas the $\mathrm{O}_{2}$ is measured using the paramagnetic principle. The volume of the sample gas at the inlet is maintained at 0.5 $\mathrm{gm} / \mathrm{s}$ and pressure between 50-60 KPa.

Drift Correction:

During the operation it is common for the calibration of the gas analyzer to drift. Therefore, it is important to note and re-calibrate the analyzer frequently during an experiment. The gas analyzer values are corrected for drift via the following steps:

1. Correct for any drift in the zero-gas calibration. In case, the zero value is positive, subtract the value from measured gas value and if the zero value is negative, add it to the measured value.

2. Correct for any drift in span-gas calibration. If $[\mathrm{G}]_{\text {measured }}$ is the measured concentration of gas $[\mathrm{G}]_{\text {calibration }}$ and $[\mathrm{G}]_{\text {Drift }}$ are the span gas concentration and drifted concentration of the calibrating gas, then the corrected value is given by

$$
[G]_{\text {corrected }}=\frac{[G]_{\text {calibration }} *[G]_{\text {measured }}}{[G]_{\text {drift }}}
$$




\section{Appendix B - Control System}

The control box houses the electronics and electrical components required to control MFC, gather data from gas analyzers and thermocouple DAQ in real-time. Two $15 \mathrm{~V}$ LS 25 AC/DC power supplies in series are installed to provide a net voltage of $30 \mathrm{~V}$ to the three mass flow controllers (MFC). The distribution box divides the power to different MFC. The Sierra Instruments MFC work based on the transducer principle and calibrated using the wet flowmeter. The National Instruments MyRio embedded device is used to relay the signals to MFCs from the computer and collect the actual flow from the MFC. Three analog signals from Horiba VA-3000 gas analyzer representing the concentrations of $\mathrm{CO}, \mathrm{CO}_{2}$ and $\mathrm{O}_{2}$ are collected in the computer using MyRio.

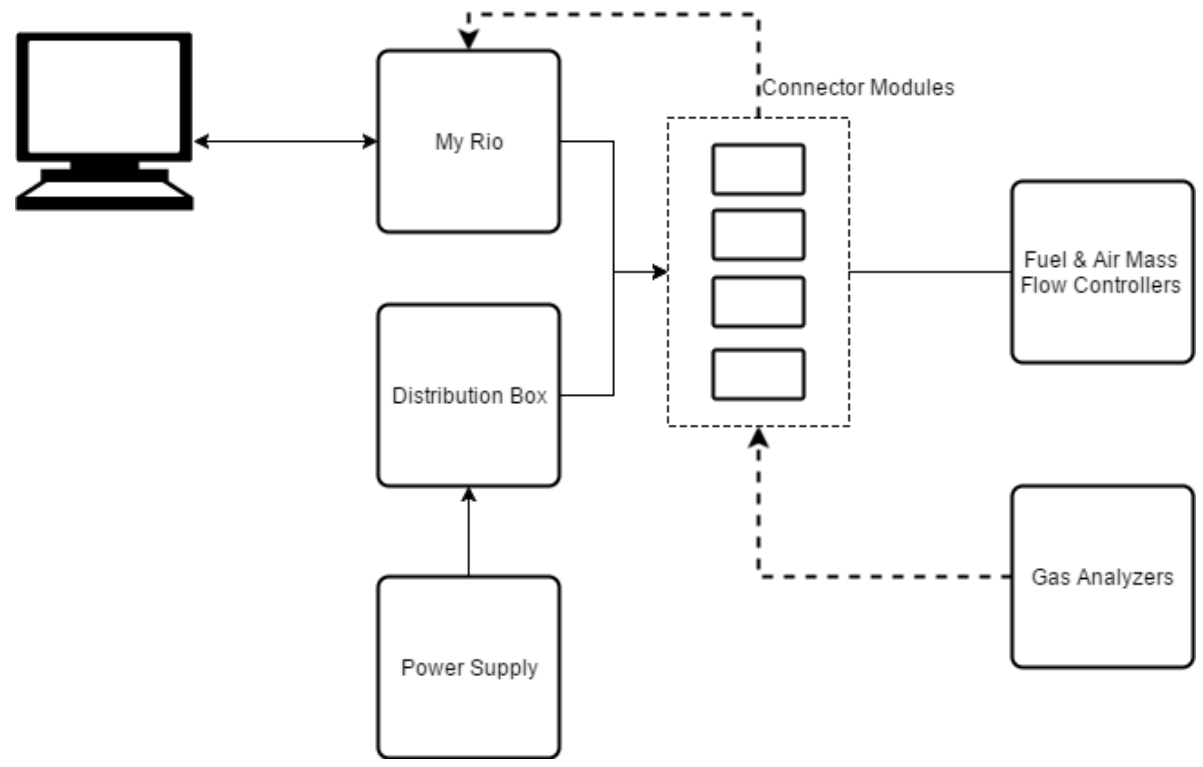

Fig. 14: Schematic diagram of control box that houses the electronics to control and gather data from JSR 


\section{Appendix C - Temperature Measurement}

The temperature is measured using R type thermocouples. An R-type thermocouple consists of wires made with $87 \%$ platinum- $13 \%$ rhodium and platinum. It senses temperatures between $0 \mathrm{C}$ and $1482 \mathrm{C}$ making it suitable for the JSR experiments. The thermocouple junction is coated with alumina to prevent oxidation on its surface. The thermocouple is placed in the jet stirred reactor using a holder and is usually located $9 \mathrm{~mm}$ from the center.

Table 3 shows that $9 \mathrm{~mm}$ from the center is an optimal distance to represent the recirculation zone. Any other location closer to the wall would cause the wall heating to influence the thermocouple readings and at a distance closer to the center the thermocouple can be exposed to cooler unburned inlet jet. The values in Table 3 are taken for air flow rate of $1.0 \mathrm{~g} / \mathrm{s}$ and at an equivalence ratio of 0.79 . Closer to the center, the temperatures are lower because of the fresh incoming mixture that is heated by surrounding hot gases. The temperature between 8 and $10 \mathrm{~mm}$ is almost constant and is highest compared to the other locations.

Table 3: Temperature measurement in the JSR at various distances from the center

\begin{tabular}{|c|c|}
\hline Distance from the center of JSR $(\mathbf{m m})$ & Uncorrected Temperature (K) \\
\hline 2 & 1206 \\
\hline 5 & 1600 \\
\hline 7 & 1733 \\
\hline 8 & 1743 \\
\hline 9 & 1746 \\
\hline 10 & 1744 \\
\hline 11 & 1737 \\
\hline 12 & 1749 \\
\hline
\end{tabular}




\section{Appendix D - Igniter}

An electric arc ignitor is used for igniting the hydrogen during the startup. For the JSR experiments, a Webster Ignition transformer is used. The transformer converts the primary voltage input of $120 \mathrm{~V}$ and $1.85 \mathrm{Amps}$ to secondary voltage of $8.5 \mathrm{KV}$ and $20 \mathrm{Amps}$. The terminals of the transformer are connected to the electrodes using a copper wire. Tungsten is used for the electrodes. The two electrodes are placed in a ceramic tube and are separated using the thin ceramic wall. The ceramic tube provides structural support and insulation for the electrodes and protects them from the high-temperature environment inside the combustor during startup. An epoxy resin/JB weld is used to seal and insulate the junction between copper wire and electrodes. The distance between the electrodes is maintained at $1 \mathrm{~mm}$, and $0.75 \mathrm{~mm}$ of the electrodes are exposed outside the ceramic tubing to generate the arc. The electrodes should not be exposed to each other except at the tip, where the arc is generated. During startup, the ignitor is placed at the center of the premixed fuel-air inlet jet and switched on while increasing the hydrogen flow rate until ignition occurs.

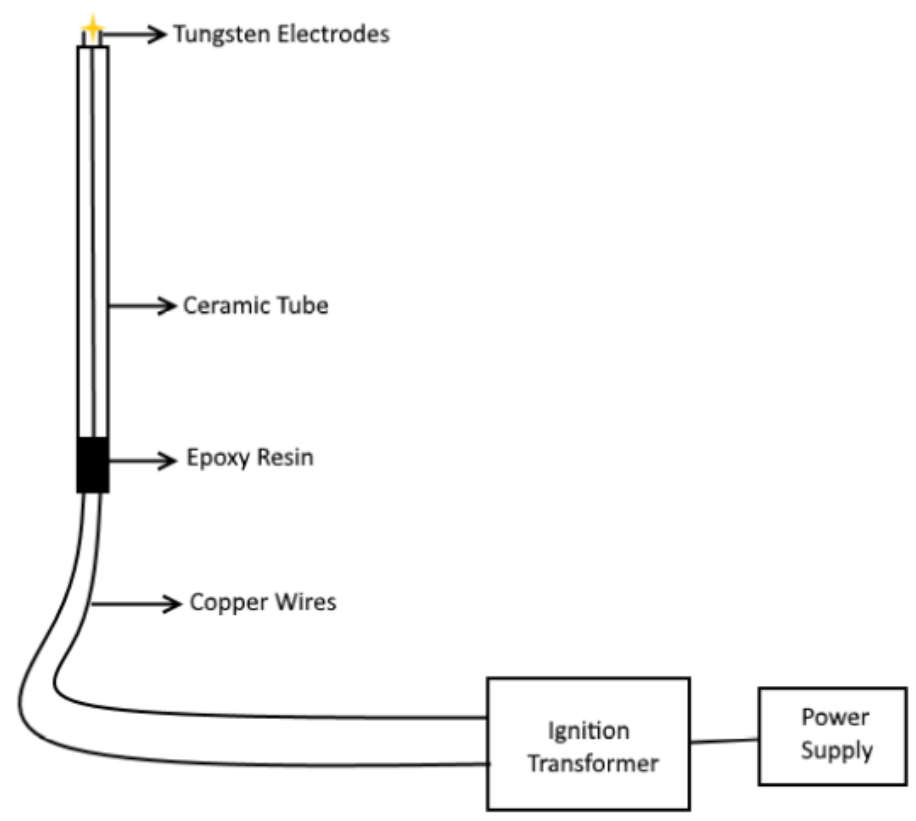

Fig. 15: Schematic diagram of igniter and transformer. 


\section{Appendix E- Experimental Standard Operating Procedure Before igniting the reactor}

1. Open lab garage door.

2. Connect the ribbon wires from MyRio Control box to the Fuel, primary and secondary air Mass Flow Controllers.

3. Connect the analog outputs of the gas analyzers and Thermocouple DAQ to MyRio.

4. Open the LabVIEW and run the 'Main' program under MyRio to activate the MFC.

5. Before turning on the MFCs, close the air valves to rotometers and set the pressure inlet at the MFC to 50 psig before ignition and 80 psig after ignition.

6. Completely open the air outlet valves immediately upstream of the JSR inlet.

7. Set up thermocouple
a. Move to center of reactor, check from side port and there should be an audible difference

b. Back up $9 \mathrm{~mm}$ from center

c. Secure in place with screw

8. Set up fuel lines
a. Set $\mathrm{H} 2$ pressure to $30 \mathrm{vpsig}$
b. Check pressure on the rig (not bottle)
c. Check for flow on rotameter by slightly opening
d. Turn off $\mathrm{H}_{2}$ before proceeding
e. Set up $\mathrm{CH}_{4}$ in the same manner but with pressure at 80psig
f. Turn all the fuel off before proceeding

9. Check ignitor
a. Plug in orange plug
b. Turn switch on and off (bottom right of rig)
c. Should see spark only on tip
d. Insert ignitor through rubber sling into center of JSR
e. Confirm through side (should be able to see spark and there should be an audible difference)
f. Turn off ignitor

10. Set up sample probe 
a. Center probe and secure by hand tightening nylon screws

b. Turn on warm water and make sure there is good flow through the probe

c. Turn on the Omega Lux heating tape around the sample and set the heating to $25 \%$.

d. Direct the flow through impingers $(2 / 3)$ before entering the gas analyzer, in order to remove the water in the sampled gas.

11. Turn on the computer

a. Open PDaQ view

b. Select desired data channels for the secondary thermocouple in the JSR and thermocouples inside the premixer.

c. Choose file destination

12. Labview:

a. Open the 'JSROperate' Labview project file on Desktop.

b. Connect the UWNRG-MyRio by right-clicking > connect.

c. Run the 'Main_MyRio.vi', which acts as link between computer and MyRio

d. Run the 'Main_Mycomp.vi' which contains the controls to set MFC flow rates.

e. Switch on the air control on 'Main_Mycomp.vi' by clicking on 'Air On' and set an initial total air flow rate of $38 \mathrm{LPM}(0.80 \mathrm{~g} / \mathrm{s})$ and set 'Percent primary' to 50.

f. Set the control type to 'Control fuel and air'.

\section{Ignition and Warm-up}

1. Turn on ignitor.

2. Slowly increase $\mathrm{H} 2$ until a continuous roar occurs.

3. Immediately turn off, unplug, and gently remove ignitor.

4. Increase the air pressure to $80 \mathrm{psig}$.

5. Add air in steps of 2 LPM until the total air flow rate is 50 LPM (1.0 g/s).

6. Simultaneously, adjust $\mathrm{H} 2$ flow rate until JSR temperature is $1350 \mathrm{C}$ on computer

7. After heating the rig for $15 \mathrm{~min}$ on $\mathrm{H}_{2}$, start adding Methane by turning on 'Methane fuel on' button on Labview.

8. Set the initial flow rate to 0.9 LPM (or an equivalene ratio of 0.2 at $1.0 \mathrm{~g} / \mathrm{s}$ air) of Methane at 80 psi.

9. Slowly add methane in steps of $0.05 \Phi$ while turning down $\mathrm{H}_{2}$. 
10. Now add Methane until the JSR is running without any H2.

11. Allow JSR to warm up until thermocouples read constant values.

\section{Blowout experiment}

1. Set the control type to 'Control fuel and $\Phi$ '.

2. Decrease the $\Phi$ (Fuel-air equivalence ratio in steps of 0.1)

3. Run the 'Sensor_Mycomp.vi' which contains the data collection capability from thermocouple DAQ and gas analyzers.

4. Use the 'Record data' button on 'Sensor_Mycomp.vi' when you want to collect the experimental data in excel format ('JSROP.xlsx') . The file is located in the folder, 'C:I...IDesktoplJSR OperatelOutputs'

5. Similarly, use the 'CRN_MyComp.vi' to run the CRN in real time and record data.

\section{Warnings!}

1. Make sure that there is no water in the sample gas line entering gas analyzer.

2. Check the pressure gauges constantly.

3. Verify that the data acquisition is working before proceeding with data recording. 


\section{Appendix F - Equivalence ratios using gas analyzers}

The mass flow controller readings are calibrated using the wet flowmeters. But as time passes, the calibration of the MFCs drift and due to errors in calibration, the readings might not be correct. Therefore, it is important to calculate the flowrates using the exhaust gas measurements. The chemical reaction for lean combustion of Methane is given by:

$$
\Phi \mathrm{CH}_{4}+2\left(\mathrm{O}_{2}+3.76 \mathrm{~N}_{2}\right) \rightarrow \Phi \mathrm{CO}_{2}+2 \Phi \mathrm{H}_{2} \mathrm{O}+2(1-\Phi) \mathrm{O}_{2}+7.52 \mathrm{~N}_{2}
$$

While calculating the $\Phi$ from exhaust gases, assume the complete combustion of $\mathrm{CH}_{4}$ i.e assume that no $\mathrm{CO}$ is produced. This means that the measured $\mathrm{CO}$ values are converted to $\mathrm{CO}_{2}$. From the equation:

$$
\mathrm{CO}+0.5 \mathrm{O}_{2} \rightarrow \mathrm{CO}_{2}
$$

Each mole of $\mathrm{CO}$ produces one mole of $\mathrm{CO}_{2}$ while consuming half a mole of $\mathrm{O}_{2}$. Therefore, using reactions 1 and 2, the equivalence ratio is found out by,

$$
\Phi=\frac{\left[\mathrm{N}_{\mathrm{CO} 2}+\mathrm{N}_{\mathrm{CO}}\right]}{\left[\left(\mathrm{N}_{\mathrm{O} 2}-0.5 * \mathrm{~N}_{\mathrm{CO}}\right)+2 *\left(\mathrm{~N}_{\mathrm{CO} 2}+\mathrm{N}_{\mathrm{CO}}\right)\right]}
$$

Where, $\mathrm{N}_{\mathrm{CO}}, \mathrm{N}_{\mathrm{CO} 2}$ and $\mathrm{N}_{\mathrm{O}}$, are the measured values of $\mathrm{CO}, \mathrm{CO}_{2}$ and $\mathrm{O} 2$ respectively. The $\Phi_{\text {Gas }}$ is consistently less than $11.4 \%$ for air flow rates of $1.0 \mathrm{~g} / \mathrm{s}$ and $1.2 \mathrm{~g} / \mathrm{s}$ and $13.7 \%$ for air flow rate of $1.5 \mathrm{~g} / \mathrm{s}$ (Table 4$)$. The very lean values are not considered for the analysis as the $\Phi_{\text {Gas }}$ values deviate significantly from $\Phi_{\mathrm{MFC}}$ due to the presence of other unburned hydrocarbons. 
Table 4: Equivalence ratio calculated using MFC flow rates $\left(\Phi_{M F C}\right)$ and exhaust gases ( $\left.\Phi_{\text {Gas analyzer }}\right)$

\begin{tabular}{|c|c|c|}
\hline Air flow rate & $\Phi_{M F C}$ & $\boldsymbol{\Phi}_{\text {Gas analyzer }}$ \\
\hline \multirow[t]{6}{*}{$1.0 \mathrm{~g} / \mathrm{s}$} & 0.89 & 0.79 \\
\hline & 0.85 & 0.75 \\
\hline & 0.82 & 0.72 \\
\hline & 0.80 & 0.71 \\
\hline & 0.77 & 0.68 \\
\hline & 0.75 & 0.66 \\
\hline \multirow[t]{7}{*}{$1.2 \mathrm{~g} / \mathrm{s}$} & 0.90 & 0.80 \\
\hline & 0.87 & 0.77 \\
\hline & 0.85 & 0.75 \\
\hline & 0.83 & 0.73 \\
\hline & 0.81 & 0.71 \\
\hline & 0.79 & 0.69 \\
\hline & 0.77 & 0.68 \\
\hline \multirow[t]{6}{*}{$1.5 \mathrm{~g} / \mathrm{s}$} & 0.90 & 0.78 \\
\hline & 0.87 & 0.75 \\
\hline & 0.85 & 0.73 \\
\hline & 0.83 & 0.72 \\
\hline & 0.81 & 0.70 \\
\hline & 0.79 & 0.68 \\
\hline
\end{tabular}




\section{Appendix G - Analysis of Free Radicals and Data for Additional Air Flow Rates}

This section includes modeled free radical data for $1.2 \mathrm{~g} / \mathrm{s}$ and the experimental and CRN data for additional air flow rates of $1.0 \mathrm{~g} / \mathrm{s}$ and $1.5 \mathrm{~g} / \mathrm{s}$. Figures 16 - 17 shows the experimental data corrected for delay in sample line (approx. 18s) and modeled data for steady state experiments.

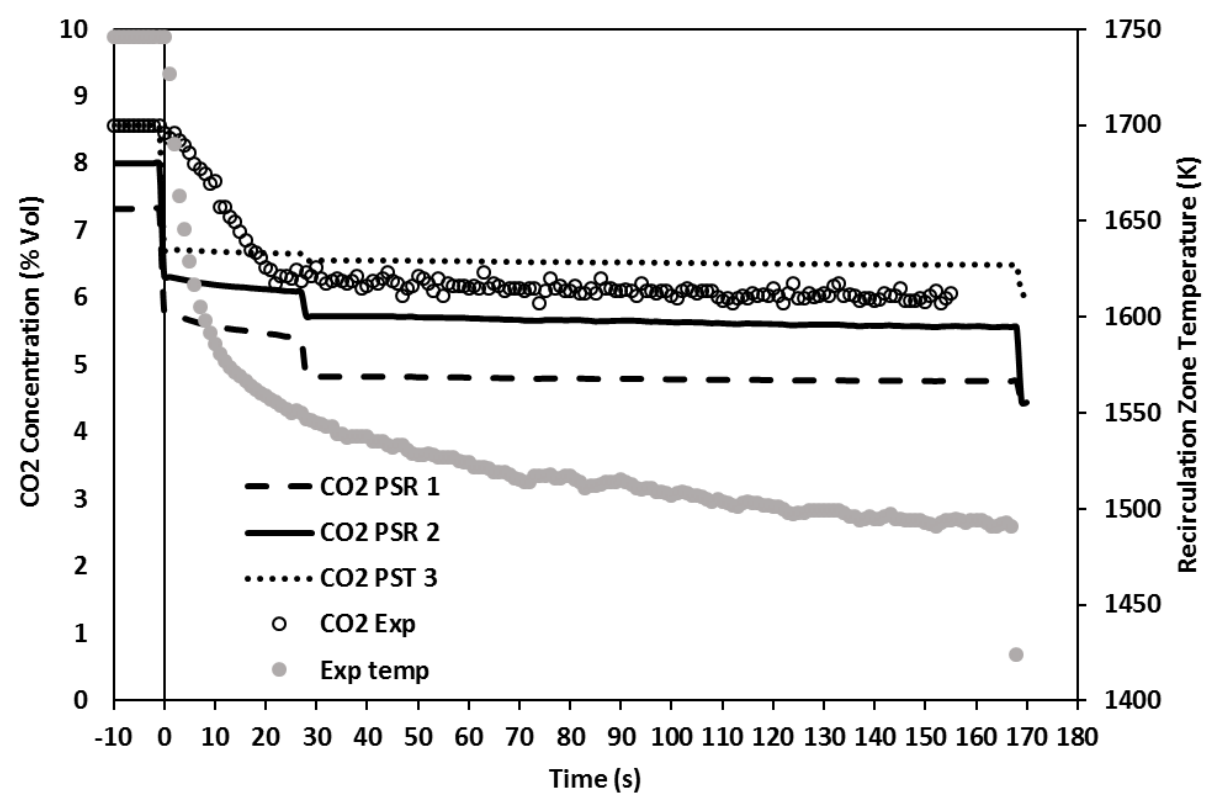

(a)

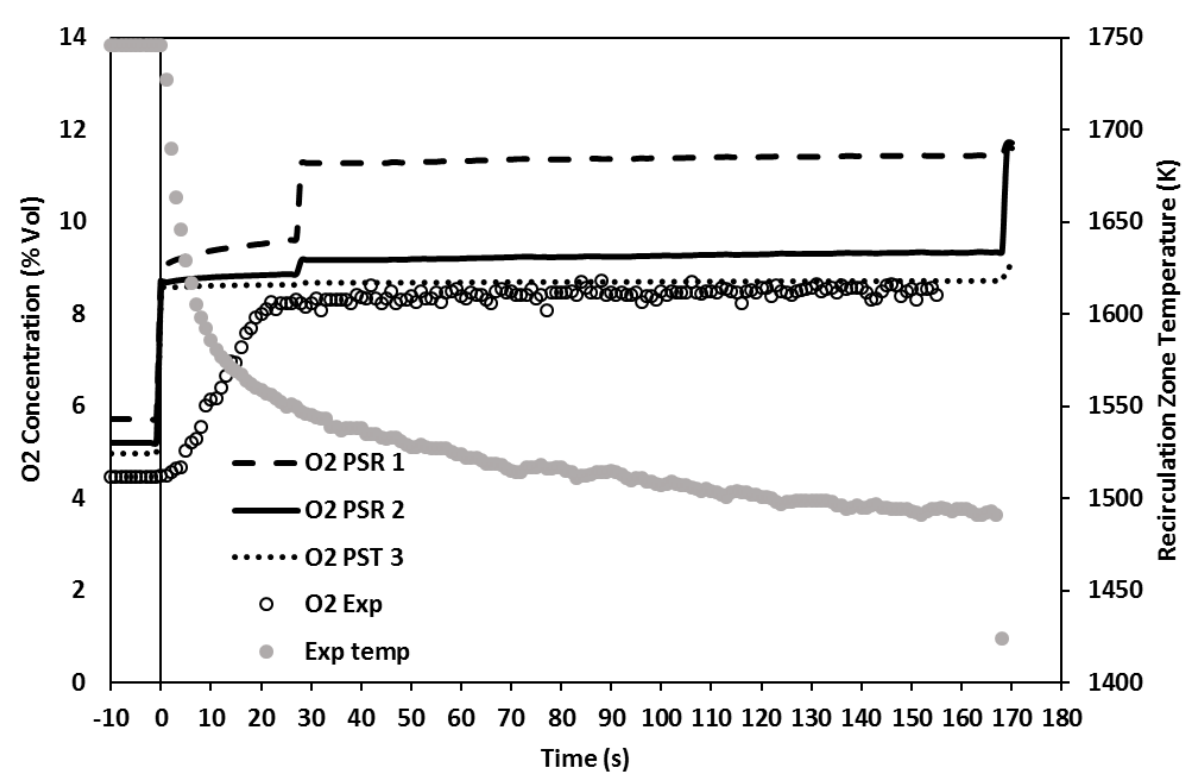

(b) 


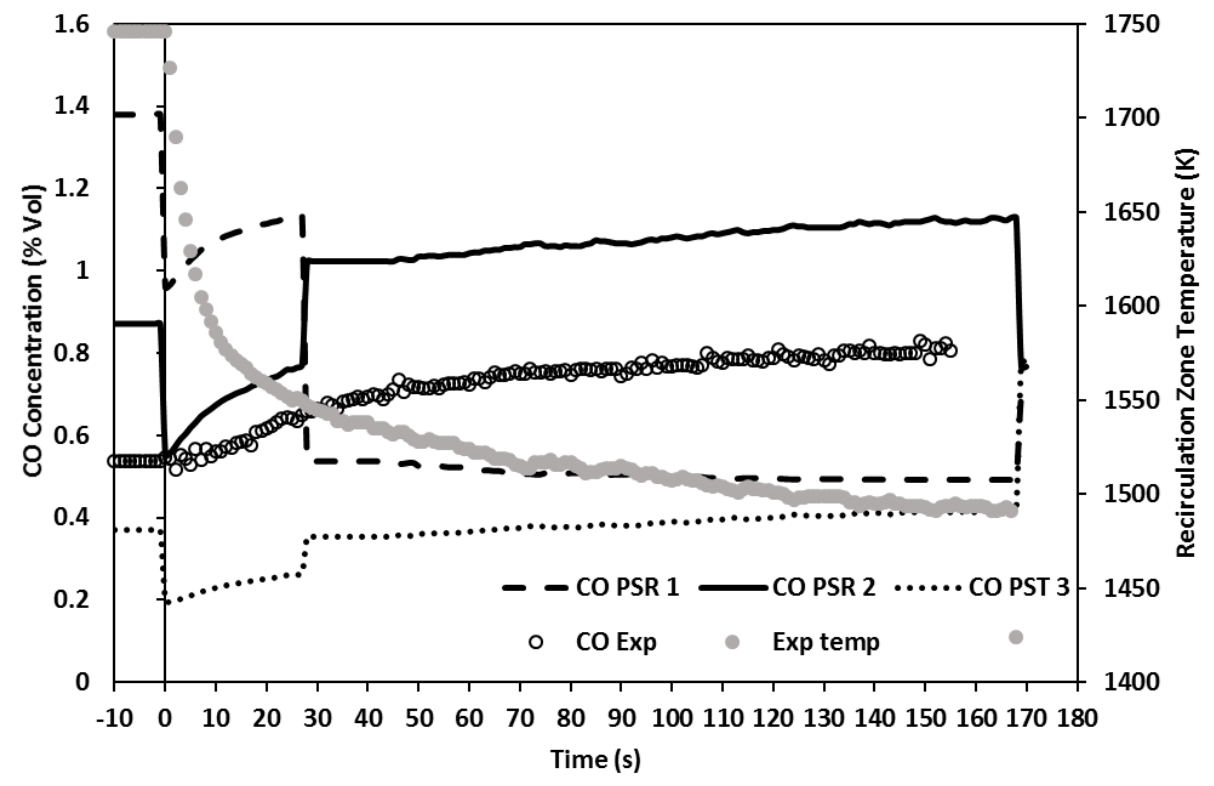

(c)

Fig. 16: Experimental and modeled concentrations of (a) $\mathrm{CO}_{2}(\mathrm{~b}) \mathrm{O}_{2}$ and (c) $\mathrm{CO}$ for an air flow rate of $1.0 \mathrm{~g} / \mathrm{s}$ and blowout equivalence ratio of 0.62 (initial $\Phi=0.79$ ). The experimental concentrations are corrected for the 18 seconds delay in sampling line.

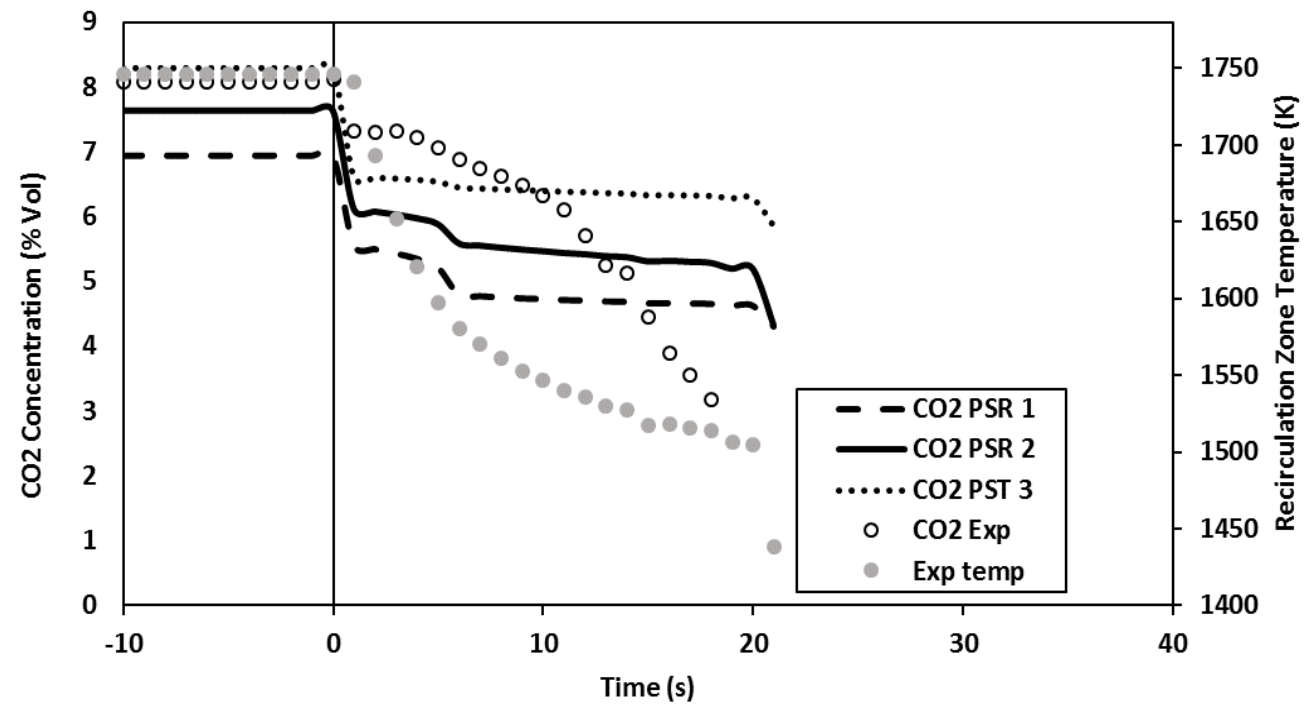

(a) 


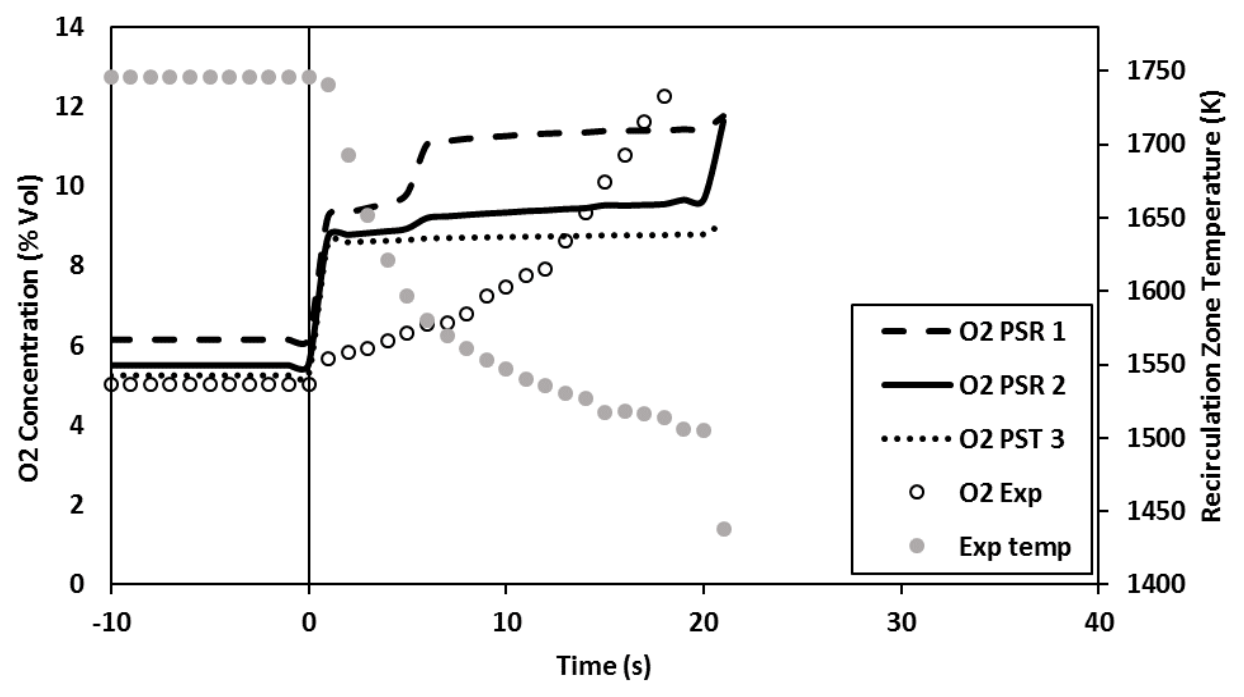

(b)

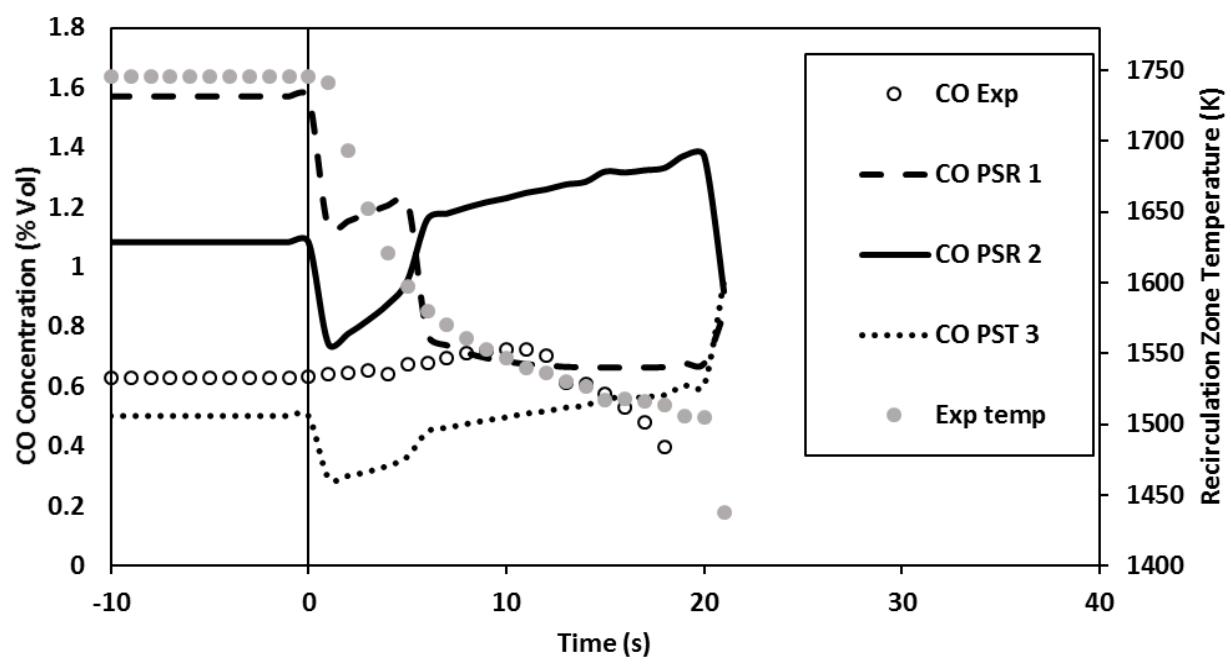

(c)

Fig. 17: Experimental and modeled concentrations of (a) $\mathrm{CO}_{2}(\mathrm{~b}) \mathrm{O}_{2}$ and (c) $\mathrm{CO}$ for an air flow rate of $1.5 \mathrm{~g} / \mathrm{s}$ and blowout equivalence ratio of 0.62 (initial $\Phi=0.78$ ). The experimental concentrations are corrected for the 18 seconds delay in sampling line. 
Figures 18 - 20 shows the $\mathrm{CO}_{2}, \mathrm{O}_{2}$ and $\mathrm{CO}$ concentrations with delay included for air flow rates of $1.0 \mathrm{~g} / \mathrm{s}, 1.2 \mathrm{~g} / \mathrm{s}$ and $1 / 5 \mathrm{~g} / \mathrm{s}$.

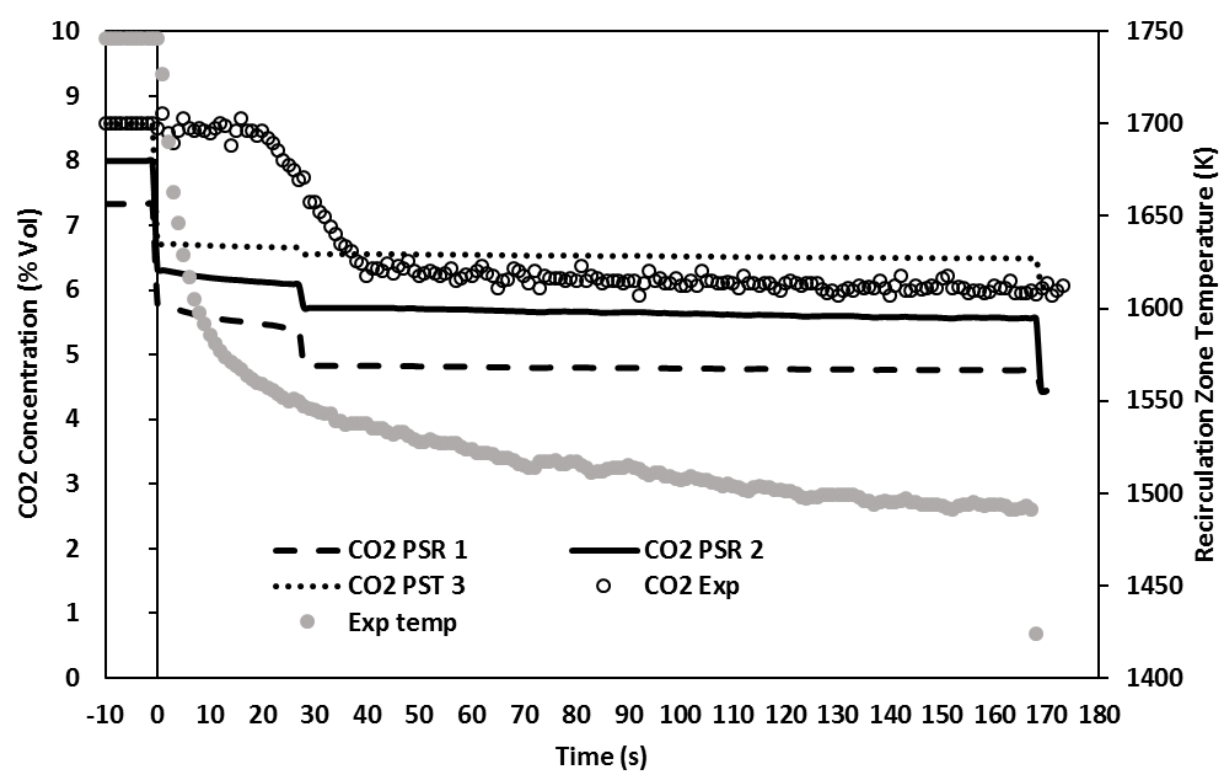

(a)

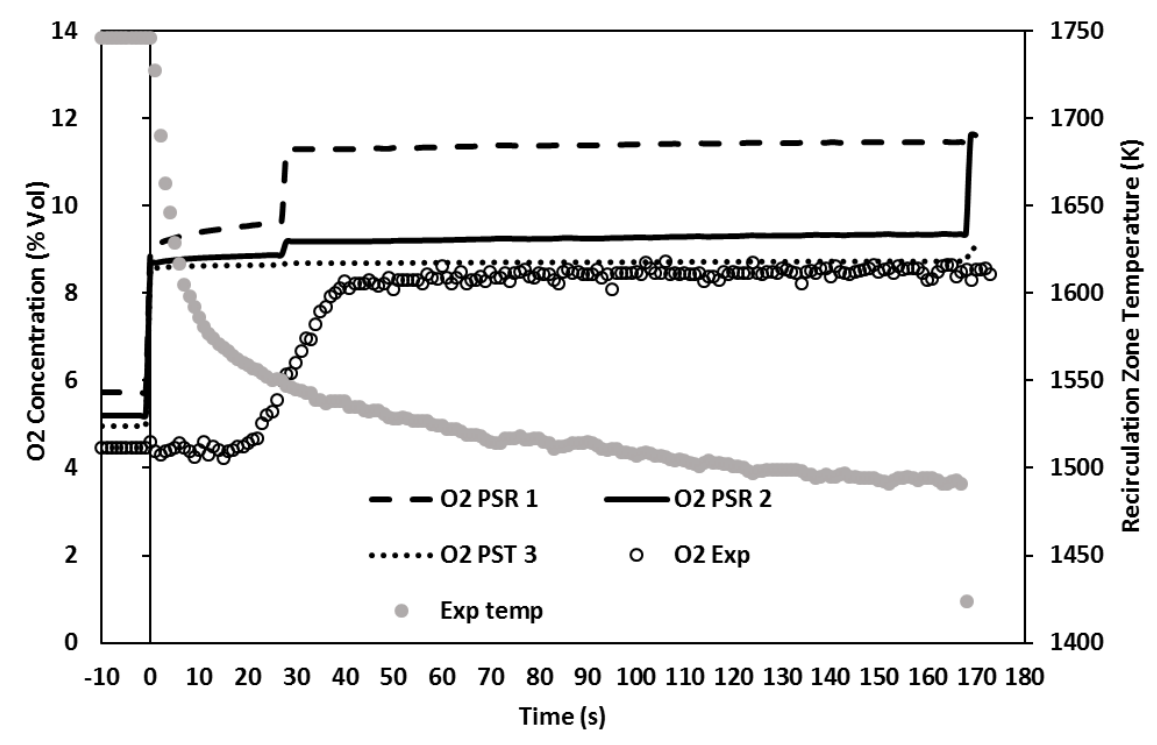

(b) 


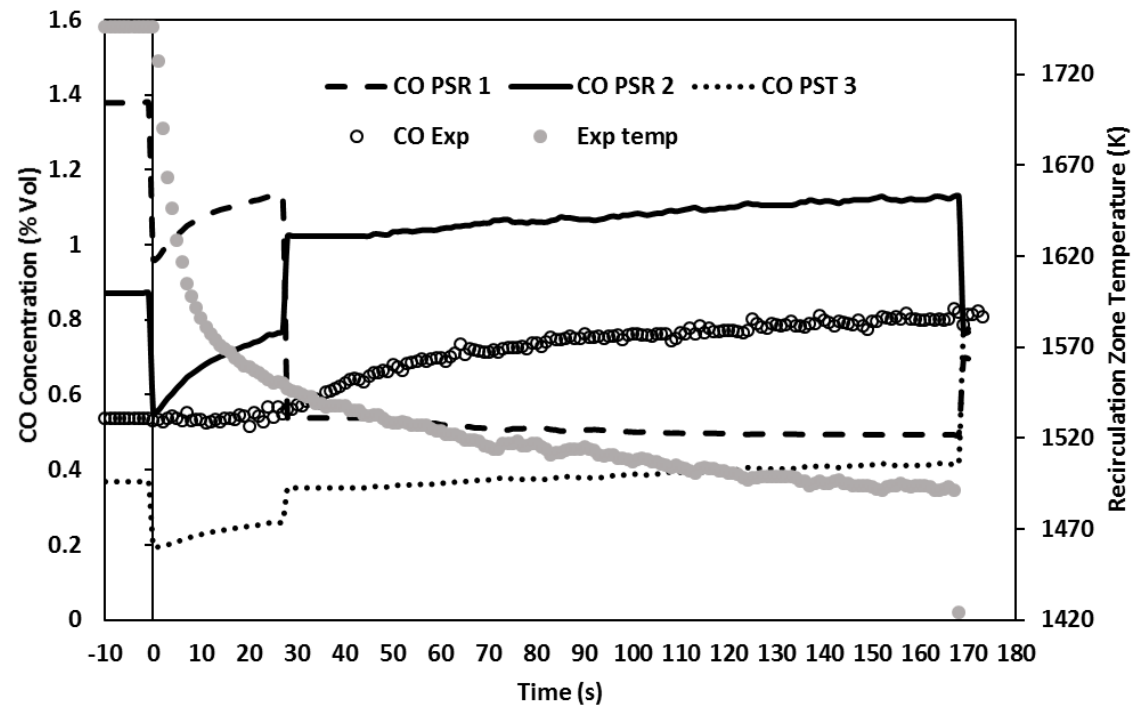

(c)

Fig. 18: Experimental and modeled concentrations of (a) $\mathrm{CO}_{2}$ (b) $\mathrm{O}_{2}$ and (c) $\mathrm{CO}$ for an air flow rate of $1.0 \mathrm{~g} / \mathrm{s}$ and blowout equivalence ratio of 0.62 (initial $\Phi=0.79$ ). The experimental concentrations are not corrected for the 18 seconds delay in sampling line.

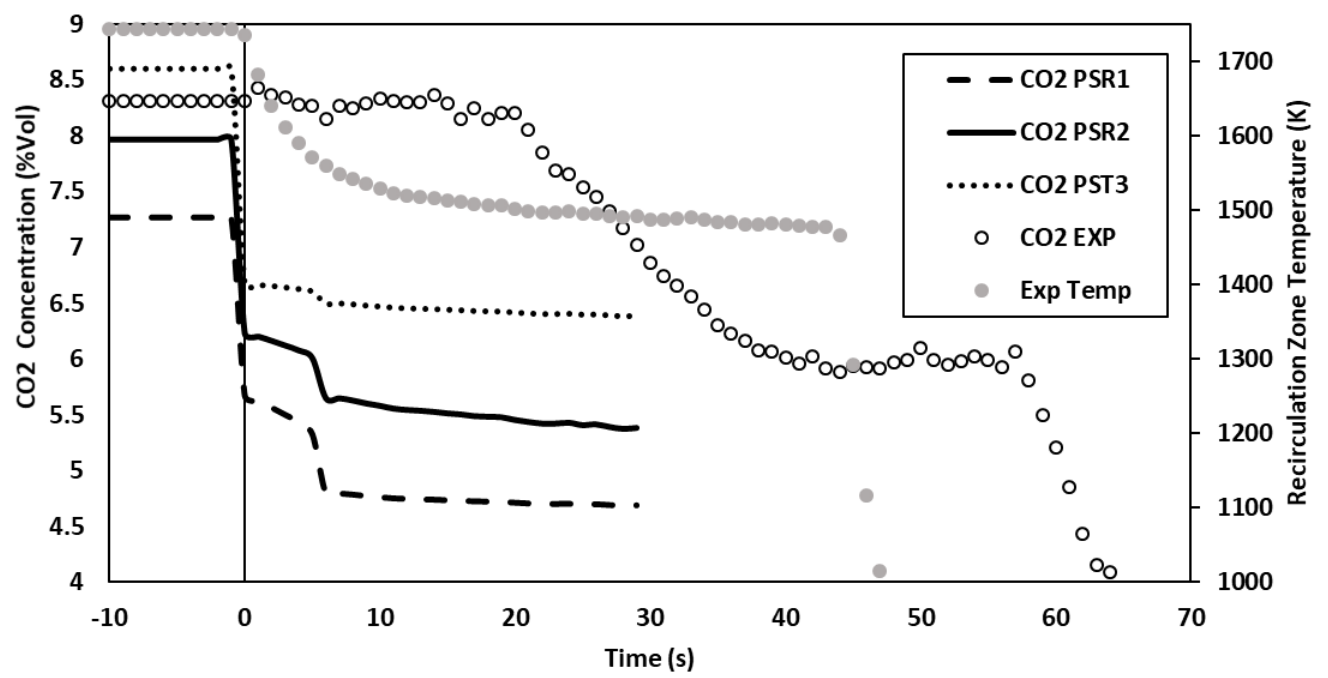

(a) 


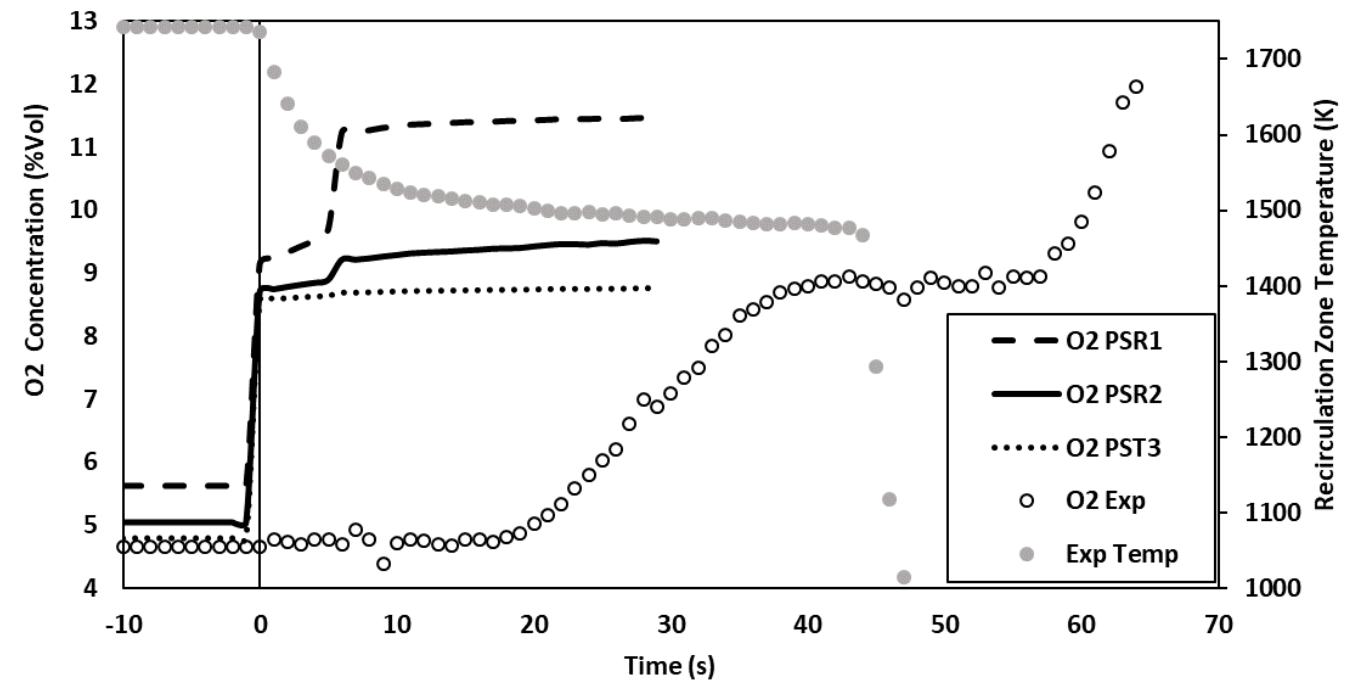

(b)

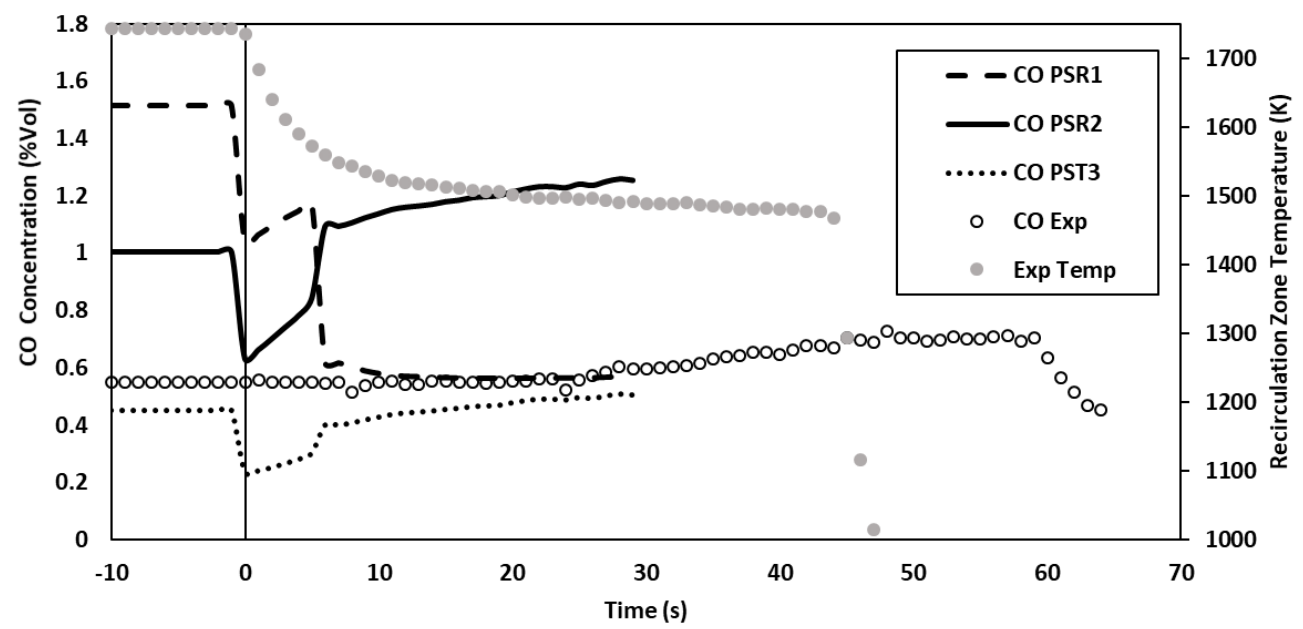

(c)

Fig. 19 Experimental and CRN concentrations of (a) $\mathrm{CO}_{2}$ (b) $\mathrm{O}_{2}$ and (c) $\mathrm{CO}$ for an air flow rate of $1.2 \mathrm{~g} / \mathrm{s}$ and blowout equivalence ratio of 0.62 (Starting $\Phi$ 0.80). The experimental concentrations are not corrected for the 18 seconds delay in sampling line. 


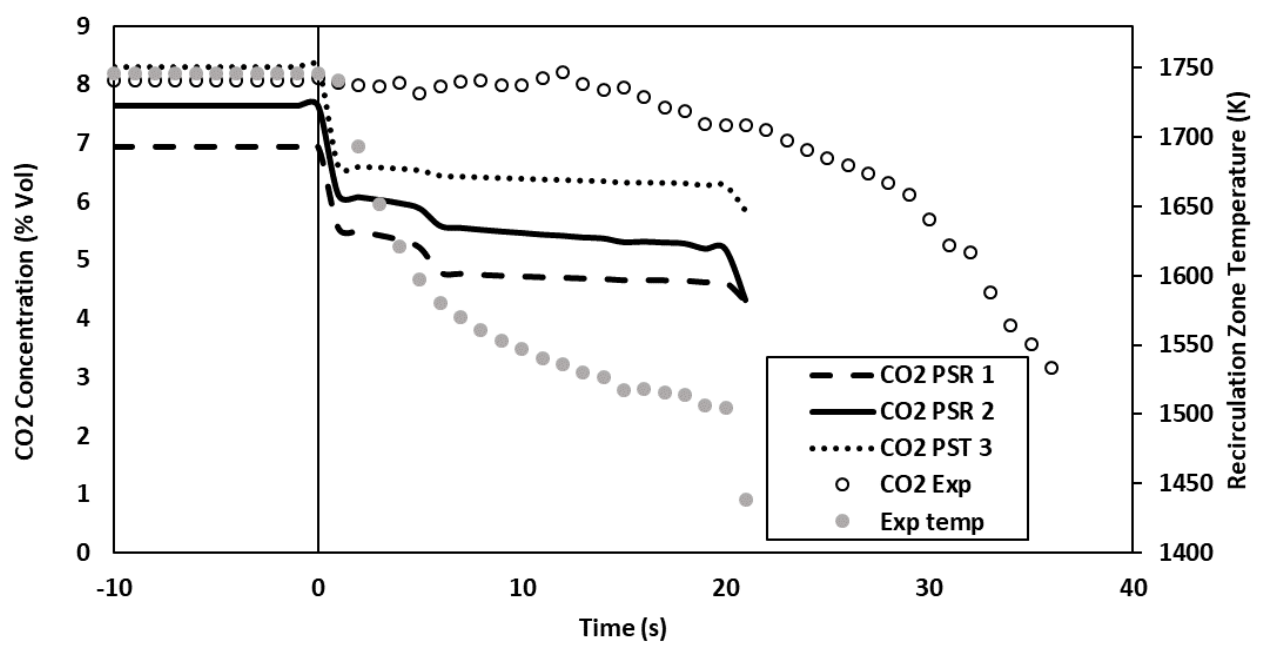

(a)

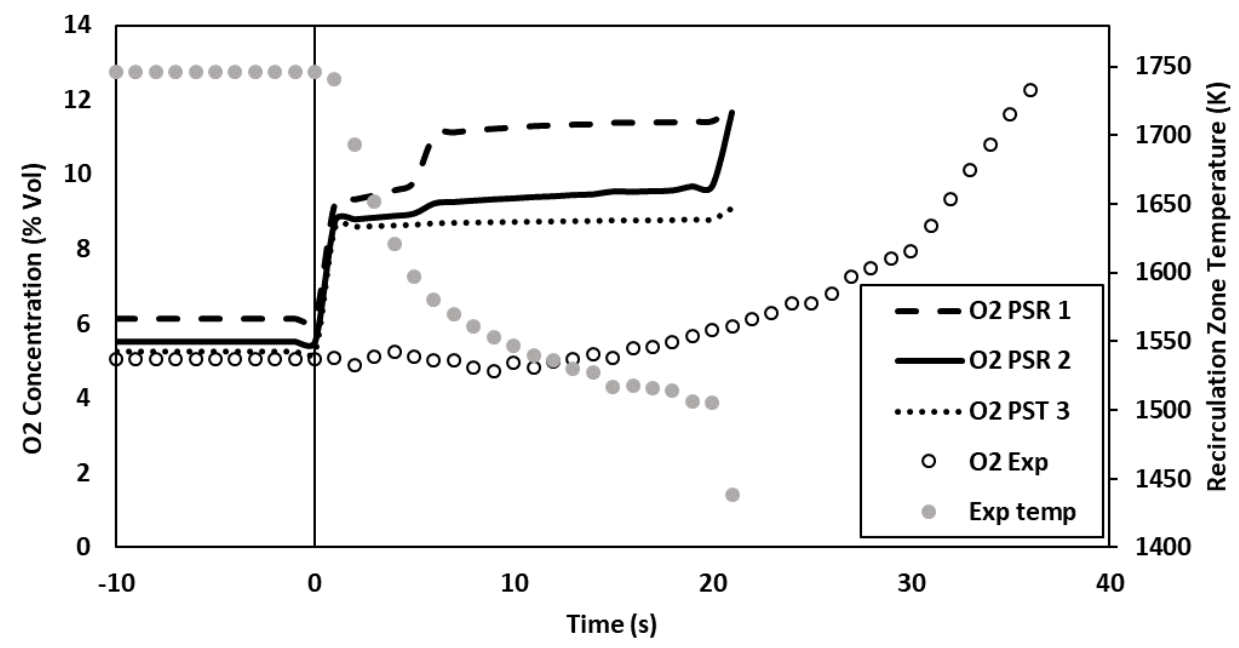

(b) 


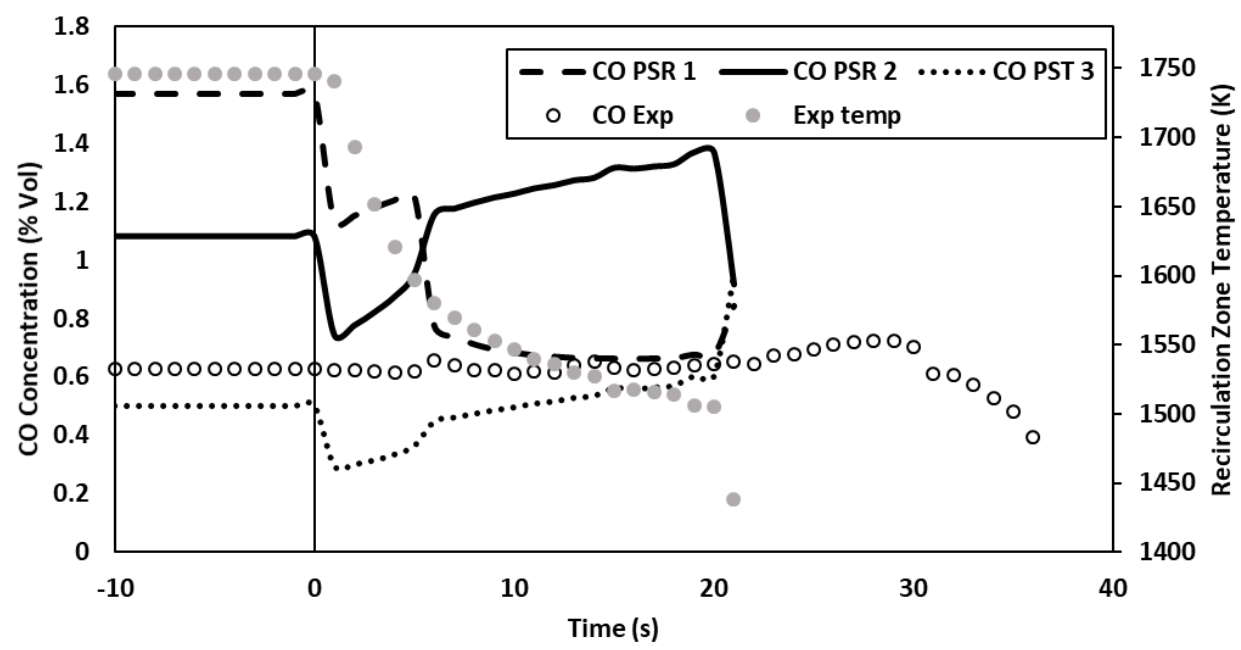

(c)

Fig. 20 Experimental and CRN concentrations of (a) $\mathrm{CO}_{2}$ (b) $\mathrm{O}_{2}$ and (c) $\mathrm{CO}$ for an air flow rate of $1.5 \mathrm{~g} / \mathrm{s}$ and blowout equivalence ratio of 0.62 (Starting $\Phi$ 0.78). The experimental concentrations are not corrected for the 18 seconds delay in sampling line.

\section{Analysis of Free Radical in the JSR}

After the PSR1 blowout, the $\mathrm{OH}$ concentration in PSR1 remains low though there is $75 \%$ reentrainment gas (including $\mathrm{OH}$ radical) from the PST3. The depletion of the re-entrained $\mathrm{OH}$ in the PSR1 is likely to be attributed to the pre-combustion reactions in PSR1. A preliminary discussion pertaining to the pre-flame reactions is presented here, however further study is required to establish the conclusions. Figures 21 - 26 show the concentrations of other free radicals important for flame stability. After a reduction in the equivalence ratio, the concentration of $\mathrm{CH}_{3}$ radicals in PSR1 increases initially as shown in Figure 23a after the PSR1 blowout. This can be due to the abstraction of $\mathrm{H}$ from $\mathrm{CH}_{4}$ by the $\mathrm{OH}$ radical causing production of $\mathrm{CH}_{3}$. However, as the reactor is cooling down, at $\mathrm{t} \sim 8 \mathrm{~s}$, the $\mathrm{OH}$ concentration in PSR2 and PST3 start decreasing, correspondingly reducing the available $\mathrm{OH}$ radicals for $\mathrm{H}$ abstraction from $\mathrm{CH}_{4}$ in PSR1. This is seen as a decrease in $\mathrm{CH}_{3}$ concentration while the increase in $\mathrm{CH}_{4}$ concentration (Figure 11) in PSR1 at t 8s. Another possible mechanism for the decrease in $\mathrm{H}$ atoms near blowout could be correlated to increase in the concentration of formyl radical (HCO), shown in Figure 24 which is an important source of $\mathrm{H}$ radical. Analysis of $\mathrm{HCO}$ radical behavior is presented later in the document. The free radical trends for air flow rates of $1.0 \mathrm{~g} / \mathrm{s}$ and $1.5 \mathrm{~g} / \mathrm{s}$ follow similar trends and are shown in this appendix. 

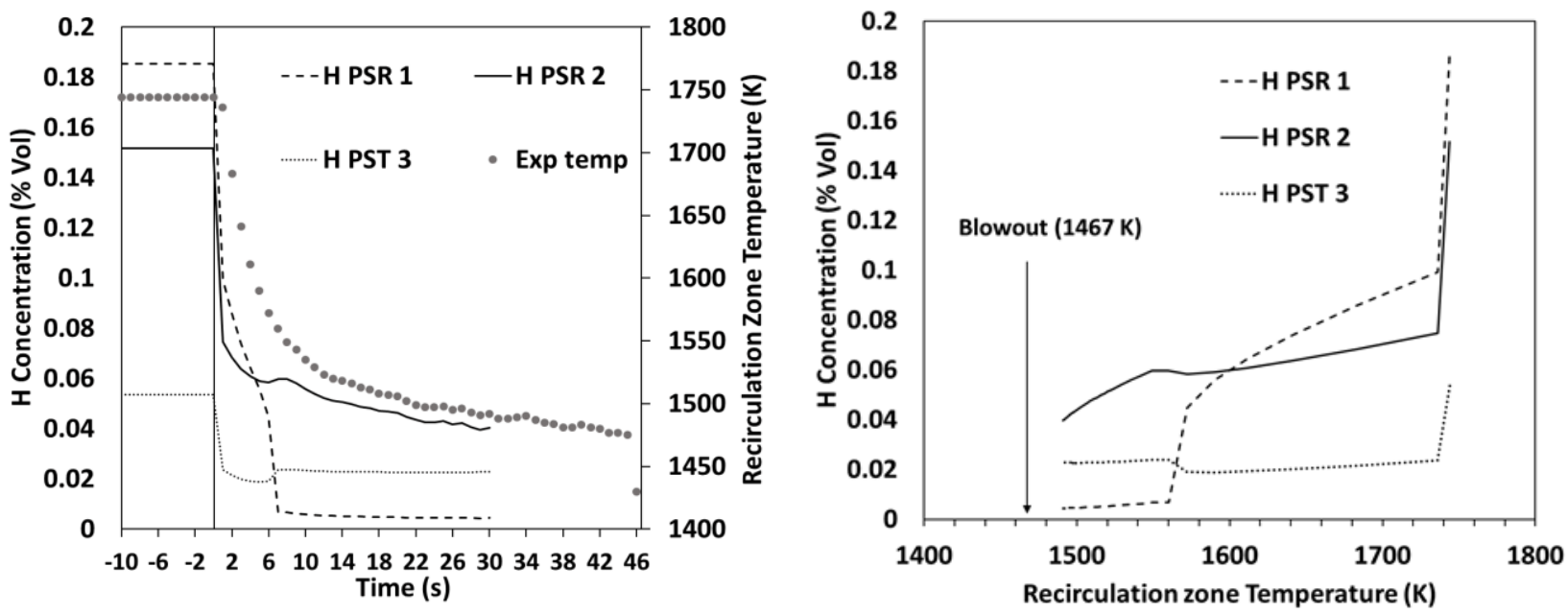

Fig. 21: Left - The concentration of $H$ atom as a function of time for each CRN element and the corresponding experimental temperature. Right - $\mathrm{H}$ atom concentrations as the function of measured temperature for the air flow rate of $1.2 \mathrm{~g} / \mathrm{s}$ and a final $\Phi=0.62$
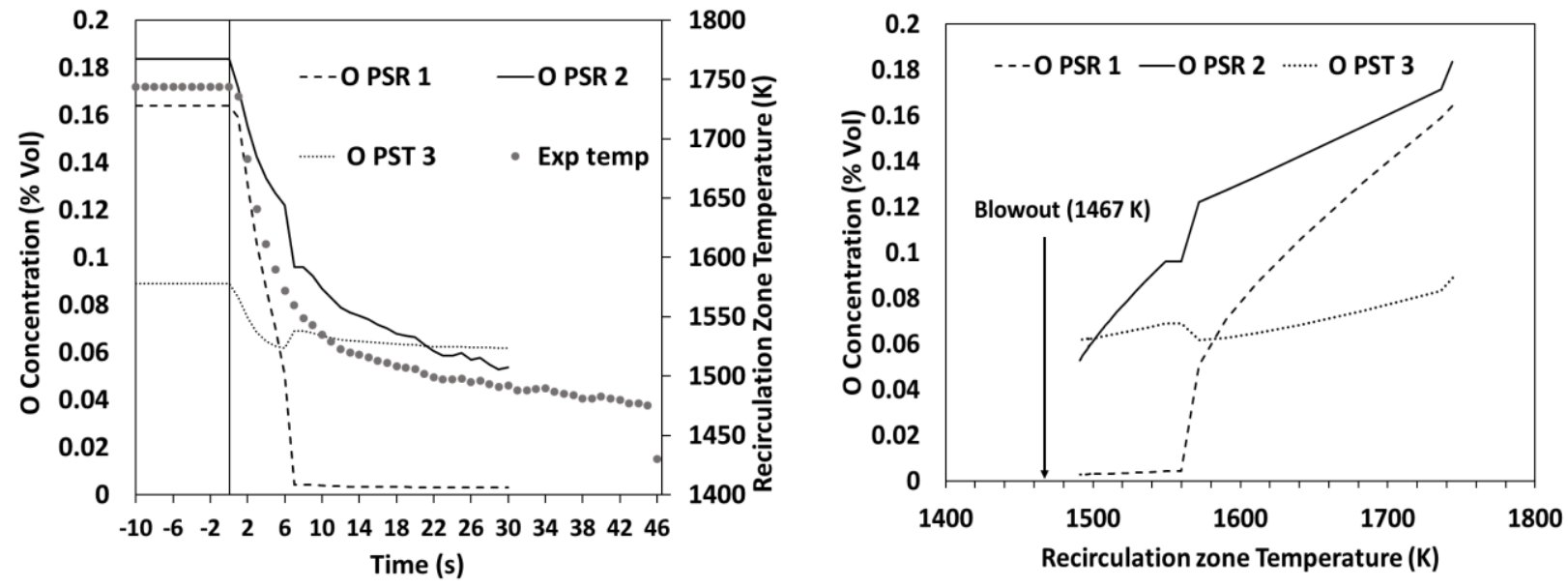

Fig. 22: Left - The concentration of $O$ atom as a function of time for each CRN element and the corresponding experimental temperature. Right - $O$ atom concentrations as the function of measured temperature for the air flow rate of $1.2 \mathrm{~g} / \mathrm{s}$ and a final $\Phi=0.62$ 

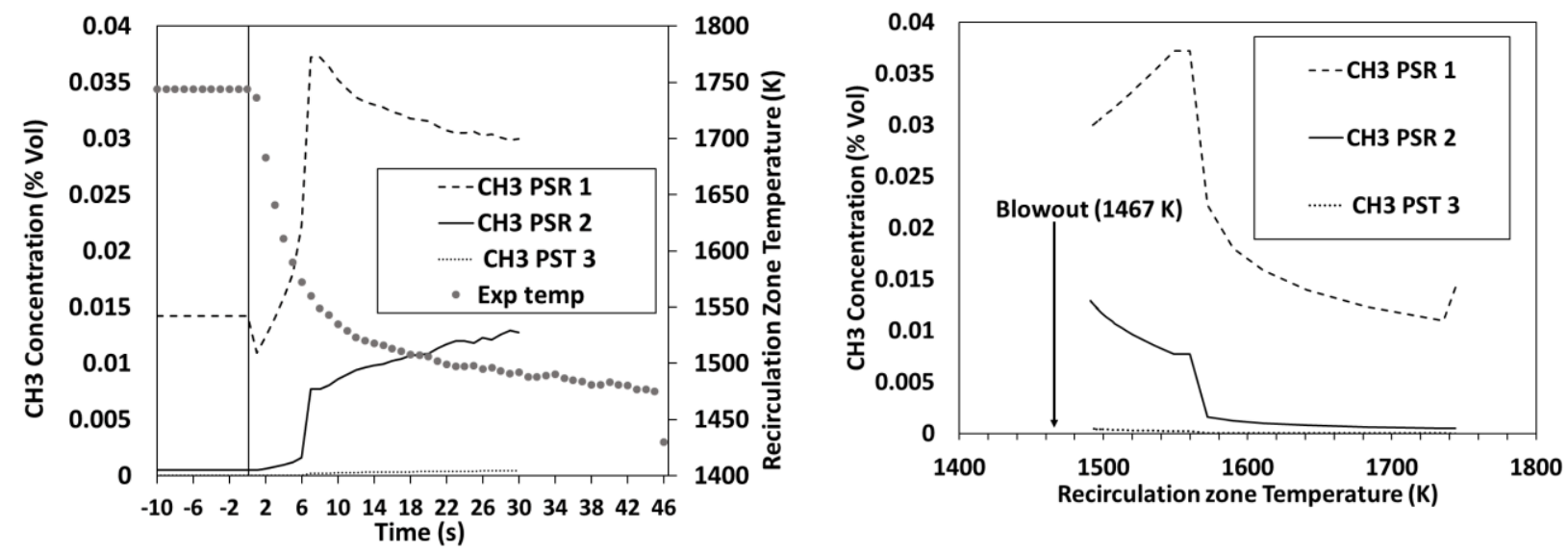

Fig. 23: Left - The concentration of $\mathrm{CH}_{3}$ atom as a function of time for each $\mathrm{CRN}$ element and the corresponding experimental temperature. Right - $\mathrm{CH}_{3}$ atom concentrations as the function of measured temperature for the air flow rate of $1.2 \mathrm{~g} / \mathrm{s}$ and a final $\Phi=0.62$.
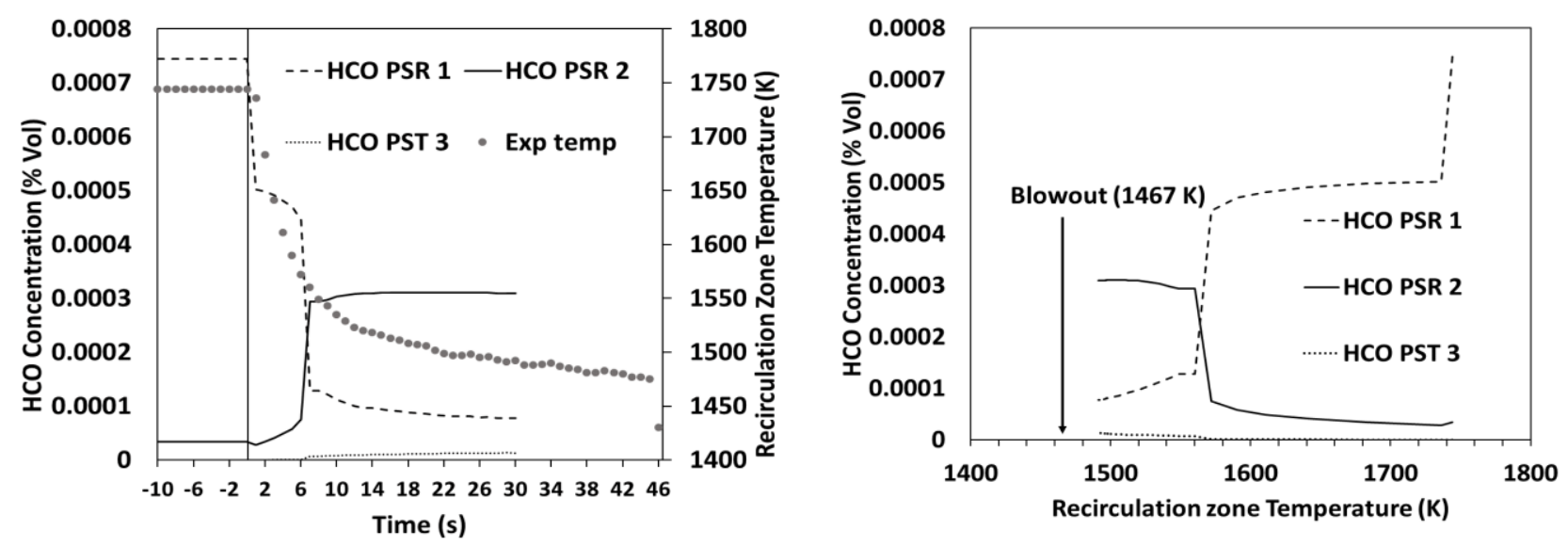

Fig. 24: Left - The concentration of $\mathrm{HCO}$ atom as a function of time for each CRN element and the corresponding experimental temperature. Right - HCO atom concentrations as the function of measured temperature for the air flow rate of $1.2 \mathrm{~g} / \mathrm{s}$ and a final $\Phi=0.62$ 

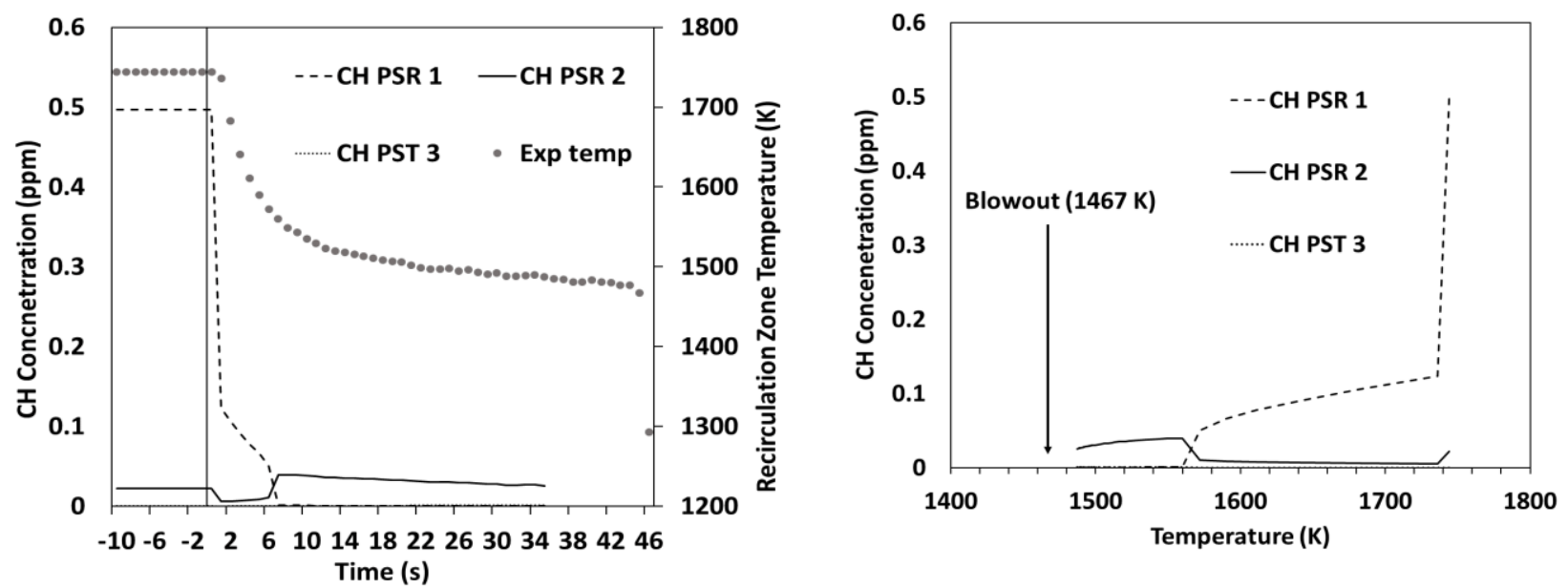

Fig. 25: Left - The concentration of $\mathrm{CH}$ atom as a function of time for each $\mathrm{CRN}$ element and the corresponding experimental temperature. Right - $\mathrm{CH}$ atom concentrations as the function of measured temperature for the air flow rate of $1.2 \mathrm{~g} / \mathrm{s}$ and a final $\Phi=0.62$
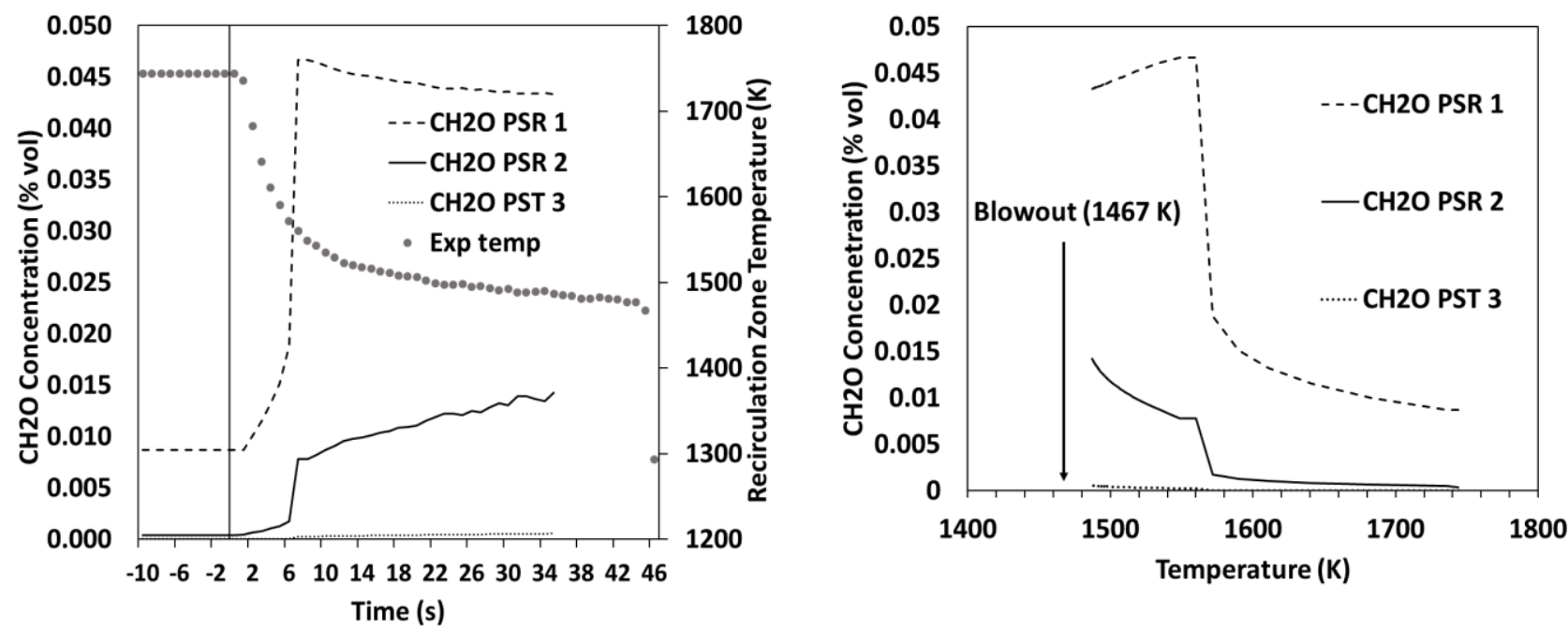

Fig. 26: Left - The concentration of $\mathrm{CH}_{2} \mathrm{O}$ atom as a function of time for each $\mathrm{CRN}$ element and the corresponding experimental temperature. Right - $\mathrm{CH}_{2} \mathrm{O}$ atom concentrations as the function of measured temperature for the air flow rate of $1.2 \mathrm{~g} / \mathrm{s}$ and a final $\Phi=0.62$

Figure 27 shows the behavior of formyl radical ( $\mathrm{HCO})$, an important intermediate in methane combustion, as a function of residence time in the JSR for an air flow rate of $1.2 \mathrm{~g} / \mathrm{s}$ and after the $\Phi$ is reduced from 0.80 to 0.62 . Thermal decomposition of $\mathrm{HCO}$ to $\mathrm{H}$ and $\mathrm{CO}$ is an important chain propagating mechanism $[30,54,55]$. GRI 3.0 mechanism is found to be in good agreement with experimental data of HCO radical $[56,57]$. The primary path of formyl production in a flame is through oxidation of methyl radical $\left(\mathrm{CH}_{3}\right)$ to formaldehyde $\left(\mathrm{CH}_{2} \mathrm{O}\right)$ and eventual abstraction of hydrogen to form HCO. Since methyl radical is known to be an important flame zone species [58], 
the presence of HCO in flame indicates the flame zone. Immediately after the $\Phi$ is dropped to 0.62 , when the flame is still relatively stable $(\mathrm{t}=1 \mathrm{~s}-6 \mathrm{~s})$, the HCO radical is found in high concentration in PSR1 and is mostly decomposed by the time the gas reaches PSR2. However, near blowout, the peak values of $\mathrm{HCO}$ are found in PSR2, and the concentrations are lower than during the stable combustion. This HCO behavior suggests flame movement away from PSR1. This can also be seen in $\mathrm{CH}_{3}$ behavior (Figure 23) where a spike in methyl concentration is observed in PSR2 after PSR1 blowout. In addition, the rate of decomposition of HCO near blowout is lower compared to when the reactor is relatively stable $(t=1 \mathrm{~s}$ and $\mathrm{t}=6 \mathrm{~s})$. At a later time the peak HCO concentrations are shifted to PSR2. The PSR1 shows some lower HCO concentration due to pre-combustion chemistry in the jet region.

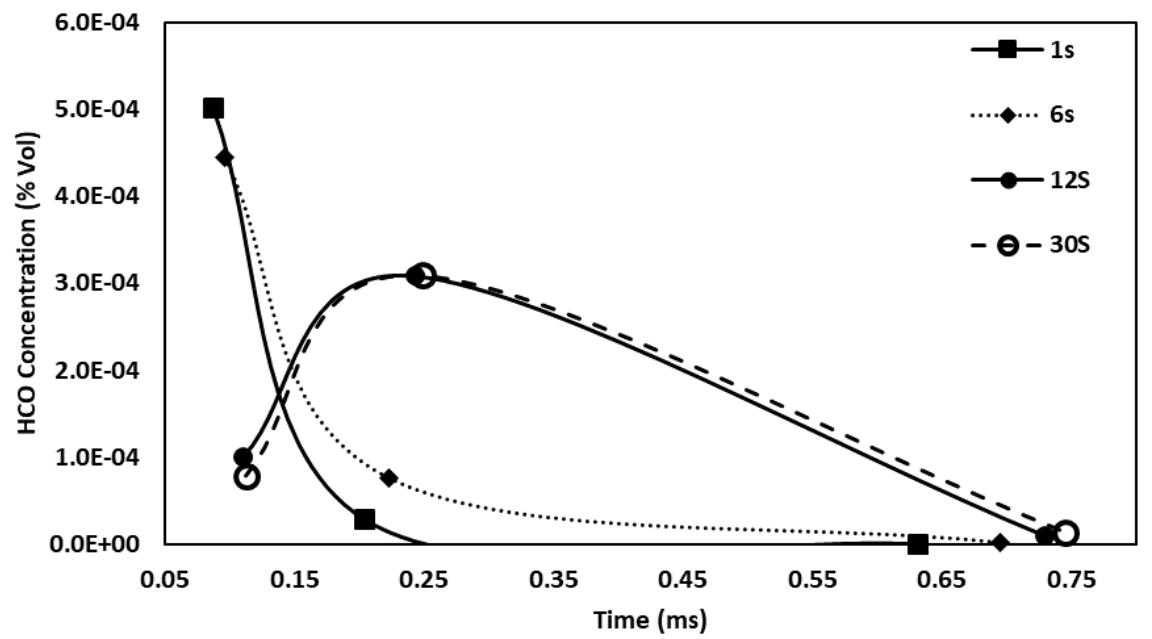

Fig. 27 Concentration of Formyl radical (HCO) in different elements, of the CRN as a function of time inside the JSR at different lab times near the blowout and for air flow rate of $1.2 \mathrm{~g} / \mathrm{s}$ and $\Phi=0.62$

Production of early flame radicals $\left(\mathrm{HCO}, \mathrm{CH}_{3}, \mathrm{CH}\right)$ and consumption of $\mathrm{OH}$ radical in the non-ignited PSR1 indicates that some pre-flame chemistry associated with initial fuel decomposition takes place in the PSR1 after the blowout. The partial decomposition of the fuel in the PSR1 aids the ignition and the sustained combustion in the PSR2. The RT-CRN running on GRI 3.0 is able to describe the fuel-air charge preheat and early fuel break-up via ignition delay chemistry.

Figure 28 shows the behavior of $\mathrm{OH}$ in each element of the CRN, as a function of time and temperature, for air flow rates of $1.0 \mathrm{~g} / \mathrm{s}$ and $1.5 \mathrm{~g} / \mathrm{s}$. 

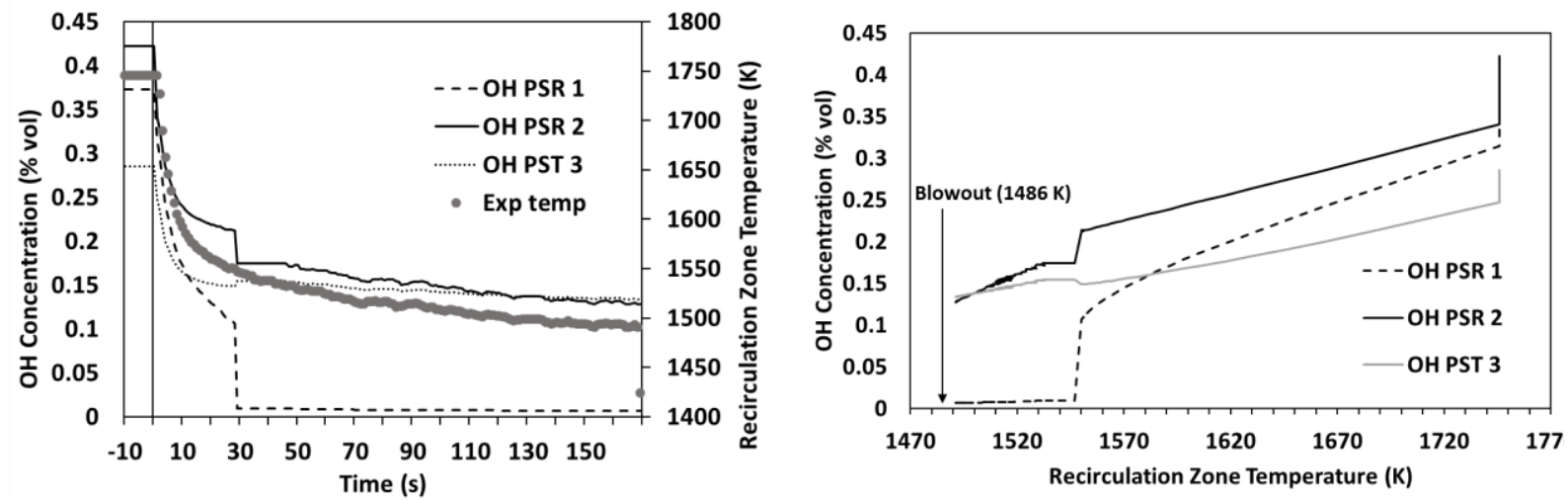

(a)
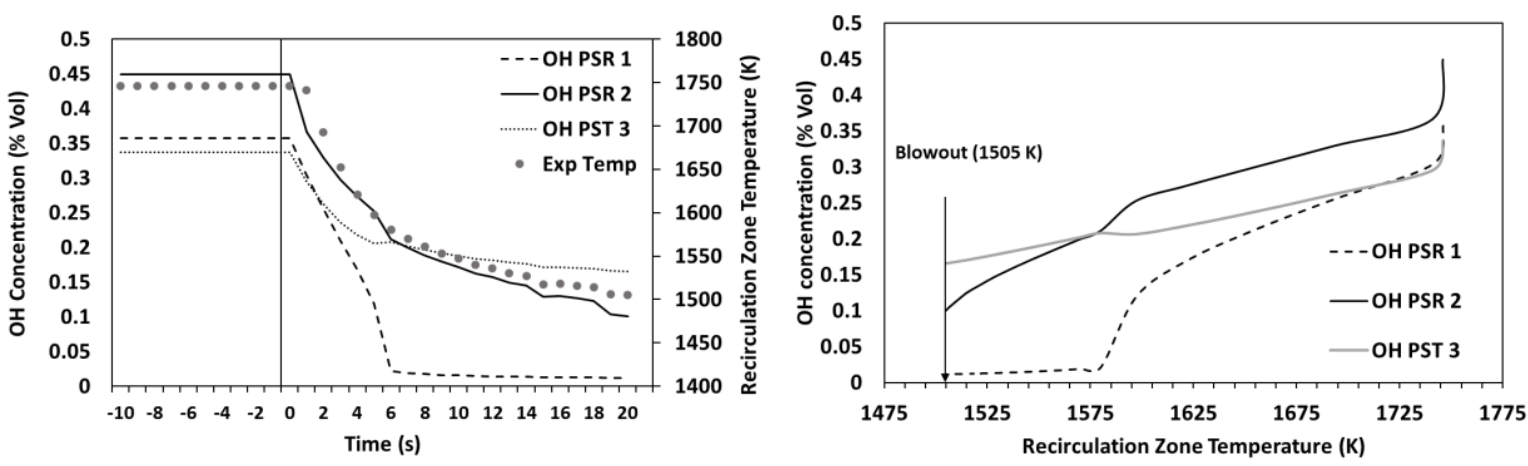

(b)

Fig. 28: Left - The concentration of $\mathrm{OH}$ atom as a function of time for each CRN element and the corresponding experimental temperature. Right - $\mathrm{OH}$ atom concentrations as the function of measured temperature for air flow rates of (a) $1.0 \mathrm{~g} / \mathrm{s}$ and (b) $1.5 \mathrm{~g} / \mathrm{s}$ and blowout equivalence ratios of 0.62 .

Figures 29 - 40 shows the behavior of other free radicals for air flow rates of $1.0 \mathrm{~g} / \mathrm{s}$ and 1.5 $\mathrm{g} / \mathrm{s}$.
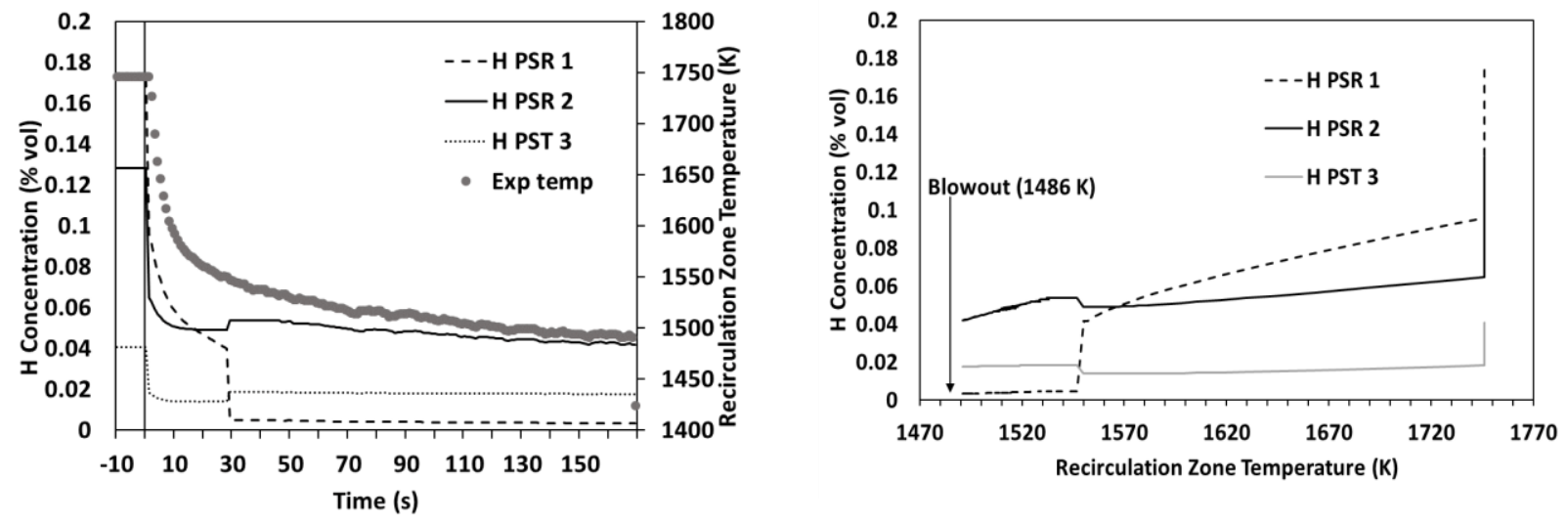

Fig. 29 Left - The concentration of $H$ atom as a function of time for each CRN element and the corresponding experimental temperature. Right - $\mathrm{H}$ atom concentrations as the function of measured temperature for the air flow rate of $1.0 \mathrm{~g} / \mathrm{s}$ and a final $\Phi=0.62$ 

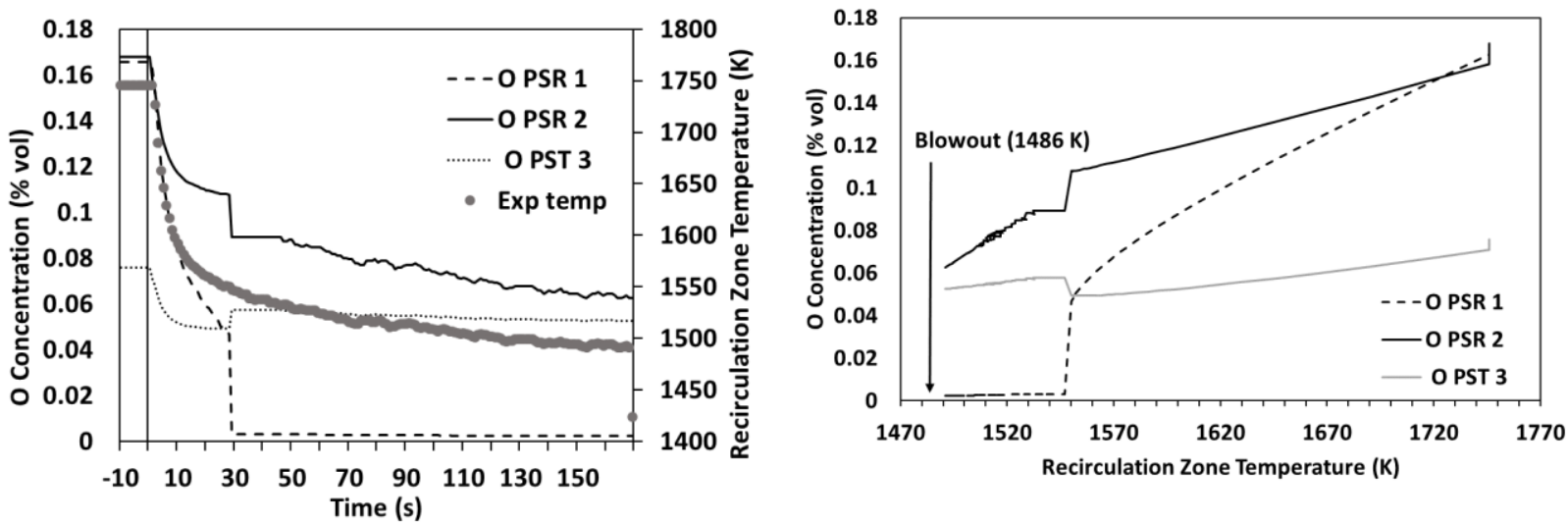

Fig. 30: Left - The concentration of $O$ atom as a function of time for each CRN element and the corresponding experimental temperature. Right - $O$ atom concentrations as the function of measured temperature for the air flow rate of $1.0 \mathrm{~g} / \mathrm{s}$ and a final $\Phi=0.62$
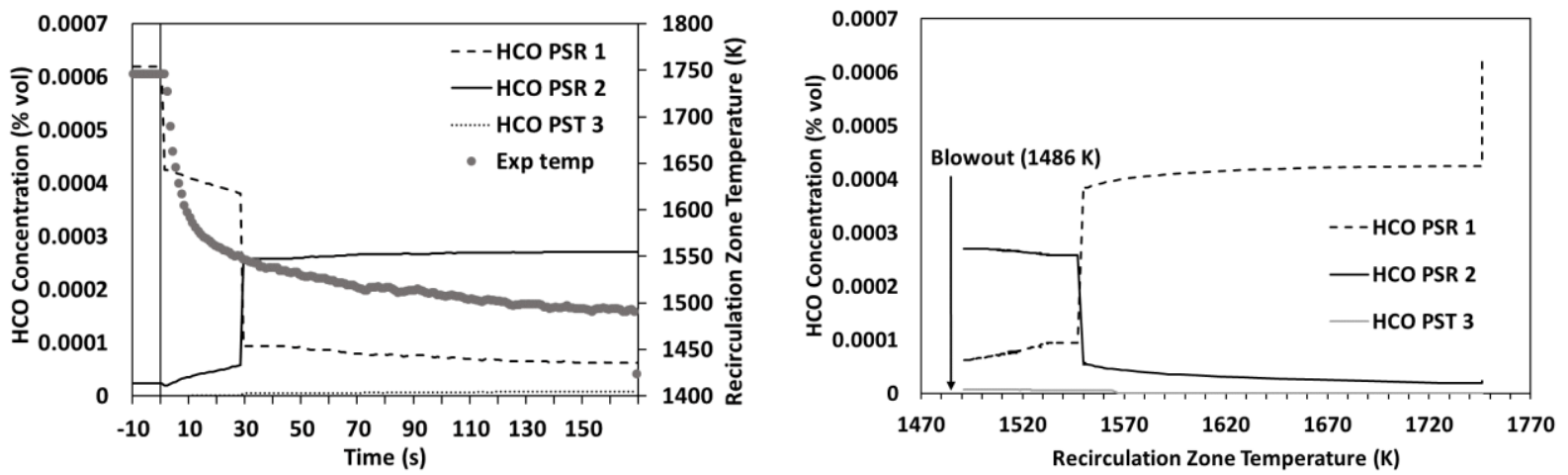

Fig. 31: Left - The concentration of HCO atom as a function of time for each CRN element and the corresponding experimental temperature. Right - HCO atom concentrations as the function of measured temperature for the air flow rate of $1.0 \mathrm{~g} / \mathrm{s}$ and a final $\Phi=0.62$
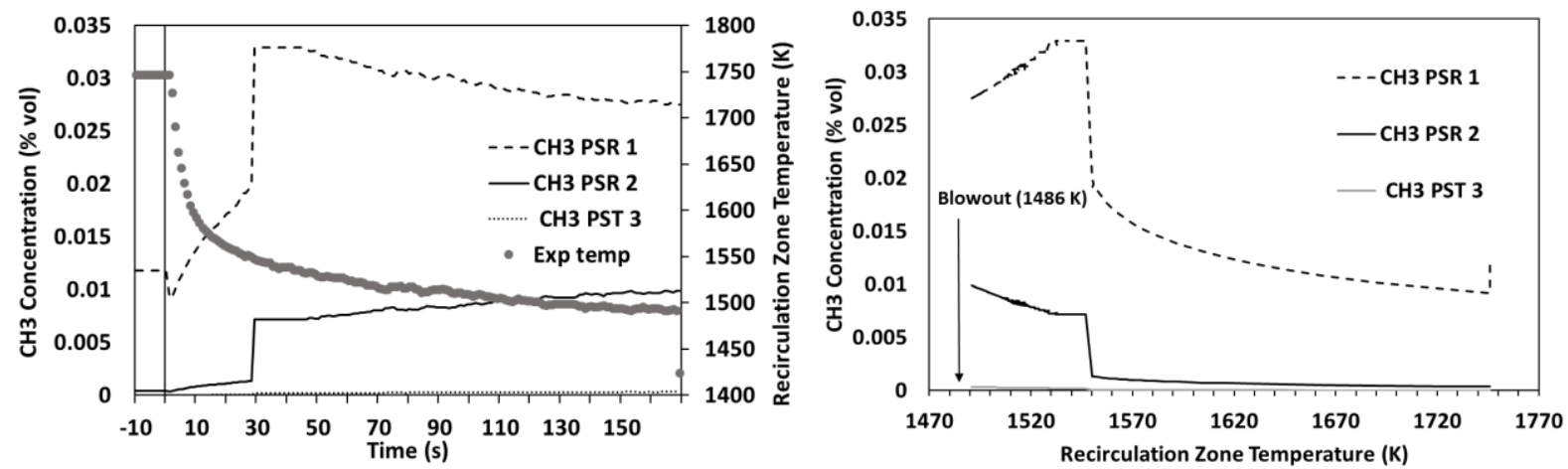

Fig. 32: Left - The concentration of $\mathrm{CH}_{3}$ atom as a function of time for each CRN element and the corresponding experimental temperature. Right - $\mathrm{CH}_{3}$ atom concentrations as the function of measured temperature for the air flow rate of $1.0 \mathrm{~g} / \mathrm{s}$ and a final $\Phi=0.62$ 

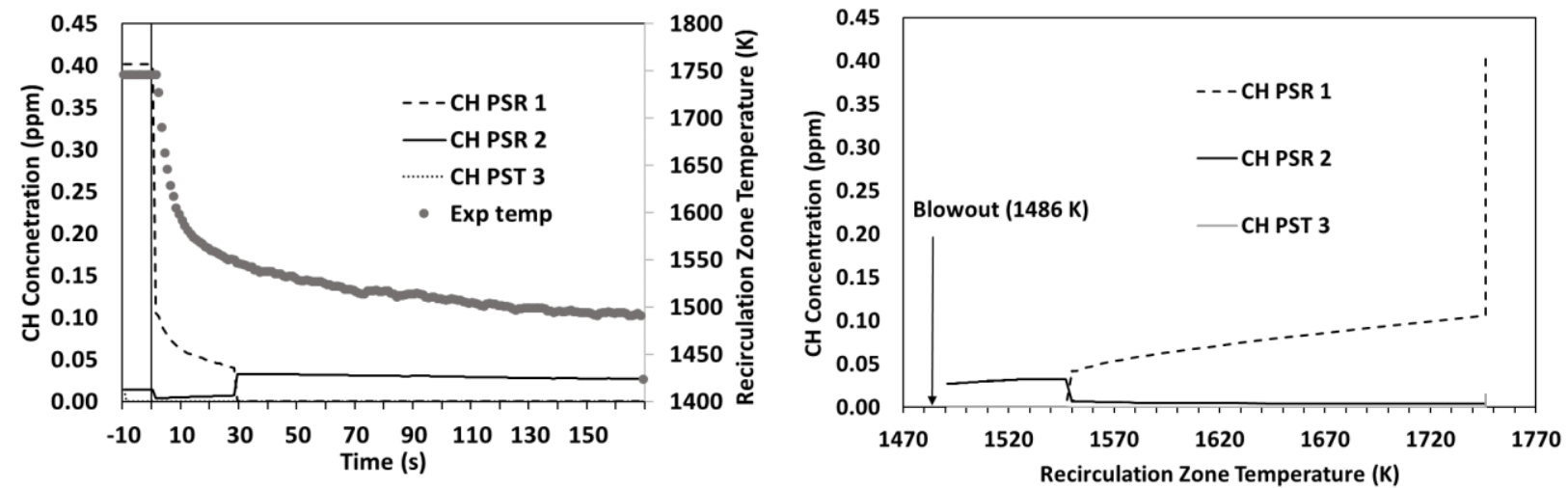

Fig. 33: Left - The concentration of $\mathrm{CH}$ atom as a function of time for each CRN element and the corresponding experimental temperature. Right - $\mathrm{CH}$ atom concentrations as the function of measured temperature for the air flow rate of $1.0 \mathrm{~g} / \mathrm{s}$ and a final $\Phi=0.62$
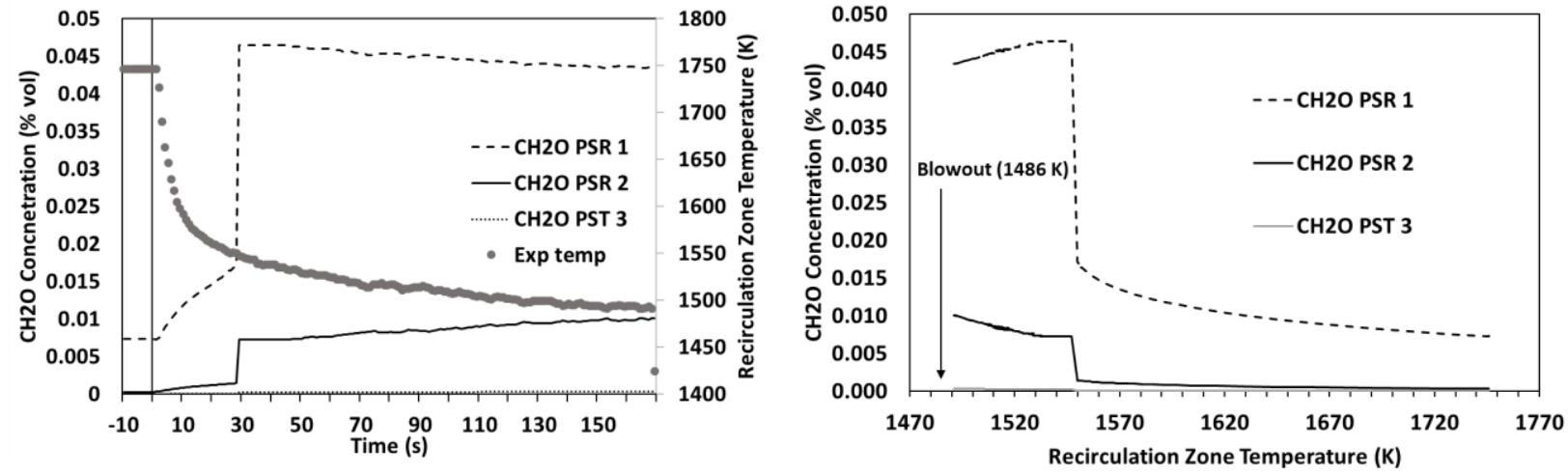

Fig. 34: Left - The concentration of $\mathrm{CH}_{2} \mathrm{O}$ atom as a function of time for each CRN element and the corresponding experimental temperature. Right - $\mathrm{CH}_{2} \mathrm{O}$ atom concentrations as the function of measured temperature for the air flow rate of $1.0 \mathrm{~g} / \mathrm{s}$ and a final $\Phi=0.62$
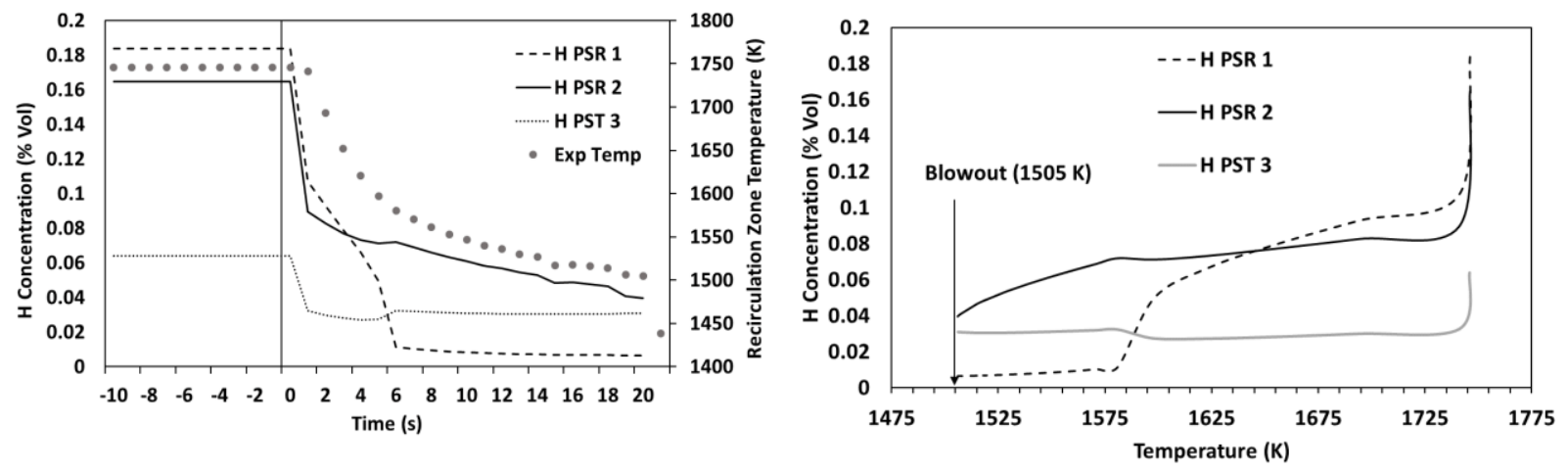

Fig. 35: Left - The concentration of $H$ atom as a function of time for each CRN element and the corresponding experimental temperature. Right - $\mathbf{H}$ atom concentrations as the function of measured temperature for the air flow rate of $1.5 \mathrm{~g} / \mathrm{s}$ and a final $\Phi=0.62$ 

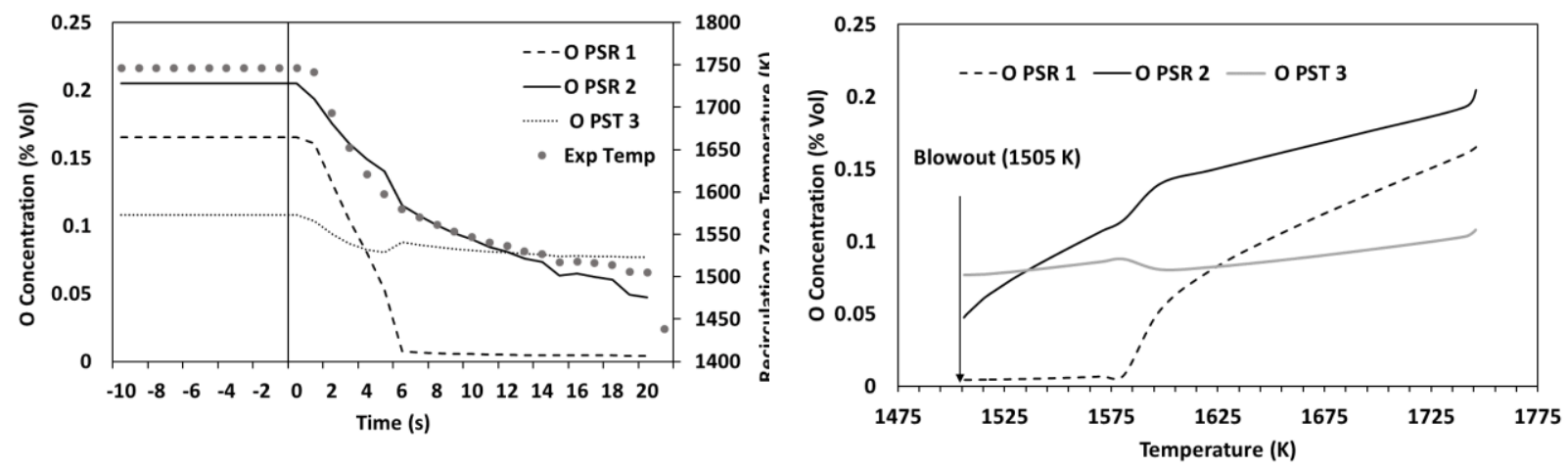

Fig. 36: Left - The concentration of $O$ atom as a function of time for each $C R N$ element and the corresponding experimental temperature. Right - $O$ atom concentrations as the function of measured temperature for the air flow rate of $1.5 \mathrm{~g} / \mathrm{s}$ and a final $\Phi=0.62$
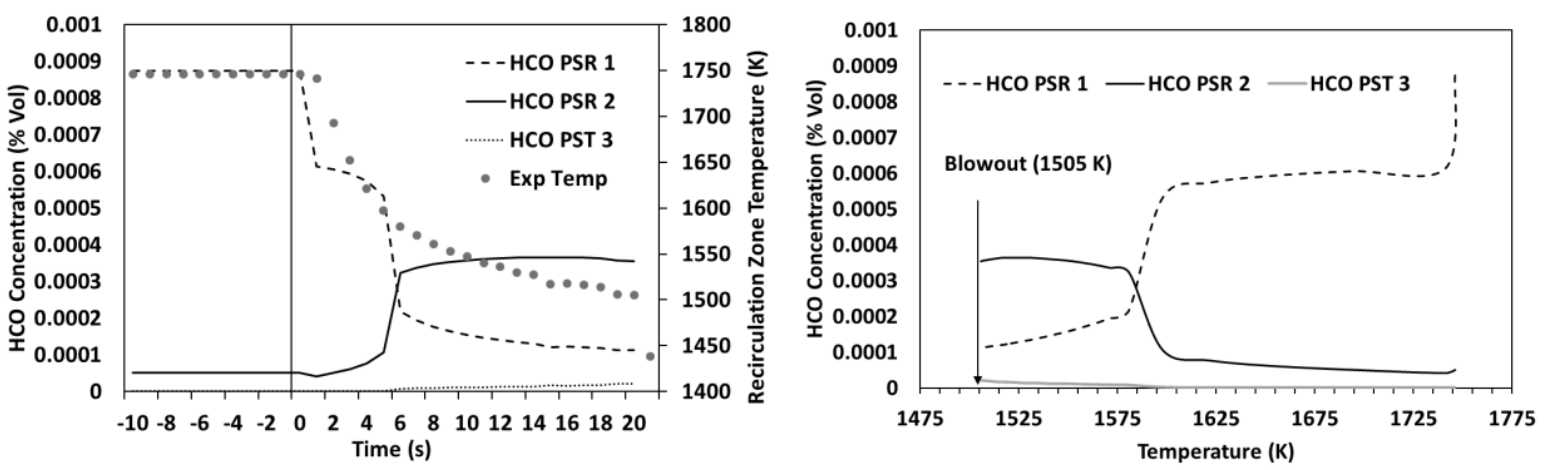

Fig. 37: Left - The concentration of $\mathrm{HCO}$ atom as a function of time for each CRN element and the corresponding experimental temperature. Right - HCO atom concentrations as the function of measured temperature for the air flow rate of $1.5 \mathrm{~g} / \mathrm{s}$ and a final $\Phi=0.62$
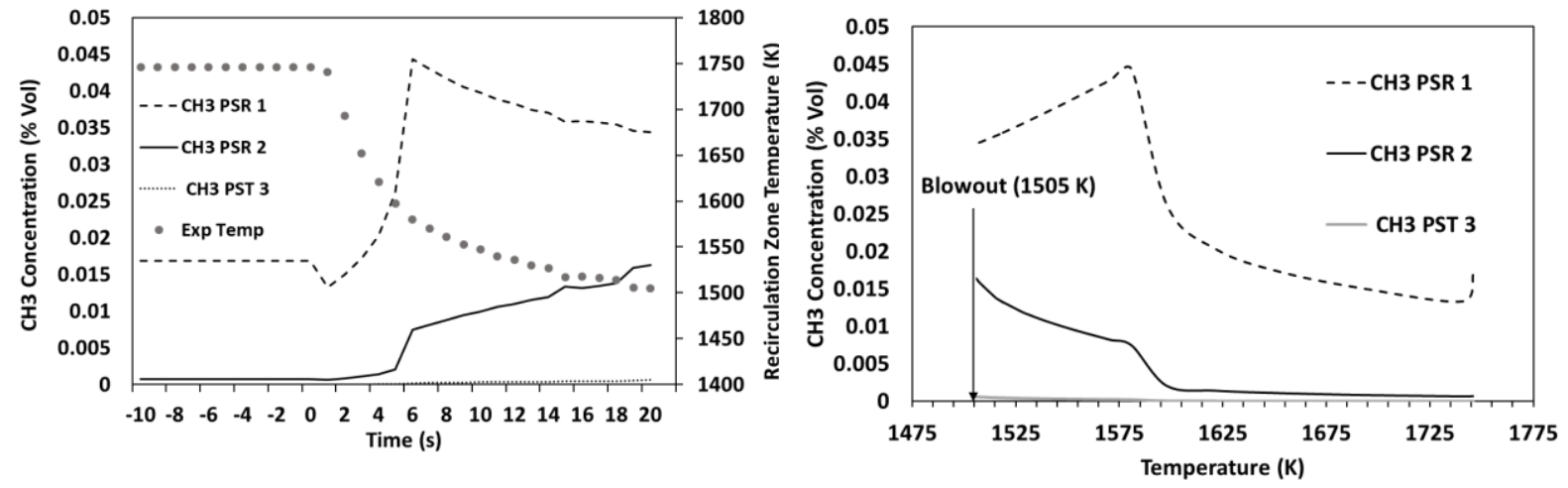

Fig. 38: Left - The concentration of $\mathrm{CH}_{3}$ atom as a function of time for each $\mathrm{CRN}$ element and the corresponding experimental temperature. Right - $\mathrm{CH}_{3}$ atom concentrations as the function of measured temperature for the air flow rate of $1.5 \mathrm{~g} / \mathrm{s}$ and a final $\Phi=0.62$ 

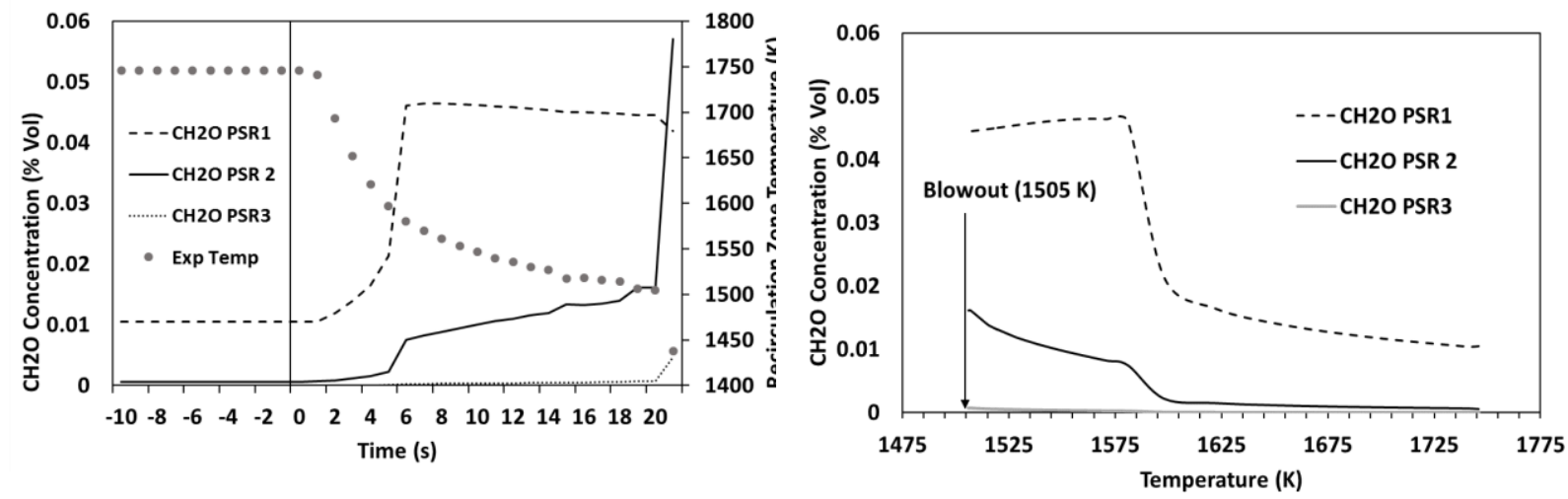

Fig. 39: Left - The concentration of $\mathrm{CH}_{2} \mathrm{O}$ atom as a function of time for each $\mathrm{CRN}$ element and the corresponding experimental temperature. $\mathrm{Right}-\mathrm{CH}_{2} \mathrm{O}$ atom concentrations as the function of measured temperature for the air flow rate of $1.5 \mathrm{~g} / \mathrm{s}$ and a final $\Phi=0.62$
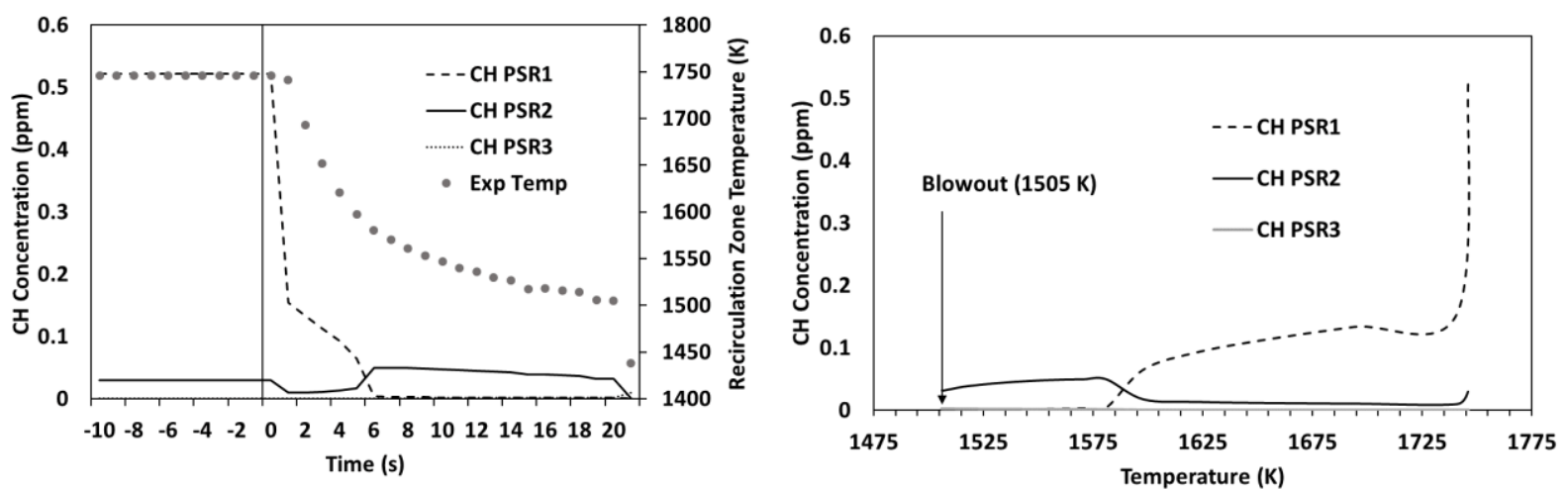

Fig. 40: Left - The concentration of $\mathrm{CH}$ atom as a function of time for each $\mathrm{CRN}$ element and the corresponding experimental temperature. Right - $\mathrm{CH}$ atom concentrations as the function of measured temperature for the air flow rate of $1.5 \mathrm{~g} / \mathrm{s}$ and a final $\Phi=0.62$ 
Figure 41 shows the behavior of $\mathrm{OH}$ as a function of Lagrangian convection time in the reactor.

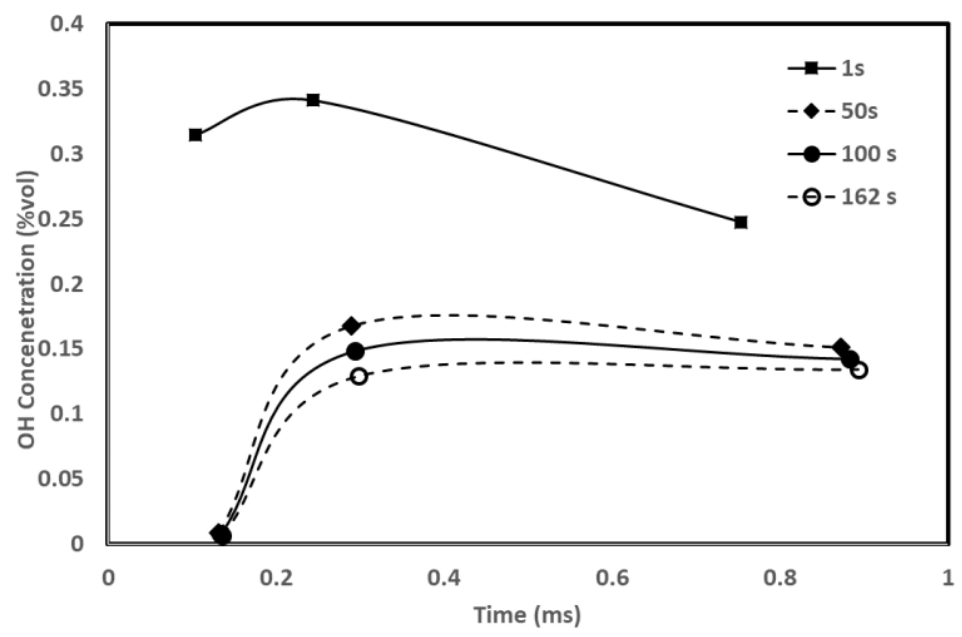

(a)

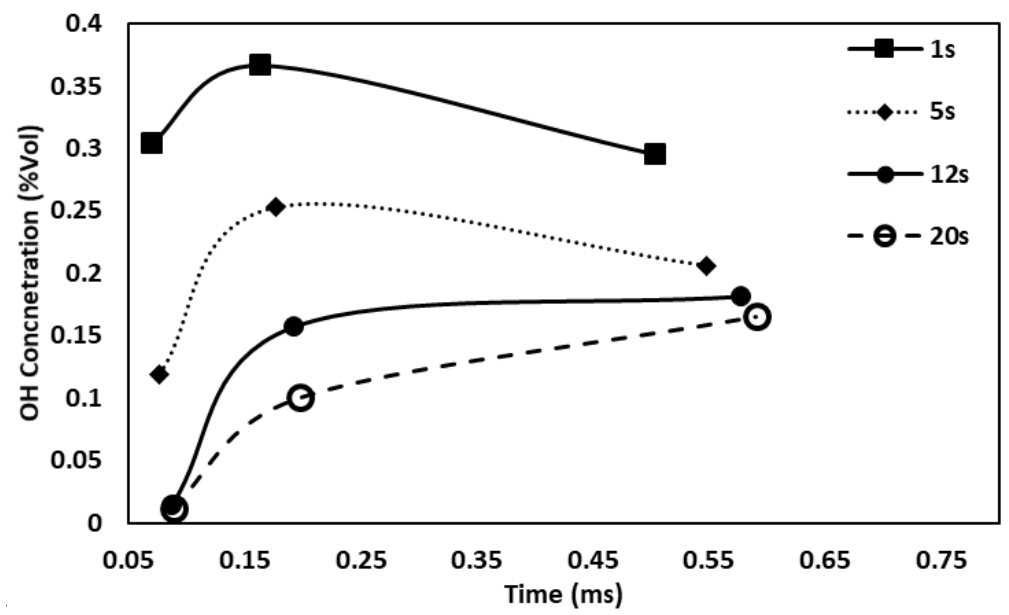

(b)

Fig. 41: Concentration of hydroxyl radicals $(\mathrm{OH})$ in different elements, of the CRN as a function of residence time inside the JSR at different lab times near the blowout and for air flow rates of (a) $1.0 \mathrm{~g} / \mathrm{s}(\mathrm{b}) \mathbf{1 . 5} \mathrm{g} / \mathrm{s}$ and a final $\Phi=0.62$ 
Figure 42 shows formyl radical behavior as a function of concentration for air flow rates of $1.0 \mathrm{~g} / \mathrm{s}$ and $1.5 \mathrm{~g} / \mathrm{s}$ as a function of Lagrangian convection time in the reactor.

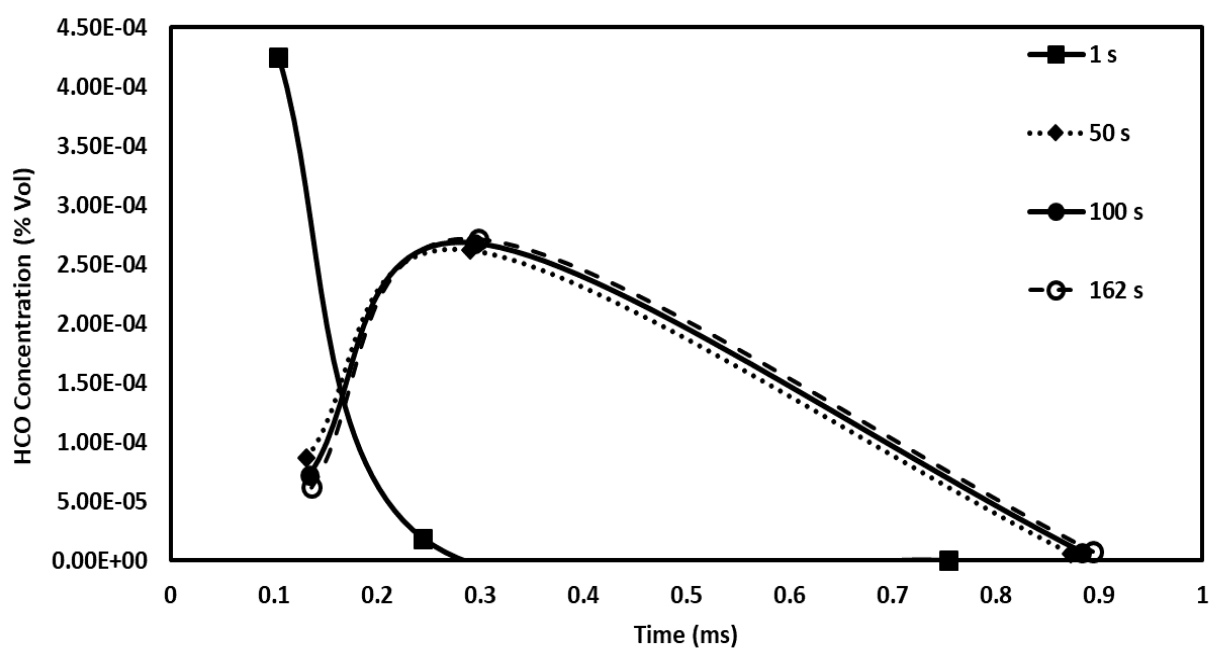

(a)

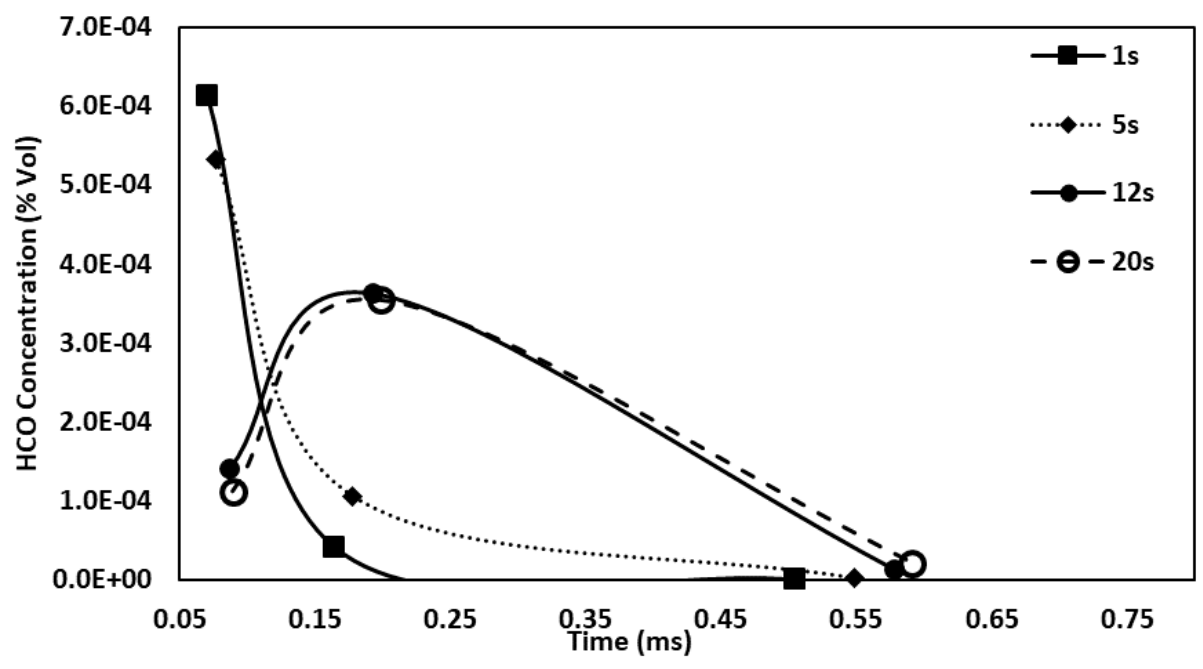

(b)

Fig. 42: Concentration of Formyl radicals (HCO) in different elements, of the CRN as a function of time inside the JSR at different lab times near the blowout and for air flow rates of (a) $1.0 \mathrm{~g} / \mathrm{s}$ and (b) $1.5 \mathrm{~g} / \mathrm{s}$ at $\Phi 0.62$ 


\section{Appendix H - Damkohler number analysis}

The Damkohler Number (Da) is defined as the ratio of mixing time to the chemical time $\left(\tau_{\text {mix }} / \tau_{\text {chem }}\right)$. The mixing time uses reactor residence time which is given by,

$$
\tau_{\text {res }}=\frac{\rho V}{\dot{\mathrm{m}}}
$$

Where $\rho$ : density of gas inside the reactor

$\mathrm{V}$ : Volume of the element

$\dot{m}$ : Mass flow rate in the element.

The residence time is computed by the CRN and is based on the time spent by a fluid particle in the element of the reactor. The mixing time defined using global reactor residence time consists of the recirculation zone time that creates the radical pool for ignition along with the flame and post flame residence times where the ignition occurs. Previous Da numbers are based on flow time calculated using characteristic length scale proportional to recirculation zone length $[59,60]$. The chemical time scale is defined as the ratio of the laminar flame thickness $\left(\delta_{\mathrm{L}}\right)$ to laminar flame speed (SL) [61]:

$$
\tau_{\text {Chem }}=\delta_{L} / S_{L}
$$

Where $\delta_{\mathrm{L}}$ and $\mathrm{S}_{\mathrm{L}}$ are the laminar flame thickness and laminar flame speed respectively. The laminar flame speed is measured using the following empirical equation for methane provided by Gottgens et al. [62]:

$$
\mathrm{S}_{\mathrm{L}}=13.9\left[\frac{\Phi}{1+\frac{1}{0.0622 \Phi}}\right]^{0.565175}\left[\frac{\mathrm{T}_{\mathrm{b}}-1220.7}{\mathrm{~T}_{\mathrm{b}}-390}\right]^{2.5158}
$$

Where,

$\Phi$ : Fuel/Air equivalence Ratio

$\mathrm{Tb}$ : Temperature at Uळ, burned gas temperature

Recirculation zone temperature is chosen instead of adiabatic flame temperature for $T_{b}$ for the calculation of flame speed, as the measured temperature would capture the transient combustion 
state near blowout. The laminar flame thickness is calculated based in thermal diffusivity $(\alpha)$ and flame speed as,

$$
\delta_{\mathrm{L}}=\alpha / \mathrm{S}_{\mathrm{L}}
$$

The thermal diffusivity is calculated based on inlet temperature and pressure of the JSR. Figure 43 shows the Damkohler number for a blowout equivalence ratio of 0.62 and air flow rates of $1.0 \mathrm{~g} / \mathrm{s}, 1.2 \mathrm{~g} / \mathrm{s}$, and $1.5 \mathrm{~g} / \mathrm{s}$. It could be seen that initially, at temperatures around 1725-1750 K, the reactor has a higher $\mathrm{Da}$, suggesting that the chemistry is faster than the mixing time, but as approaching blowout, the Da attains a value of $\sim 0.1$ in all the cases. For a particular temperature, the Da for higher loading parameter is lower compared to that of lower loading, as the residence time is lower at higher loading (Figure 44a).

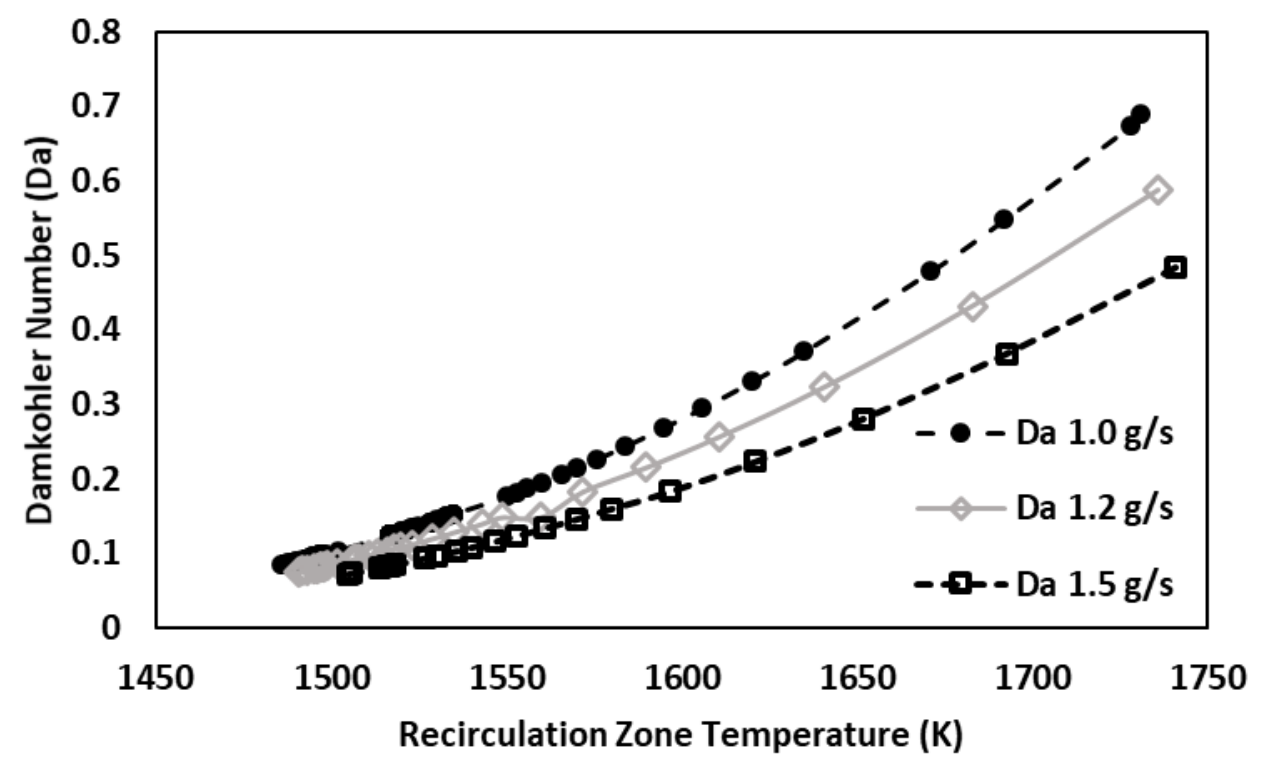

Fig. 43: Damkohler number (Da) as a function of time inside the JSR at different lab times near the blowout and for air flow rates of (a) $1.0 \mathrm{~g} / \mathrm{s}$ (b) $1.2 \mathrm{~g} / \mathrm{s}$ and (c) $1.5 \mathrm{~g} / \mathrm{s}$ and a blowout $\Phi 0.62$

Figure 44 shows that as the temperature is decreasing and the reactor is nearing blowout, the rate of increase in chemical time scale is more than that of mixing time scale. 


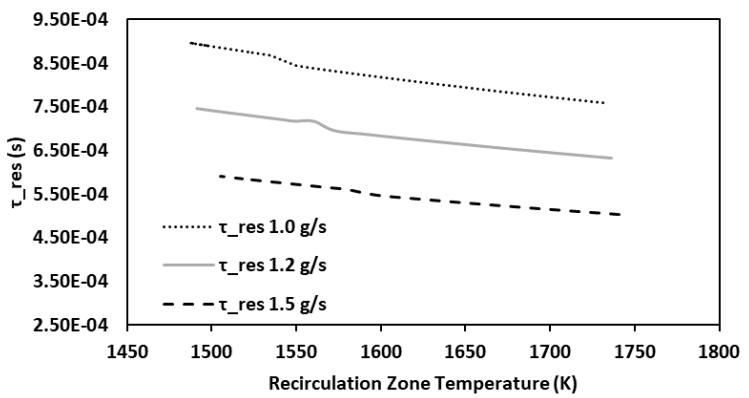

(a)

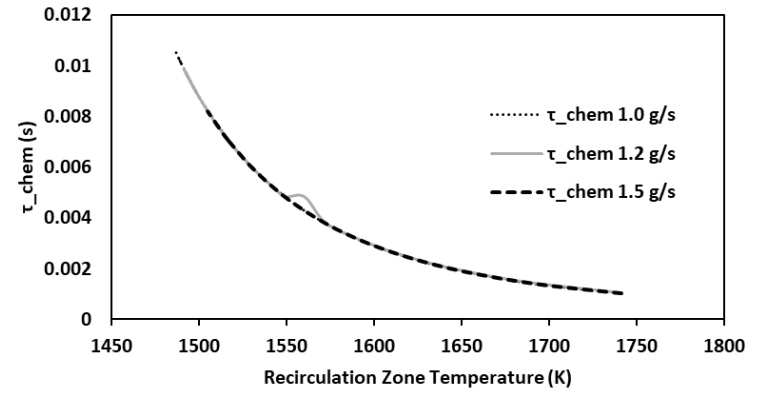

(b)

Fig. 44: (a) Mixing and (b) Chemical timescales used for calculation of Da for different air flow rates of $1.0 \mathrm{~g} / \mathrm{s}, 1.2 \mathrm{~g} / \mathrm{s}$, and $1.5 \mathrm{~g} / \mathrm{s}$

Table 5 shows the initial Da number and Da near blowout for other air flow rates and $\Phi$. The median case based on time for each $\Phi$ is selected to calculate the Da. For all the cases the blowout Da number is around $\sim 0.1$ which can be used as a blowout parameter.

Table 5: Blowout Damkohler Number for various experimental air flow rates and blowout $\Phi$

\begin{tabular}{|c|c|c|c|}
\hline $\begin{array}{c}\text { AIR } \\
(\mathbf{G} / \mathbf{S})\end{array}$ & $\mathbf{\Phi}$ & INITIAL DA & BO DA \\
\hline $\mathbf{1}$ & 0.58 & 0.63 & 0.07 \\
\hline & 0.60 & 0.67 & 0.07 \\
\hline & 0.62 & 0.70 & 0.08 \\
\hline & 0.63 & 0.78 & 0.07 \\
\hline $\mathbf{1 . 2}$ & 0.60 & 0.64 & 0.08 \\
\hline & 0.62 & 0.60 & 0.08 \\
\hline & 0.64 & 0.70 & 0.10 \\
\hline & 0.65 & 0.70 & 0.11 \\
\hline $\mathbf{1 . 5}$ & 0.62 & 0.48 & 0.07 \\
\hline & 0.64 & 0.50 & 0.10 \\
\hline & 0.65 & 0.58 & 0.15 \\
\hline
\end{tabular}

